\title{
Luiz de Abreu Junior
}

\section{Comparação entre as técnicas de dacriocistografia por ressonância magnética e por raios $X$ no diagnóstico da obstrução das vias lacrimais}

Tese apresentada à Faculdade de Medicina da Universidade de São Paulo para obtenção do título de Doutor em Ciências

Área de concentração: Radiologia

Orientador: Prof. Dr. Cláudio Campi de Castro

São Paulo

2008 


\section{DEDICATÓRIA}

Aos meus pais, Ivone e Luiz. Ela, pessoa iluminada, exemplo de dedicação, amor e zelo incondicionais à família e àqueles que cruzam seu caminho. Ele, símbolo da integridade, exemplo de honestidade, retidão de caráter e compromisso com seus valores.

À minha esposa, amiga e companheira, Fernanda, mãe nata e inigualável, exemplo de generosidade e desprendimento, incentivadora e suporte para todos os momentos.

Aos meus filhos, Rebeca e Tiago, sentido da minha vida. A cada pequena descoberta e experiência vivida por eles, entendo melhor o significado do amor. 


\section{AGRADECIMENTOS}

Ao Prof. Dr. Cláudio Campi de Castro, exemplo de competência e pragmatismo, agradeço pela forma amistosa com que me acolheu e pela oportunidade de ter realizado esta tese.

À Dra. Ângela Maria Borri Wolosker, cujo companheirismo e bom-humor a tornam uma pessoa especial, pelo auxílio na seleção do tema e na interpretação dos resultados deste trabalho.

Ao Prof. Dr. Giuseppe D'lppolito, modelo de perseverança e de entusiasmo pelo espírito científico, por ter-me proporcionado a oportunidade de efetuar os exames de Ressonância Magnética no Hospital São Luiz.

À Prof ${ }^{a}$ Dra. Maria Lucia Borri, aos Drs. Luiz Guilherme de Carvalho Hartmann e Mario de Melo Galvão Filho, companheiros de trabalho, pelos momentos compartilhados e pelo incentivo.

Aos Prof. Dr. Sérgio Aron Ajzen e Prof. Dr. Artur Rocha Correa Fernandes, pelas oportunidades oferecidas e pela compreensão demonstrada.

Ao Prof. Dr. Nelson Wolosker, pela sua participação no início das minhas atividades na Pós-graduação, estimulando-me e orientando-me.

Ao Dr. João Amaro Ferrari Silva, por ter acreditado neste projeto e pelo apoio em todas as fases de sua execução.

Aos Biomédicos do setor de Ressonância Magnética do Hospital São Luiz, Silvana Vieira Fernandes, Tatiana S. Gracio, Fabiana Goldenberg, Roseli Yoshida, Benedito Herbert de Souza e Homero José de Farias e Melo pela ajuda na execução dos exames, pela disponibilidade (a despeito do horário), pelo respeito e profissionalismo demonstrados.

Aos auxiliares de enfermagem do setor de Ressonância Magnética do Hospital São Luiz, Fabiana de Oliveira Coutinho, Ana Paula do Nascimento Alves, Janaína Lemes Soares e Marcelo Carlos Santos, pela forma carinhosa e humana com que receberam os pacientes incluídos neste estudo, pelo respeito e consideração dispensados.

À Prof ${ }^{a}$ Neli Ortega, pela revisão do tratamento estatístico dos resultados deste trabalho. 
Aos médicos dos setores de Tomografia Computadorizada e Ressonância Magnética do Hospital São Luiz, pelo companheirismo e estímulo constante ao meu aperfeiçoamento.

À Srta. Valéria Graziano, pela colaboração no atendimento aos pacientes.

À Srta. Gisele Santos Sousa, pela assistência na digitação e formatação do texto deste trabalho.

À Sra. Sandra P. de Barros, pela forma carinhosa e receptiva com que acompanhou o desenrolar deste trabalho.

À Sra. Magali Crescini pelo auxílio na revisão deste trabalho. 


\section{SUMÁRIO}

Lista de Abreviaturas

Lista de Figuras

Lista de Tabelas

Resumo

Summary

1. INTRODUÇÃO

1.1 Objetivos

2. REVISÃO DA LITERATURA 9

2.1 Anatomia das vias lacrimais 9

2.2 Fisiopatologia da obstrução das vias lacrimais $\quad 12$

$\begin{array}{ll}2.3 \text { Exame Clínico } & 18\end{array}$

2.3.1 Inspeção externa 18

2.3.2 Exame em lâmpada de fenda 19

2.3.3 Cateterização e irrigação 20

2.4 Diagnóstico por Imagem 22

2.4.1 Dacriocistografia 23

2.4.2 Ultra-sonografia $\quad 25$

2.4.3 Dacriocintilografia 26

2.4.4 Tomografia Computadorizada 28

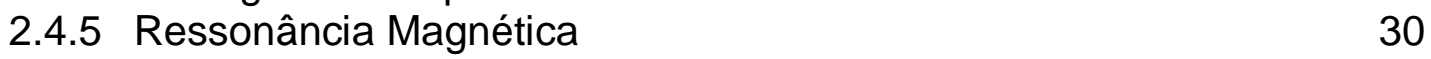

3. MÉTODOS 36

3.1 Tipo de estudo, seleção de pacientes de variáveis clínicas. 36

3.2 Dacriocistografia por Ressonância Magnética 40

3.2.1 Equipamento de RM e preparo para a realização do exame $\quad 40$

3.2.2 Técnica de exame e seqüências utilizadas 41

3.3 Dacriocistografia por Raios X 46

3.3.1 Equipamento, preparo e técnica para a realização do exame. $\quad 46$

3.4 Interpretação dos exames de RM e Raios X $\quad 47$

3.4.1 Avaliação dos exames de RM 48

3.4.2 Avaliação dos exames de Raios X (Dacriocistografia) 50

3.5 Análise Estatística 
4. RESULTADOS

4.1 Resultados - Diagnóstico da presença ou ausência de obstrução da via lacrimal

4.1.1 Análise da concordância entre os diagnósticos realizados por meio de cada seqüência de RM e pela DCG para cada observador individualmente.

4.1.2 Análise da concordância dos diagnósticos realizados entre as seqüências de RM pelos observadores individualmente.

4.1.3 Análise da concordância dos diagnósticos dos dois 70 observadores em relação a cada uma das seqüências de RM e da DCG.

4.1.4 Avaliação da sensibilidade, especificidade, valor preditivo positivo e valor preditivo negativo de cada uma das seqüências de RM conforme cada um dos observadores.

4.2 Resultados - Diagnóstico da Identificação do nível da obstrução da via lacrimal.

4.2.1 Análise da concordância entre os diagnósticos do nível de obstrução realizados para cada seqüência de RM e pela DCG, conforme cada observador individualmente.

4.2.2 Análise da concordância dos diagnósticos do nível de obstrução das vias lacrimais realizados entre cada uma das seqüências de $\mathrm{RM}$, conforme cada observador individualmente.

4.2.3 Análise da concordância dos diagnósticos do nível de obstrução realizados para cada uma das seqüências de RM e pela DCG entre os dois observadores.

5. DISCUSSÃO

6. CONCLUSÕES

7. ANEXOS

8. REFERÊNCIAS BIBLIOGRÁFICAS 


\section{LISTA DE ABREVIATURAS}

AO - Ambos os olhos

AP - Anatomopatológico

DCG - Dacriocistografia

DCR - Dacriocistorrinostomia

DNL - Ducto Nasolacrimal

FFE - Fast Field-echo

Gd - Gadolínio

K - Índice Kappa

MIP - Projeção de Intensidade Máxima

MN - Medicina Nuclear

OD - Olho direito

OE - Olho esquerdo

OPADN - Obstrução Primária Adquirida do Ducto Nasolacrimal

PANDO - Primary Acquired Naso-lacrimal Duct Obstruction

RM - Ressonância Magnética

RX - Raios X

SF - Soro fisiológico

SL - Saco lacrimal

SPIR - Spectral Presaturation by Inversion Recovery

STIR - Short-tau Inversion Recovery

TC - Tomografia Computadorizada 
TE - Tempo de eco

TI - Tempo de inversão

TR - Tempo de repetição

TSE - Turbo Spin-echo

T1 - Tempo de relaxamento T1

T2 - Tempo de relaxamento T2

US - Ultra-sonografia

VPN - Valor preditivo negativo

VPP - Valor preditivo positivo 


\section{LISTA DE FIGURAS}

Figura 1 Exame clínico. Hard stop (a) e Soft stop (b). Modificado de Kanski JJ. Clinical Ophthalmology: a systematic approach. London: Butterworth-Heinemann. $3^{\text {rd }}$ ed. 1994.

Figura 2 Caso número 19. Reconstruções MIP das seqüências STIR 39 sem (a) e com instilação de soro fisiológico (b), imagemfonte da seqüência $\mathrm{T} 1$, após instilação de gadolínio diluído (c) e DCG (d). Obstrução da via lacrimal direita no nível da transição saco - ducto - nasolacrimal observada por meio das seqüências de RM. A DCG evidencia que a obstrução ocorre no segmento proximal do ducto nasolacrimal, pouco mais distal do que a RM demonstrou.

Figura 3 Seqüência STIR no plano coronal, sem nenhuma instilação. Imagem-fonte (a) e reconstrução MIP (b). É possível identificarem-se o saco lacrimal (SL) e a porção proximal do ducto nasolacrimal (DNL), à direita (setas). A imagem MIP (b) mostra a via lacrimal direita parcialmente definida, com dimensões normais.

Figura 4 Seqüência STIR no plano coronal, após instilação de SF. Imagem - fonte (a) e reconstrução MIP (b). É possível identificarem-se os canalículos lacrimais (CL), o saco lacrimal (SL) e a porção proximal do ducto nasolacrimal (DNL), à direita (setas). A imagem MIP (b) mostra toda a extensão da via lacrimal direita com dimensões normais.

Figura 5 Seqüência T1 gradiente-eco no plano coronal, após instilação de gadolínio diluído. Imagens-fonte com janela habitual (a) e janela invertida (b). É possível identificarem-se - saco lacrimal (SL) e a porção proximal do ducto nasolacrimal (DNL), à direita (setas). A via lacrimal esquerda é apenas parcialmente identificada e com tênue preenchimento pelo gadolínio (cabeça de seta em b).

Figura 6 Caso número 16. Dacriocistografia por Raios X. Vias lacrimais totalmente permeáveis e com dimensões normais. Os canalículos lacrimais, superior e inferior, são bem visibilizados, à esquerda (setas). 
Figura 7 Caso número 27. Criança de cinco anos de idade, com história de epífora, à esquerda, desde o nascimento. Reconstrução MIP das seqüências STIR sem instilação (a) e com instilação de soro fisiológico (b) e imagens da DCG (c,d). A RM evidencia a obstrução no nível do ducto nasolacrimal, à esquerda (setas), caracterizando-se conteúdo heterogêneo, destacando-se material com sinal intermediário nas porções mais distais do ducto, devendo corresponder à secreção espessa. A DCG (frente e perfil) confirma o nível e o aspecto da obstrução.

Figura 8 Caso número 17. A RM com seqüências STIR sem 53 instilação (a) e após instilação de soro fisiológico (b) e com seqüência T1 após instilação de gadolínio diluído (c) evidencia que as vias lacrimais estão não preenchidas. A dacriocistografia por Raios X (d) evidenciou obstrução alta (no nível dos canalículos comuns) em ambos os olhos, justificando a ausência de preenchimento das vias lacrimais por qualquer meio de contraste à RM.

Figura 9 Distribuição da sintomatologia de hiperlacrimejamento quanto ao olho acometido $(\mathrm{OD}=$ olho direito; $\mathrm{OE}=$ olho esquerdo; $\mathrm{AO}=$ ambos os olhos).

Figura 10 Distribuição das obstruções das vias lacrimais de acordo com o nível. SL = saco lacrimal; $\mathrm{DNL}=$ ducto nasolacrimal.

Figura 11 Caso número 32. Imagem-fonte da seqüência STIR sem instilação (a), imagem-fonte (b) e reconstrução MIP (c) da seqüência STIR após instilação de soro fisiológico e DCG (d). A RM demonstra, claramente, a obstrução de ambas as vias lacrimais no nível dos sacos lacrimais (válvula de Krause), confirmada pela DCG.

Figura 12 Caso número 1. Paciente com história de trauma facial há sete anos, evoluindo com epífora, à direita, desde a época. Seqüência STIR sem nenhuma instilação. Imagem-fonte (a) e reconstrução MIP (b), evidenciando, claramente, a obstrução da via lacrimal direita no nível do ducto nasolacrimal. A DCG (c) confirma a presença e o nível da obstrução. 
Figura 13 Caso número 1. Seqüência STIR com instilação de soro fisiológico. Imagens-fonte, evidenciando a obstrução da via lacrimal direita, no nível do ducto nasolacrimal. Pode-se, também, identificar a via lacrimal esquerda (saco lacrimal em $A$ e ducto nasolacrimal em B) com calibre normal (setas).

Figura 14 Caso número 28. Imagens-fonte das seqüências STIR sem instilação (a) e com instilação de soro fisiológico (b) e DCG (c). Ambas as seqüências de RM e a DCG evidenciam obstrução da via lacrimal direita, no nível do saco lacrimal. A via lacrimal esquerda foi considerada permeável, tanto pela RM como pela DCG.

Figura 15 Caso número 27. Reconstrução MIP da seqüência T1. Após instilação de gadolínio diluído (a), confirmou-se a obstrução no nível do ducto nasolacrimal. Entretanto, o aspecto de grande distensão do saco lacrimal bem identificado à DCG (b) não se tornou evidente com essa técnica, provavelmente por diluição do meio de contraste por secreção intra-sacular.

Figura 16 Caso número 1. Seqüência T1 com instilação de gadolínio diluído, reconstrução MIP (a) evidenciando preenchimento parcial da via lacrimal direita dilatada, determinando falha na interpretação do nível correto da obstrução. Pela DCG (b), a obstrução é identificada em nível mais distal.

Figura 17 Caso número 7. Paciente com história de lacrimejamento excessivo, à esquerda. Reconstruções MIP das seqüências STIR sem (a) e com instilação de soro fisiológico (b) e da seqüência T1, após instilação de gadolínio diluído e DCG (d). Este caso exemplifica o potencial da RM para estudo de distúrbios funcionais das vias lacrimais. A DCG demonstra permeabilidade total das vias lacrimais. A RM confirma a permeabilidade da via lacrimal direita e evidencia que, à esquerda, há apenas preenchimento do saco lacrimal, inferindo a possibilidade de distúrbio funcional, com retardo no tempo de trânsito em seu interior. 
Figura 18 Caso número 3. Imagens - fonte das seqüências STIR sem (a) e com instilação de soro fisiológico (b), seqüência T2 TSE axial (c) e DCG (d). Este caso exemplifica as vantagens da RM em relação à DCG. Além de demonstrar a obstrução da via lacrimal direita (por compressão extrínseca), a RM demonstrou, também, a presença de formação expansiva no canto interno da órbita direita (setas), que não pôde ser identificada pela DCG. 


\section{LISTA DE TABELAS}

Tabela 1 Distribuição dos pacientes incluídos em nosso estudo, 115 segundo sexo, idade, tempo de sintomatologia e olho sintomático.

Tabela 2 Classificação da obstrução das vias lacrimais em 17 olhos 116 de 14 pacientes, segundo o exame oftalmológico.

Tabela 3 Principais parâmetros das seqüências de RM utilizadas na avaliação dos pacientes.

Tabela 4 Interpretação do índice Kappa (Landis e Koch, 1977).

Tabela 5 Concordância dos diagnósticos de obstrução das vias 62 lacrimais entre a seqüência STIR sem instilação e a DCG, para os observadores 1 e 2 .

Tabela 6 Concordância dos diagnósticos de obstrução das vias lacrimais entre a seqüência STIR com instilação de soro fisiológico e a DCG, para os observadores 1 e 2 .

Tabela 7 Concordância dos diagnósticos de obstrução das vias lacrimais entre a seqüência T1 com instilação de gadolínio diluído e a DCG, para os observadores 1 e 2.

Tabela 8 Concordância dos diagnósticos de obstrução das vias lacrimais entre a seqüência STIR sem instilação e STIR com instilação de soro fisiológico, para os observadores 1 e 2.

Tabela 9 Concordância dos diagnósticos de obstrução das vias lacrimais entre a seqüência STIR sem instilação e T1 com instilação de gadolínio diluído, para os observadores 1 e 2 .

Tabela 10 Concordância dos diagnósticos de obstrução das vias lacrimais entre a seqüência STIR com instilação de soro fisiológico e T1 com instilação de gadolínio diluído, para os observadores 1 e 2.

Tabela 11 Concordância interobservador para os diagnósticos de obstrução das vias lacrimais, para cada uma das seqüências de RM e para a DCG. 
Tabela 12 Sensibilidade (S), Especificidade (E), Valor Preditivo

Positivo (VPP) e Valor Preditivo Negativo (VPN) de cada uma das seqüências de RM para o diagnóstico de obstrução das vias lacrimais, para o observador 1, excluindo-se os casos não preenchidos.

Tabela 13 Sensibilidade (S), Especificidade (E), Valor Preditivo Positivo (VPP) e Valor Preditivo Negativo (VPN) de cada uma das seqüências de RM para o diagnóstico de obstrução das vias lacrimais, para o observador 2, excluindo-se os casos não preenchidos.

Tabela 14 Sensibilidade (S), Especificidade (E), Valor Preditivo Positivo (VPP) e Valor Preditivo Negativo (VPN) de cada uma das seqüências de RM para o diagnóstico de obstrução das vias lacrimais, para o observador 1, incluindo-se os casos não preenchidos.

Tabela 15 Sensibilidade (S), Especificidade (E), Valor Preditivo Positivo (VPP) e Valor Preditivo Negativo (VPN) de cada uma das seqüências de RM para o diagnóstico de obstrução das vias lacrimais, para o observador 2, incluindo-se os casos não preenchidos.

Tabela 16 Concordância dos diagnósticos do nível de obstrução das vias lacrimais entre a seqüência STIR sem instilação e a DCG, para os observadores 1 e 2 .

Tabela 17 Concordância dos diagnósticos do nível de obstrução das vias lacrimais entre a seqüência STIR com instilação de soro fisiológico e a DCG, para os observadores 1 e 2.

Tabela 18 Concordância dos diagnósticos do nível de obstrução das vias lacrimais entre a seqüência T1 com instilação de gadolínio diluído e a DCG, para os observadores 1 e 2 .

Tabela 19 Concordância dos diagnósticos do nível de obstrução das vias lacrimais entre a seqüência STIR sem instilação e STIR com instilação de soro fisiológico, para os observadores 1 e 2.

Tabela 20 Concordância dos diagnósticos do nível de obstrução das vias lacrimais entre a seqüência STIR sem instilação e T1 com instilação de gadolínio diluído, para os observadores 1 e 2 . 
Tabela 21 Concordância dos diagnósticos do nível de obstrução das vias lacrimais entre a seqüência STIR com instilação de soro fisiológico e T1 com instilação de gadolínio diluído, para os observadores 1 e 2 .

Tabela 22 Concordância interobservador para os diagnósticos do nível de obstrução das vias lacrimais, para cada uma das seqüências de RM e para a DCG.

Tabela 23 Resumo dos valores de Sensibilidade, Especificidade e Valores Preditivos Positivo e Negativo para cada uma das seqüências de RM, para cada observador individualmente, excluindo-se os casos não preenchidos.

Tabela 24 Resumo dos valores de Sensibilidade, Especificidade e Valores Preditivos Positivo e Negativo para cada uma das seqüências de RM, para cada observador individualmente, incluindo-se os casos não preenchidos.

Tabela 25 Resumo das concordâncias intra-observadores para os diagnósticos da presença de obstrução e do nível da obstrução das vias lacrimais para as seqüências de RM em comparação à DCG e para as seqüências de RM entre ela mesmas.

Tabela 26 Resumo das concordâncias interobservadores para os diagnósticos da presença de obstrução e do nível da obstrução das vias lacrimais para as seqüências de RM e para a DCG. 


\section{RESUMO}

Abreu Jr. L. Comparação entre as técnicas de dacriocistografia por ressonância magnética e por raios $X$ no diagnóstico da obstrução das vias lacrimais [tese]. São Paulo: Faculdade de Medicina, Universidade de São Paulo; 2008. 127 p.

Introdução: Epífora corresponde ao hiperlacrimejamento decorrente de causa obstrutiva. Quase sempre se indica o tratamento cirúrgico, e a determinação do nível e da natureza da obstrução solicita exames de imagem. A ressonância magnética pode ser utilizada nesse contexto. Objetivos: Verificar a eficácia da dacriocistografia por RM, na avaliação de obstrução das vias lacrimais, correlacionando com o exame de imagem padrão-ouro, a dacriocistografia por RX. Métodos: A amostra compreendeu 32 indivíduos (26 mulheres e seis homens, com média de idade de 55,4 $\pm 21,5$ anos) com tempo de sintomatologia oscilando entre três meses e vinte anos. Utilizaram-se seqüências de RM ponderadas em STIR T2 sem e com instilação de soro fisiológico e seqüência gradiente-eco ponderada em T1, após instilação de solução de gadolínio diluído (1:100). Os dados da RM foram correlacionados com o exame padrão-ouro (dacriocistografia por $\mathrm{RX}$ ). A análise foi realizada por dois observadores. Foram calculados: a sensibilidade, a especificidade e os valores preditivos - positivo (VPP) e negativo (VPN) - de cada uma das seqüências de RM, para a detecção da presença de obstrução das vias lacrimais. Calculou-se, ainda, a concordância intra- e interobservador para os diagnósticos da presença e do nível da obstrução, obtidos em cada seqüência de RM, comparando-a com o padrão-ouro (DCG), utilizando-se o teste exato de Fischer e o índice Kappa (K), com nível de significância $(p)<0,001$. Resultados: Quanto à detecção de obstrução das vias lacrimais, as seqüências de RM apresentaram sensibilidade entre $91,9 \%$ e $93,2 \%$, especificidade entre $80,3 \%$ e $100 \%$, VPP entre $88,7 \%$ e $100 \%$ e VPN entre $83,2 \%$ e $87,8 \%$. O índice Kappa revelou concordâncias intra- e interobservadores bastantes elevadas (entre 0,716 e $1,000)$. Quanto à caracterização do nível da obstrução, houve diferenças entre os resultados de cada um dos observadores. Para o observador 1, apenas a seqüência STIR, com instilação de soro fisiológico, denotou concordância estatisticamente significante com a DCG $(K=0,582)$. Em contrapartida, para 0 observador 2, todas as seqüências de RM mostraram concordância estatisticamente significante com a DCG (K entre 0,404 e 0,623). Conclusões: A RM pode ser adotada como método de imagem para a avaliação dos pacientes com suspeita de obstrução das vias lacrimais, por apresentar elevada sensibilidade e especificidade para esse diagnóstico, além de elevados índices de concordância intra - e interobservadores. Nos casos em que as vias lacrimais se revelem não preenchidas por qualquer meio de contraste na RM, outros métodos de imagem poderão ser necessários para a diferenciação entre obstruções altas ou distúrbios funcionais.

Descritores: Aparelho lacrimal. Doenças do aparelho lacrimal. Imagem por ressonância magnética. Radiografia. Técnicas de diagnóstico e procedimentos. 


\section{SUMMARY}

Abreu Jr. L. Comparison between magnetic resonance and $x$-ray dacryocystography in the evaluation of the obstruction of the lacrimal apparatus [tese]. São Paulo: Faculdade de Medicina, Universidade de São Paulo; 2008. $127 \mathrm{p}$.

Introduction: Epiphora is the hyperlachrymation related to an obstruction of the lachrymal drainage system. In such cases, the treatment is frequently surgical and the definition of the nature and level of obstruction demands imaging methods. Magnetic Resonance Imaging (MRI) may play a role in this issue. Objectives: Evaluate the efficacy of MR dacryocystography in the obstruction of the lachrymal drainage system, comparing the results to the gold standard imaging method (X-ray dacryocystography - DCG). Methods: The study comprised 32 patients ( 26 women and 6 men, mean age $55.4 \pm 21.5$ years), with a time course of symptoms ranging from 3 months to 20 years. They were evaluated using a STIR T2 sequence, without and with the instillation of saline solution and a Gradient-echo T1 sequence after instillation of 1:100 diluted gadolinium. The MRI findings were compared to the DCG ones. Two different observers performed the analysis. Sensitivity, specificity, positive predictive value (PPV) and negative predictive value (NPV) were calculated for each MRI sequence, regarding the detection of the obstruction of the lachrymal apparatus. Intra and interobserver agreement were calculated for the detection of the obstruction and for the determination of the level of obstruction, using the Fischer exact test and Kappa index - K (statistical significance $p<0,001$ ). Results: Regarding the detection of obstruction, MRI sequences presented sensitivity ranging from $91.9 \%$ to $93.2 \%$, specificity ranging from $80,3 \%$ to $100 \%$, PPV ranging from $88.7 \%$ to $100 \%$ and NPV ranging from $83.2 \%$ to $87.8 \%$. Kappa index revealed high intra and interobserver values (ranging from 0.716 to 1.000 ). Regarding the determination of the level of obstruction, the results for each observer were different. For Observer 1, the STIR T2 sequence after instillation of saline solution was the only one to be statistically concordant to DCG $(K=0.582)$. Otherwise, for Observer 2, all MR sequences were statistically concordant to DCG (K ranging from 0.404 to 0.623 ). Conclusions: MRI may be considered in the radiological evaluation of patients with epiphora, due to its high sensitivity and specificity, as well as consistent intra and interobserver agreement rates. When the lachrymal drainage system is not filled with any kind of content in the MRI examination, other imaging modalities must be considered, for differentiation between upper system obstruction and functional disease.

Descriptors: Lacrimal apparatus. Lacrimal apparatus diseases. Magnetic Resonance Imaging. Radiography. Diagnostic techniques and procedures. 
1. INTRODUÇÃO 


\section{INTRODUÇÃO}

A Dacriocistografia por Raios X (DCG) constitui o método de imagem mais amplamente utilizado e bem estabelecido para o estudo das vias lacrimais (Yoshikawa et al., 2000). Apesar da familiaridade de radiologistas e oftalmologistas com o método, devem-se considerar algumas desvantagens desse procedimento. Inicialmente, trata-se de um método relativamente invasivo, pois exige a cateterização e eventual dilatação dos pontos lacrimais, além de injeção intracanalicular de meio de contraste iodado (Weber et al., 1996). Oferece informações restritas sobre as condições dos tecidos de partes moles adjacentes às vias lacrimais ou da mucosa do ducto nasolacrimal. Além disso, por se tratar de um método que utiliza Raios $X$, determina exposição do cristalino à radiação ionizante, com doses que podem oscilar, em exames convencionais, entre 0,04 e 0,2 mSv (Som, 2003; Gmelin et al., 1987).

A exposição ocular à radiação pode determinar lesão das células proliferativas do epitélio anterior do cristalino, mediada por efeitos oxidativos, pela formação de radicais livres e por alterações de permeabilidade. As células lesionadas e os demais produtos de degradação podem acumular-se no pólo posterior do cristalino, ocasionando sua opacificação e modificação dos seus índices de refração, condição conhecida como catarata (llgit el al., 2000).

A dacriocistografia por TC tem sido utilizada como método para a avaliação das vias lacrimais. O estudo pode ser realizado após a cateterização das vias lacrimais ou apenas com a instilação do meio de contraste iodado. $\mathrm{O}$ 
fato de se obterem imagens seccionais e de se utilizar um método que permite a caracterização de grande variedade de atenuações teciduais oferece vantagens sobre a DCG convencional, principalmente pela possibilidade de identificação dos tecidos de partes moles periorbitários. Permite, além disso, o estudo dos elementos ósseos que compõem as vias lacrimais. Entretanto, como desvantagem, da mesma forma que a DCG, esse método utiliza radiação ionizante (Raios X), oscilando a dose absorvida pelo cristalino entre 1,8 a 2,6 mSv (Hahnel et al., 1995). Ao se utilizar a instilação tópica do contraste iodado, há ainda como desvantagem o potencial de irritação conjuntival determinada pelos meios de contraste iodados hidrossolúveis (Munk et al.,1989).

A Ultra-sonografia (US), método amplamente utilizado na Medicina, denota como principais vantagens o seu caráter não invasivo, ampla disponibilidade e possibilidade de inúmeras repetições sem acréscimo de risco para o paciente. Porém, sabe-se que elementos ósseos dificultam o acesso do feixe de US a estruturas anatômicas envoltas por eles. Isso ocorre com as estruturas das vias lacrimais denominadas como baixas: o saco lacrimal e o ducto nasolacrimal. O arcabouço ósseo em que estão contidos, impede o estudo adequado dessas estruturas pela US. Todavia, a identificação dos canalículos lacrimais é possível, uma vez que não há elementos ósseos interpostos a eles. A visualização dos canalículos, geralmente, exige certo grau de distensão, que pode ser obtido pela administração de materiais viscoselásticos em seu interior (Tost et al., 2003). 
A dacriocintilografia, como qualquer outro exame de Medicina Nuclear, é uma modalidade que privilegia informações funcionais e fisiológicas em detrimento das informações anatômicas. É, portanto, um método utilizado mais freqüentemente em suspeitas de processos de natureza funcional. Além da limitada resolução espacial (isto é, anatômica), outra desvantagem desse método reside na exposição do cristalino à radiação particulada, estimando-se que a dose absorvida pelo cristalino possa atingir 0,038 mGy/MBq de Tecnécio ${ }^{99 m}$ em indivíduos com vias lacrimais pérvias e até 1,09 mGy/MBq de Tecnécio ${ }^{99 m}$ em pacientes com obstrução completa das vias lacrimais (Robertson et al., 1979).

Para a avaliação de estruturas orbitárias, a Ressonância Magnética tem sido amplamente discutida na literatura médica. Em 1985, Schenck et al., comparando as bobinas de superfície com as de quadratura usadas para a avaliação do crânio descreveram os benefícios da aplicação das primeiras (de superfície) na identificação de pequenas estruturas orbitárias. A melhora da relação sinal-ruído permitiu reduzir o tamanho do voxel e o tempo de aquisição das seqüências. Ainda em 1985, Bilaniuk et al., publicaram os resultados do uso das bobinas de superfície, para a detecção tanto de lesões oculares (melanomas e hemangiomas), quanto de lesões orbitárias (meningiomas, hemangiomas, pseudotumores e mucoceles). Em 1998, Hoffman et al. exploraram ainda mais a capacidade das bobinas de superfície para o estudo de estruturas orbitárias. Esses autores comprovaram que a RM foi capaz de demonstrar pequenas estruturas orbitárias, inclusive o septo orbitário e 
músculos pré-septais. Tais trabalhos possibilitaram que o exame por meio da RM passasse a ser viabilizado no estudo das vias lacrimais.

Nesse cenário, a RM, potencialmente, ocupa uma posição diferenciada, uma vez que, de forma diferente dos métodos supracitados, não apresenta riscos de exposição do cristalino a radiação ionizante ou particulada. A exposição a campos magnéticos e pulsos de radiofreqüência é julgada segura em todas as aplicações clínicas atualmente disponíveis. Como comentado por Caldemeyer et al., em 1998 e por Yoshikawa et al., em 2000, além do benefício supracitado, há uma série de outras vantagens inerentes à $\mathrm{RM}$, dentre as quais se destacam: elevada resolução para estruturas de partes moles e ricas em água, capacidade multiplanar e, ainda, a possibilidade de obtenção simultânea de estudo bilateral. Se considerarmos a execução do estudo de RM sem cateterização das vias lacrimais, apenas com a instilação de algum meio de contraste, acrescentam-se as vantagens de ausência de invasibilidade e a possibilidade de estudos funcionais. Sem a pressão exercida pela injeção exógena de um meio de contraste, sua progressão, após o instilado, depende basicamente da capacidade funcional da via lacrimal.

$\mathrm{Na}$ literatura médica, as primeiras citações sobre o uso da RM para a avaliação das vias lacrimais datam de 1993 (Goldberg et al.) e 1994 (Rubin et al.). Esses primeiros estudos serviram-se do gadolínio diluído (1:100), tanto em instilação tópica quanto em injeção intravenosa. No decorrer dos anos 90 e a partir do ano 2000, sucederam-se vários trabalhos empregando a $\mathrm{RM}$, ora com instilação de algum meio de contraste (soro fisiológico, como escolhido por 
Caldemeyer et al., em 1998 ou gadolínio diluído, como aplicado por Kirchhof et al. em 2000), ora com cateterização das vias lacrimais e injeção de meio de contraste (Takehara et al., 2000).

Revisando os trabalhos da literatura médica, publicados entre 1993 e 2002, e que escolheram a RM para avaliação das vias lacrimais normais e patológicas, identificamos que o número de indivíduos estudados variou entre sete e vinte e cinco. Usaram-se seqüências com ponderação T1 e T2, valendo como meio de contraste o soro fisiológico, em alguns casos e o gadolínio diluído, em outros. Nenhum estudo comparou, sistematicamente, nos mesmos pacientes, diferentes técnicas de RM na caracterização de obstrução das vias lacrimais. Do ponto de vista de metodologia, os trabalhos avaliados pouco se preocuparam com o tratamento estatístico, havendo apenas descrições de cálculos da sensibilidade para a detecção da obstrução das vias lacrimais (Kirchoff et al. em 2000 e Karagulle et al. em 2002).

Identificamos, então, uma lacuna no conhecimento atual sobre o papel real da RM em pacientes com sintomatologia de lacrimejamento excessivo. $\mathrm{Na}$ tentativa de elucidar se a RM é realmente capaz de substituir o método padrãoouro (DCG) no diagnóstico de obstrução das vias lacrimais, desenhamos nosso estudo. 


\subsection{OBJETIVOS:}

1. Avaliar a eficácia da RM na identificação da obstrução das vias lacrimais, comparando-a com o método de diagnóstico por imagem considerado como padrão-ouro (DCG);

2. Avaliar a eficácia da RM na identificação do nível da obstrução das vias lacrimais, quando essa obstrução ocorrer, comparando-a com o método de diagnóstico por imagem considerado como padrão-ouro (DCG);

3. Propor um protocolo de RM para investigação de pacientes com suspeita de obstrução das vias lacrimais, incluindo um algoritmo para a propedêutica radiológica nessas condições. 
2. REVISÃO DA LITERATURA 


\section{REVISÃO DA LITERATURA}

Como ferramenta para a realização da revisão da literatura, utilizou-se o banco de dados disponibilizado pela United States National Library of Medicine / National Institutes of Health (PUBMED - www.pubmed.gov), abrangendo o intervalo compreendido entre 1975 e 2007.

\subsection{ANATOMIA DAS VIAS LACRIMAIS}

O aparelho lacrimal humano compõe-se de: glândula lacrimal, que secreta a lágrima, e sistema de excreção, formado pelos canalículos lacrimais (superior, inferior e comum), pelo saco lacrimal e pelo ducto nasolacrimal (Goss, 1988).

A glândula lacrimal está localizada na fossa lacrimal, na porção medial do processo zigomático do osso frontal. De forma ovalada, contém de seis a doze ductos de drenagem que desembocam na metade superior e lateral do fórnix conjuntival superior. Estruturalmente, a glândula lacrimal apresenta semelhanças com as glândulas salivares serosas (Goss, 1988).

O sistema excretor possui um componente ósseo e outro membranoso (Tasman e Jaeger, 1995).

O arcabouço ósseo da via lacrimal é composto pela fossa lacrimal e pelo canal nasolacrimal. 
A fossa lacrimal é identificada no processo nasofrontal da maxila, na porção ântero-inferior e nasal da órbita, e abriga o saco lacrimal. Seus limites anterior e posterior são, respectivamente, a crista lacrimal anterior e a posterior.

O canal nasolacrimal é a continuação inferior da fossa lacrimal, contém o ducto nasolacrimal e estende-se, inferiormente, na parede lateral da fossa nasal, até formar sua abertura no meato inferior, abaixo da concha nasal inferior, cerca de $17 \mathrm{~mm}$ acima do assoalho da fossa nasal. $\mathrm{O}$ canal nasolacrimal não apresenta trajeto vertical; contrariamente, identifica-se leve angulação de orientação posterior (cerca de $15^{\circ}$ a $20^{\circ}$ ) e minimamente lateral $\left(5^{\circ}\right)$. (Tasman e Jaeger, 1995; Weber et al., 1996).

Duas cavidades paranasais mantêm íntima relação com o arcabouço ósseo da via lacrimal: o seio maxilar (que forma a parede lateral da fossa nasal nessa localização) e o seio etmoidal (em contato com as paredes posteriores da fossa lacrimal e do canal nasolacrimal).

Os canalículos lacrimais estão localizados em cada uma das pálpebras, e recebem o nome delas: superior e inferior. Iniciam-se em pequenas aberturas localizadas acerca de seis $\mathrm{mm}$ do canto interno, os pontos lacrimais cujo diâmetro mede, aproximadamente, 0,3 mm. Os canalículos apresentam trajeto inicial de orientação vertical $(2 \mathrm{~mm})$ e, em seguida, curvam-se medialmente, em um trajeto horizontal de cerca de sete a dez $\mathrm{mm}$. A ampola canalicular, um pequeno segmento de discreta dilatação, é identificada na junção dos segmentos vertical e horizontal. O diâmetro dos canalículos é de $0,5 \mathrm{~mm}$, porém, em virtude de suas paredes elásticas, pode distender-se até três vezes 
seu diâmetro normal. Esse fato, associado à possibilidade de sua retificação por tensão lateral na pálpebra, facilita instrumentações do canalículo, segundo Wolff (1976) ${ }^{1}$ apud Russell et al. (1985). Em 90\% dos indivíduos, os canalículos unem-se antes de drenar as lágrimas para o saco lacrimal, formando o canalículo comum. Quando presente, esse canalículo possui extensão de um a três $\mathrm{mm}$ e termina em um pequeno divertículo da parede lateral do saco lacrimal, o seio de Maier. Nessa localização, dobras da mucosa formam a válvula de Rosenmüller, uma das constrições fisiológicas do sistema lacrimal. Acima do ponto de abertura do canalículo lacrimal comum, na junção do terço superior com os dois terços inferiores do saco lacrimal, restam cerca de três mm de extensão, conhecidos como dômus do saco lacrimal (Tasman e Jaeger, 1995).

O saco lacrimal pode variar em diâmetro, segundo Malik et al. (1969) ${ }^{2}$ apud Som e Curtin (2003): de 6 a $14 \mathrm{~mm}$ (vertical), de 1 a $4 \mathrm{~mm}$ (lateral) e de 1 a $6 \mathrm{~mm}$ (ântero-posterior). O saco lacrimal termina pouco acima da borda inferior da órbita, e na transição com o ducto nasolacrimal, há outra constrição fisiológica chamada de válvula de Krause (Tasman e Jaeger, 1995).

\footnotetext{
${ }^{1}$ Wolff E. Anatomy of the eye and orbit. Philadelphia: WB Saunders. 1976.

${ }^{2}$ Malik SRK, Gupta AK, Chaterjee S, Bhardwaj OP, Saha M. Dacryocystography of normal and pathological lacrimal passages. Br J Ophthalmol. 1969; 53: 174-179.
} 
O ducto nasolacrimal mostra as seguintes variações de dimensões, segundo Malik et al. (1969) ${ }^{3}$ apud Som e Curtin (2003): de 13 a 26 mm (vertical), de 1 a 4 mm (lateral) e de 1 a 4 mm (ântero-posterior). Existem, também, constrições mucosas fisiológicas no ducto, uma delas no nível da porção inferior do componente ósseo da concha nasal inferior (válvula de Taillefer) e a outra no nível da abertura do ducto no meato nasal inferior, a válvula de Hasner (Tasman e Jaeger, 1995).

O epitélio de revestimento das estruturas da via lacrimal é do tipo colunar pseudoestratificado ciliado, semelhante ao encontrado no trato respiratório superior. As paredes contêm muito tecido elástico, especialmente as dos canalículos, permitindo sua distensibilidade. Fibras de colágeno e tecido linfóide são identificadas no saco e ducto nasolacrimal.

\subsection{FISIOPATOLOGIA DA OBSTRUÇÃO DAS VIAS LACRIMAIS}

O mecanismo de eliminação das lágrimas já foi muito estudado. $\mathrm{Na}$ literatura médica, há teorias que divergem quanto à cadeia de eventos que resultam na drenagem lacrimal normal.

Múltiplos processos contribuem para a eliminação normal, incluindo mecanismos indiretos, isto é, passivos, tais como evaporação da lágrima, absorção pela mucosa do saco lacrimal, ação da gravidade e microciliação do ducto nasolacrimal (Tasman e Jaeger, 1995).

\footnotetext{
${ }^{3}$ Malik SRK, Gupta AK, Chaterjee S, Bhardwaj OP, Saha M. Dacryocystography of normal and pathological lacrimal passages. Br J Ophthalmol. 1969; 53: 174-179.
} 
Jones (1956) ${ }^{4}$ apud Amanat et al. (1983) realizou estudos anatômicos caracterizando inserções musculares (de músculos pré-tarsais e pré-septais) em estruturas das vias lacrimais. Dessas constatações, criou-se a teoria da bomba palpebral-canalicular, sugerindo um mecanismo ativo para a drenagem das lágrimas.

Segundo essa teoria, com as pálpebras abertas os canalículos lacrimais já se encontram cheios de lágrimas, decorrentes de enchimento por capilaridade. Ao fechamento das pálpebras, os pontos lacrimais mantêm-se em íntimo contato e permanecem fechados. A contração do músculo pré-tarsal encurta os canalículos e a contração do músculo pré-septal traciona lateralmente a parede lateral do saco lacrimal, criando, então, pressão negativa que orienta a lágrima em direção a ele. À abertura palpebral, o retorno do saco lacrimal para a sua configuração habitual determina progressão da lágrima em direção ao ducto nasolacrimal. Nessa fase do ato de piscar, a abertura dos pontos lacrimais, que estavam ocluídos, associa-se a um fenômeno de vácuo parcial (pop-open), permitindo entrada de lágrimas nos canalículos (Tasman e Jaeger, 1995).

\footnotetext{
${ }^{4}$ Jones LT. Epiphora: its relation to the anatomic structures and surgery of the medial canthal region. Trans Pac Coast Oto-Ophthalmol Soc. 1956; 37: 31-46.
} 
Entretanto, Brienen e Snell (1969) ${ }^{5}$ apud Amanat et al. (1983) e François e Neetens (1973) ${ }^{6}$ apud Amanat et al. (1983) não conseguiram comprovar, em seus estudos, a presença de inserções musculares em estruturas das vias lacrimais. Segundo esses autores, o ato de piscar não seria suficiente para modificar a configuração dos canalículos e do saco lacrimal e a progressão da lágrima pelo sistema excretor seria motivada apenas pelo aumento da pressão no saco conjuntival, determinada pelo fechamento palpebral.

Convém enfatizar que, a despeito da forma pela qual esse mecanismo ativo realmente atue na excreção das lágrimas, 0 ato de piscar desempenha papel muito importante, haja vista a presença de epífora em pacientes com deficiência do mesmo, como por exemplo, nos casos de paralisia facial (Tasman e Jaeger, 1995).

Estima-se que a epífora seja responsável por cerca de 3\% das visitas a consultórios oftalmológicos (Linberg e McCormick, 1986).

Diante de paciente com queixa de lacrimejamento, a primeira diferenciação a ser feita consiste em pesquisar qual o mecanismo envolvido: o excesso de produção de lágrimas (hiperlacrimejamento) ou a deficiência ou obstrução de drenagem (epífora). Dentre as causas de hiperlacrimejamento incluem-se: a triquíase, corpos estranhos superficiais irritando a conjuntiva, maus posicionamentos palpebrais (ectrópio) e irritação do nervo trigêmeo (Camara e Bengzun, 2006).

${ }^{5}$ Brienen JA, Snell CARD. The mechanism of the lacrimal flow. Ophthalmologica. 1969; 159: 223-232.

${ }^{6}$ François J, Neetens A. Tear flow in man. Am J Ophthalmol. 1973; 76: 351-358 
A deficiência de drenagem lacrimal por sua vez, pode ser atribuída a alteração do mecanismo de excreção (funcional) ou a obstrução ao livre trânsito da lágrima (anatômica). Dentre as causas de distúrbios funcionais, devemos lembrar-nos da frouxidão palpebral, da fraqueza da musculatura orbicular e da paralisia do nervo facial, que, mesmo na vigência de uma via lacrimal completamente permeável, determinarão epífora por comprometimento do mecanismo de "bomba lacrimal" (Kanski, 1994).

O hiperlacrimejamento decorrente de obstrução das vias lacrimais pode ser classificado em primário ou secundário (Camara e Bengzun, 2006).

A Obstrução Primária Adquirida do Ducto Nasolacrimal - OPADN (da literatura americana PANDO - Primary Acquired Nasolacrimal Duct Obstruction) consiste em uma doença inflamatória de etiologia desconhecida, na qual o processo inflamatório crônico estabelece um círculo vicioso em que inflamação, obstrução e estase se sucedem, culminando com fibrose e atrofia (Camara e Bengzun, 2006).

Em 1986, os autores Linberg e McCormick publicaram um trabalho divulgando os aspectos histopatológicos em pacientes com a síndrome clínica OPADN. Em doze pacientes, os autores puderam demonstrar as variações do comprometimento das vias lacrimais, de acordo com a fase evolutiva, oscilando desde processo inflamatório crônico ativo, nos casos iniciais, até obliteração fibrótica difusa do ducto nasolacrimal, nas fases mais avançadas da doença. 
OPADN é uma doença mais freqüente em mulheres (50 a 83\% dos casos) e, na maior parte das vezes, compromete pacientes a partir da quinta década de vida (Camara e Bengzun, 2006).

O processo inflamatório característico da doença determina congestão vascular e edema, resultando em restrição ao fluxo normal da lágrima no sistema excretor. A presença de debris celulares e de secreção mucosa espessa no interior do saco lacrimal e ducto nasolacrimal, por estase crônica e comprometimento infeccioso secundário, potencializa os danos às paredes mucosas da via excretora. O resultado final das agressões teciduais é fibrose e atrofia (Linberg e McCormick, 1986).

Em 2003, Anderson et al. publicaram os resultados de seu estudo em que os produtos histológicos obtidos de 377 dacriocistorrinostomias foram submetidos à análise anatomopatológica, evidenciando como conseqüência mais freqüente um processo inflamatório não granulomatoso $(85,1 \%)$, provavelmente relacionado à OPADN. Baseando-se nas identificações de lesões neoplásicas em cerca de $4,6 \%$ dos pacientes incluídos em sua casuística, os autores sugerem estudo anatomopatológico de rotina em produtos obtidos de DCR.

A origem do processo inflamatório que compromete as vias lacrimais ainda é incerta. Os estudos de Linberg e McCormick não estabeleceram relação entre o processo inflamatório e uma causa bacteriana específica. Entretanto, DeAngelis et al. estudaram 114 pacientes submetidos à dacriocistorrinostomia e obtiveram culturas positivas em $44,7 \%$ dos casos, independentemente da 
história de dacriocistites ou mucoceles prévias. Essas ocorrências sugerem que possa haver influência de um processo infeccioso no desencadeamento do processo inflamatório da via lacrimal.

Groessl et al., em 1997, cogitaram uma explicação anatômica para a gênese da OPADN. Em seu trabalho, os diâmetros das vias lacrimais mostraram-se diferentes entre homens e mulheres, significativamente menores nas mulheres. Em 2001, Janssen et al. estudaram os diâmetros das vias lacrimais de indivíduos assintomáticos e de indivíduos acometidos pela OPADN, utilizando a TC. Esses autores confirmaram a diferença significativa de diâmetros, de acordo com o sexo, sendo menores em mulheres. Esse fato pode estar relacionado ao desenvolvimento da doença, ou, ao menos possivelmente, torna a via lacrimal mais suscetível aos efeitos do processo inflamatório.

As obstruções das vias lacrimais podem, também, ser secundárias a variada gama de processos patológicos, enumerados abaixo (Camara e Bengzun, 2006):

$\checkmark$ Infecções (bacterianas, virais, fúngicas ou parasitárias);

$\checkmark$ Doenças granulomatosas (sarcoidose) e vasculites (granulomatose de Wegener);

$\checkmark$ Uso de colírios (antiglaucomatosos);

$\checkmark$ Quimioterápicos (5-FU e Docetaxel);

$\checkmark$ Radioterapia;

$\checkmark$ Neoplasias (primárias das vias lacrimais ou secundárias extensão de lesão palpebral); 
$\checkmark$ Trauma (fraturas de face, após manipulação cirúrgica em seios paranasais).

\subsection{EXAME CLÍNICO}

Perante um paciente com quadro clínico de hiperlacrimejamento, o exame oftalmológico deve englobar (Kanski, 1994):

$\checkmark$ Inspeção externa

$\checkmark$ Exame em Lâmpada de fenda

$\checkmark$ Cateterização e Irrigação

$\checkmark$ Testes especiais

\subsubsection{INSPEÇÃO EXTERNA}

Consiste no exame das pálpebras, buscando caracterizar-se a presença de: ectrópio, triquíase, eversão do ponto lacrimal inferior ou frouxidão palpebral inferior, condições que podem determinar comprometimento do mecanismo normal de propulsão da lágrima à via excretora ou aumento da produção de lágrimas por mecanismo irritativo, como na triquíase (Tasman e Jaeger, 1995).

Deve-se realizar também a palpação do saco lacrimal na fossa lacrimal. A identificação de um saco lacrimal distendido e tenso pode estar relacionada a dacriocistite aguda ou eventualmente a mucocele - dacriocistocele (Tasman e Jaeger, 1995). 
A última etapa dessa fase do exame consiste na compressão do saco lacrimal. Se, ao comprimi-lo, houver exteriorização (por refluxo) de material muco-purulento através dos canalículos, há a indicação que deve existir dacriocistocele por obstrução baixa da via lacrimal (base do saco lacrimal ou ducto nasolacrimal), com sistema canalicular permeável (Kanski, 1994).

\subsubsection{EXAME EM LÂMPADA DE FENDA}

Inicialmente, deve-se caracterizar a quantidade de lágrimas coletada no saco conjuntival, tendo em vista que muitos pacientes com epífora não ostentam lágrimas que "escorrem" pela face, e o diagnóstico será feito baseando-se no aumento dessa "lâmina lacrimal" (Kanski, 1994).

Com o auxílio da lâmpada de fenda, o exame dos pontos lacrimais pode ser realizado com mais acurácia, permitindo identificarem-se maus posicionamentos, estenoses ou obstruções. Se a expressão dos canalículos lacrimais revelar exteriorização de material purulento, o diagnóstico de canaliculite deve ser considerado (Tasman e Jaeger, 1995).

A dinâmica do ato de piscar também pode ser avaliada nessa fase do exame. O examinador solicita ao paciente que feche os olhos. Em condições normais, com a pálpebra fechada, os pontos lacrimais devem estar em aposição completa; se houver frouxidão palpebral, por exemplo, os pontos lacrimais podem sobrepor-se, tornando ineficaz o mecanismo de transporte da lágrima pelo sistema excretor (Camara e Bengzun, 2006). 
Nessa fase do exame, inclui-se o Teste de desaparecimento da Fluoresceína. Procede-se à instilação de uma gota de fluoresceína a 2\% nos sacos conjuntivais e avalia-se seu desaparecimento, ou não, após cinco a dez minutos. Se a fluoresceína persistir, prolongadamente, no saco conjuntival, a possibilidade de algum distúrbio no transporte da lágrima deve ser considerada (Kim e Tsirbas, 2005).

\subsubsection{CATETERIZAÇÃO E IRRIGAÇÃO}

Nesse momento do exame, instila-se colírio anestésico nos sacos conjuntivais, para que uma cânula lacrimal reta, fixada em uma seringa com soro fisiológico, seja inserida através do canalículo lacrimal inferior. Ao progredir com a cânula, o examinador tenta caracterizar qual o tipo de resistência que percebe. Segundo Kanski (1994), é possível identificar-se uma resistência "mole" (Soft stop) ou uma resistência "dura" (Hard stop).

Ocorre resistência "dura" (Hard stop), quando a cânula encosta no osso lacrimal, que delimita a parede medial do saco lacrimal. Portanto, assume-se que a cânula conseguiu entrar no interior do saco lacrimal, descartando-se obstrução completa do sistema canalicular. O examinador procede, em seguida, à irrigação do saco lacrimal, mantendo um dedo na fossa lacrimal. Duas situações poderão ser encontradas (Kanski, 1994; Tasman e Jaeger, 1995):

$\checkmark$ O soro fisiológico atinge a fossa nasal, sugerindo não haver obstrução completa da via lacrimal inferior. As possibilidades a 
serem consideradas são a obstrução parcial (suplantada pela pressão utilizada durante a irrigação) ou a ausência de qualquer obstrução (via lacrimal permeável - hiperlacrimejamento ou falência da bomba lacrimal);

$\checkmark$ O soro fisiológico não atinge a fossa nasal e o saco lacrimal distende-se durante a irrigação (sentido à palpação). Nessa situação, considera-se a possibilidade de obstrução completa da via lacrimal inferior (transição saco - ducto ou ducto nasolacrimal). Pode haver refluxo do soro fisiológico pelo ponto lacrimal superior (Figura 1A).

A resistência "mole" (Soft stop) consiste na sensação de algo relativamente elástico, decorrente da compressão do canalículo comum e da parede lateral do saco lacrimal contra a parede medial do mesmo. Tal ocorrência indica que a cânula não adentrou o saco lacrimal e a obstrução é, provavelmente, canalicular. Não deverá haver distensão do saco lacrimal com a irrigação. O refluxo da solução salina pelo canalículo lacrimal inferior indica sua obstrução. Se houver refluxo pelo canalículo superior (Figura 1 B), a obstrução deve situar-se no canalículo comum (Kanski, 1994; Tasman e Jaeger, 1995). 


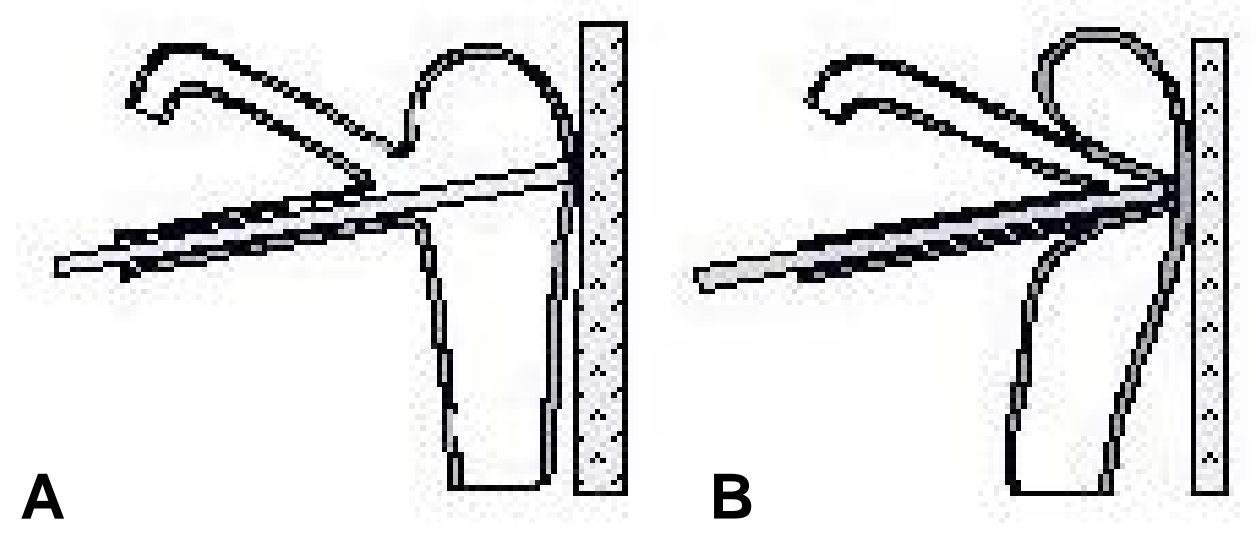

Figura 1. Exame clínico. Hard stop (a) e Soft stop (b). Modificado de Kanski JJ. Clinical Ophthalmology: a systematic approach. London: Butterworth-Heinemann. $3^{\text {rd }}$ ed. 1994.

Existem ainda testes especiais (conhecidos como testes de Jones primário - I e secundário - II) que se aplicam apenas a indivíduos em que há suspeita de obstrução parcial da via lacrimal. Nesses pacientes, há epífora, mas, com a irrigação, a solução salina transita por toda a via lacrimal, atingindo a fossa nasal (Kanski, 1994; Tasman e Jaeger, 1995).

\subsection{DIAGNÓSTICO POR IMAGEM}

Embora o diagnóstico da obstrução das vias lacrimais possa ser realizado, com relativa acurácia, por meio dos exames clínicos (Stupp et al. 2004), há necessidade de estudos por imagem para confirmar o diagnóstico e para caracterizar o exato nível da obstrução. Essas informações são indispensáveis 
para a seleção da técnica cirúrgica adequada, com impacto sobre os resultados, em longo prazo (Guzek et al., 1997).

Os métodos de diagnóstico por imagem disponíveis para o estudo das vias lacrimais são: Dacriocistografia (por Raios X), Ultra-sonografia, Dacriocintilografia (Medicina Nuclear), Tomografia Computadorizada e a Ressonância Magnética.

\subsubsection{DACRIOCISTOGRAFIA}

O estudo das vias lacrimais por meio dos Raios X (Dacriocistografia) foi descrito pela primeira vez por Ewing, em $1909^{7}$ (apud Weber,1996), ao empregar radiografias da região orbitária, após administração de um meio de contraste (subnitrato de bismuto), para a demonstração de uma cavidade infectada na via lacrimal. Desde esse primeiro relato, a DCG tornou-se o exame de diagnóstico por imagem de primeira linha, para a avaliação das vias lacrimais, combinando a excelente visualização das estruturas ósseas perilacrimais, conferida pelos Raios X, com a opacificação do lúmen pelo meio de contraste administrado pelos canalículos. O método permite a identificação das principais estruturas das vias lacrimais e, em presença de obstrução, possibilita a sua caracterização e a do nível em que ocorre (Weber et al., 1996).

7 Ewing AE. Roentgen ray demonstrations of the lacrimal abcess cavity. Am J Ophthalmol. 1909; 24: 1-4. 
Para a sua execução, é necessária a introdução de um cateter em um dos canalículos lacrimais, a fim de que um meio de contraste possa opacificar a via lacrimal, que então será observada nas radiografias.

Desde a descrição original da técnica, muitas variações foram propostas. De todas essas variações, as mais comumente utilizadas são a Dacriocistografia por distensão e a Dacriocistografia por subtração digital (Som e Curtin, 2003).

Na DCG por distensão, radiografias simples são obtidas, durante a administração (injeção) do meio de contraste através de um dos canalículos lacrimais, distendendo continuamente a via lacrimal, até se caracterizar a passagem à fossa nasal em seu meato inferior (via lacrimal pérvia) ou se identificar a obstrução (Som e Curtin, 2003).

Na DCG por subtração digital, a injeção do meio de contraste na via lacrimal é acompanhada por meio de controle fluoroscópico, permitindo-se a identificação imediata do ponto obstrutivo, resultando, de uma forma geral, em um menor número de exposições do que com a técnica convencional. A subtração digital oferece, ainda, a vantagem de reduzir os efeitos indesejáveis ocasionados pela sobreposição de estruturas ósseas. Essa combinação acaba resultando em uma dose de radiação menor, quando confrontada com a técnica convencional. Galloway et al. (1984) estimaram que essa dose pode chegar a ser treze vezes menor, quando comparada a exames com técnica convencional. 


\subsubsection{ULTRA-SONOGRAFIA}

A ultra-sonografia é um método de diagnóstico por imagem amplamente utilizado em Oftalmologia. A utilização de transdutores de alta freqüência permite a avaliação detalhada tanto da câmara anterior quanto de estruturas retro-oculares e intra-orbitárias. Dessa forma, tem-se utilizado a ultra-sonografia para o estudo das mais variadas afecções orbitárias.

Considerando-se os aspectos anatômicos relacionados às vias lacrimais, fica claro que há algumas limitações ao uso da ultra-sonografia para seu estudo. O principal fator limitante reside na presença dos elementos ósseos que englobam algumas das estruturas anatômicas. Dessa forma, a ultrasonografia encerra pouca utilidade no estudo das vias lacrimais baixas, uma vez que o saco lacrimal e o ducto nasolacrimal estão intimamente envolvidos por ossos da face (Stupp et al., 2004).

Entretanto, a ultra-sonografia tem sido utilizada para o estudo de estruturas lacrimais superiores (canalículos), segundo vários relatos da literatura compulsada.

Em 2003, Tost et al. e Ostenford e Tost, publicaram seus trabalhos adotando transdutores de alta freqüência (20 Mhz) para a avaliação dos canalículos lacrimais. Valendo-se da administração de um material viscoelástico para distensão dos canalículos lacrimais, esses autores conseguiram identificar alterações (canaliculite crônica com a presença de concreções), concluindo que transdutores de $20 \mathrm{Mhz}$ proporcionam a melhor relação entre 
penetração (profundidade) e resolução. Segundo esses autores, transdutores com freqüência mais alta (33 a $50 \mathrm{Mhz}$ ), utilizados, por exemplo, para os estudos de biomicroscopia da câmara anterior, não se aplicam ao estudo das vias lacrimais.

Um uso potencial da ultra-sonografia convencional está na caracterização da dacriocistocele congênita. Há muitos relatos na literatura, (como o de D’Addario et al., 2001), do diagnóstico pré-natal dessa condição por meio de exames ultra-sonográficos de rotina durante a gestação.

Portanto, o uso da ultra-sonografia como um método completo para a avaliação de pacientes com obstrução das vias lacrimais é ainda limitado.

\subsubsection{DACRIOCINTILOGRAFIA}

Utilizam-se os métodos de Medicina Nuclear em várias áreas da Medicina. Esses métodos partilham como característica comum a utilização de um radiofármaco, que, distribuído das mais variadas formas (inalação, injeção intravascular, ingestão ou instilação), oferece imagens que assinalam como grande vantagem a avaliação funcional do órgão ou estrutura estudada. Outra característica peculiar aos métodos é a baixa resolução espacial inerente à imagem cintilográfica, produzindo um detalhamento anatômico limitado. Portanto, ao se solicitar um estudo cintilográfico, convém ponderar que a informação obtida terá um significado mais funcional do que anatômico. 
A utilização da Medicina Nuclear para o estudo das vias lacrimais teve seu primeiro relato em 1972, quando Rossomondo et al. ${ }^{8}$ apud Amanat et al. (1983) descreveram o método.

O estudo baseia-se na instilação de uma gota de Pertecnetato de Tecnécio ${ }^{99 m}$ no saco conjuntival, com o paciente em posição sentada, e com a cabeça apoiada em um suporte acoplado a uma gama-câmara. Em seguida, procede-se à aquisição das imagens, iniciando-se com um estudo dinâmico com aquisições a cada dez segundos, durante os primeiros 160 - 180 segundos. Posteriormente, são obtidas imagens estáticas após cinco, dez, quinze e vinte minutos da instilação inicial. Além das imagens anatômicas conseguidas, o método permite a obtenção de análises quantitativas, com curvas que relacionam tempo e atividade do radiofármaco em cada um dos pontos da via lacrimal (Rossomondo et al., 1972) ${ }^{8}$.

Em virtude das características de aquisição das informações na dacriocintilografia, esse método torna-se bastante útil na avaliação de distúrbios funcionais das vias lacrimais.

Em 1999, Wearne et al. publicaram um estudo comparando a dacriocintilografia com a DCG na verificação das obstruções funcionais das vias lacrimais. Os dois métodos em conjunto mostraram sensibilidade de $98 \%$ para a detecção de distúrbios funcionais. Isoladamente, a cintilografia manifestou

8 Rossomondo RM, Carlton WH, Trueblood JH, Thomas RP. A new method of evaluating lacrimal drainage. Arch Ophthalmol. 1972; 88: 523-525. 
sensibilidade maior que a DCG (95\% vs $93 \%$ respectivamente). Baseando-se nesses dados, os autores sugerem como algoritmo de investigação, a avaliação inicial com a DCG, reservando a cintilografia aos casos em que a DCG parecer normal.

\subsubsection{TOMOGRAFIA COMPUTADORIZADA}

A Tomografia Computadorizada (TC) constitui um método de diagnóstico por imagem seccional que tem sido amplamente aproveitado para o estudo das órbitas, em virtude de sua ótima resolução espacial e capacidade de diferenciação de atenuações teciduais, admitindo a caracterização tanto de estruturas ósseas como de partes moles. Vários estudos foram conduzidos na década de 80, aferindo o papel da TC em doenças inflamatórias, neoplásicas e traumáticas das órbitas (Gyldensted et al., $1977^{9}$ apud Russell et al, 1985; Forbes et al., 1980; Schramm et al., 1982).

Em 1985, Russel et al. descreveram os aspectos anatômicos normais e as principais condições patológicas que comprometem o canto ínfero-medial orbitário e as vias lacrimais, detectadas por meio da TC em cem pacientes. Segundo os autores, além das vantagens relacionadas à resolução temporal, a TC ainda pode auxiliar o estudo dessas regiões orbitárias com a obtenção de reconstruções multiplanares (sagital e coronal).

\footnotetext{
${ }^{9}$ Gyldensted C, Lester J, Fledelius H. Computed tomography of orbital lesions: a
} radiological study of 144 cases. Neuroradiology. 1977; 13: 141-150. 
Em 1990, Zinreich et al. descreveram uma nova forma de utilização da TC para a avaliação das vias lacrimais, associando as imagens anatômicas com a instilação tópica de contraste iodado (dacriocistografia por TC). Vários relatos dessa nova técnica se sucederam, ressaltando as suas vantagens em casos complexos e em estudos pós-cirúrgicos (Massoud et al., 1993).

Moran et al. publicaram, em 1995, um artigo citando o uso da TC helicoidal para a avaliação das vias lacrimais, após a instilação de contraste iodado. Os autores ressaltaram que a TC helicoidal, por conseguir um volume maior de informações (cortes mais finos e interpolados) e com melhor resolução temporal (mais rápidos), admite a obtenção de reconstruções multiplanares e tridimensionais, que podem auxiliar na interpretação de obstruções das vias lacrimais.

Em 1998, Caldemeyer et al. publicaram seu trabalho em que expuseram o uso da dacriocistografia por TC e por RM em voluntários assintomáticos. No exame tomográfico, os indivíduos foram submetidos à instilação de lopamidol (duas gotas / minuto por cinco minutos) e no exame de RM utilizou-se a instilação de soro fisiológico (duas gotas / minuto por cinco minutos). Os autores concluíram que ambos os métodos possibilitaram a identificação das vias lacrimais normais, com relativa vantagem em relação à dacriocistografia por Raios X, em virtude de seu cunho mais fisiológico. Os autores informaram, ainda, que a TC apontou pequenas estruturas das vias lacrimais (canalículos), de forma mais consistente do que a RM. 


\subsubsection{RESSONÂNCIA MAGNÉTICA}

Ressonância Magnética (RM) refere-se a um método de diagnóstico por imagem fundamentado na aplicação de pulsos de radiofreqüência que alteram a distribuição espacial de spins de moléculas de Hidrogênio, expostas a um campo magnético determinado (magneto). O tempo de relaxamento desses spins, após a cessação do pulso de radiofreqüência, é característico de cada tecido, e ocorre nos eixos longitudinal (T1) e transversal (T2). Isso dá à RM a grande vantagem de caracterização tecidual normal e patológica. Sua elevada resolução (contraste) para estruturas de partes moles, associada a sua capacidade multiplanar (obtenção de imagens nos três planos ortogonais) fazem-na um excelente método para o estudo das órbitas e de seus componentes.

O uso de bobinas de superfície, que resultam em uma melhor relação sinal-ruído, é indispensável para o estudo das estruturas orbitárias. Hoffman et al. (1998) narraram a experiência com o uso de bobinas de superfície $(4,0 \mathrm{~cm}$ de diâmetro), em estudo do septo orbitário. Em seu trabalho, os autores demonstraram que imagens de alta resolução do septo orbitário podem ser obtidas em aparelho de alto campo magnético, auxiliando, por exemplo, na caracterização da extensão de processos inflamatórios superficiais.

Em 1993, Goldberg et al. promoveram o primeiro relato na literatura acerca da utilização da RM para a avaliação das vias lacrimais, de uma forma semelhante à DCG. Em seu trabalho, os autores estudaram onze indivíduos, 
alguns assintomáticos e outros com problemas nas vias lacrimais, administrando uma solução composta por gadolínio diluído em soro fisiológico e metilcelulose (diluição final 1:100). Foram utilizadas tanto a instilação tópica, quanto a injeção canalicular da referida solução. Os autores observaram boa tolerância dos indivíduos à administração da solução de gadolínio, sem relatos de efeitos colaterais significativos. Quanto aos resultados, os autores mencionaram que o gadolínio instilado topicamente promoveu bom preenchimento das estruturas anatômicas das vias lacrimais, salvo em situações em que estenoses canaliculares estavam presentes. Nessas circunstâncias, os autores consideraram como opção a injeção canalicular do gadolínio (semelhante à DCG). Os autores realçaram, também, as vantagens potenciais da RM em casos complicados, em virtude da possibilidade de estudo das partes moles, relação com seios paranasais e outros. Salientou-se, ainda, a aplicação potencial da RM com instilação de gadolínio, para estudo de alterações funcionais, vantagem marcante em relação à DCG.

Em 1994, Rubin et al. publicaram os resultados do uso da RM em doenças das vias lacrimais. Os autores enfatizaram que a localização relativamente superficial das estruturas lacrimais as torna excelentes objetos de estudo, com o uso de bobinas de superfície em exames de RM. Nos casos citados nesse trabalho, o gadolínio foi administrado ora por via endovenosa, ora por injeção canalicular. Entre as doenças estudadas, incluíram-se papilomas intralacrimais, mucoceles do saco lacrimal e outras alterações de natureza inflamatória. Os autores concluíram que a RM oferecia maiores vantagens em relação à $\mathrm{DCG}$ e 
à TC, entre elas: a maior resolução espacial, a capacidade multiplanar e o maior contraste entre estruturas de partes moles. Considerando-se o estágio da tecnologia naquela época, os autores arrolaram, ainda, como desvantagens relativas da RM: o tempo de execução do exame (necessitando muita colaboração por parte do paciente), a presença de artefatos de movimento (mais evidentes em virtude do uso de bobinas de superfície) e o custo elevado.

Em 1998, Caldemeyer et al. publicaram os resultados de um trabalho efetuado com voluntários assintomáticos, em que se investigavam as vias lacrimais por meio da RM, após a instilação de soro fisiológico. Os autores usaram uma seqüência com ponderação T2 e com técnica para supressão do sinal da gordura, instilando duas gotas de soro fisiológico por minuto, durante cinco minutos antes de sua aquisição. As estruturas das vias lacrimais normais puderam ser visibilizadas pela RM; entretanto, quando comparada à dacriocistografia por TC (realizada no mesmo estudo), estruturas de menores dimensões (canalículos) foram caracterizadas mais consistentemente com essa última técnica.

Em 2000, Yoshikawa et al., conduziram um estudo comparando os aspectos observados em exames de dacriocistografia por RM, empregando a instilação de soro fisiológico e de gadolínio diluído (1:100), com a DCG convencional. O estudo foi desenhado com uma avaliação experimental e com uma avaliação clínica. $\mathrm{Na}$ avaliação experimental, tubos com diâmetros de 0,7; 0,$9 ; 1,1 ; 1,4$ e $1,7 \mathrm{~mm}$, preenchidos com soro fisiológico e gadolínio diluído foram avaliados com seqüências ponderadas em T2 e T1, respectivamente. Os 
tubos foram identificados em toda a sua extensão em ambas as seqüências; entretanto, com a seqüência ponderada em T2, os diâmetros mensurados pela RM concordaram mais com os reais. A avaliação clínica constituiu-se no estudo de dezoito pacientes com quadro clínico de epífora, que foram submetidos à RM com instilação de soro fisiológico e gadolínio diluído. Em catorze pacientes efetuou-se, também, DCG. Apesar de a RM ter identificado vinte obstruções das vias lacrimais, houve discrepância entre os seus resultados e os da DCG, em metade dos casos.

Entre os anos de 1997 e 2002, vários trabalhos foram publicados, com aplicação da técnica de dacriocistografia por RM, após a instilação de gadolínio diluído.

Em 1997, Wilhelm et al. utilizaram a RM para a avaliação de 32 vias lacrimais de 16 pacientes, após instilação de gadolínio com diluição 1:10. Os autores concluíram que a RM oferecia avaliação morfológica detalhada das vias lacrimais, com a vantagem de potencial avaliação funcional. Entretanto, nesse estudo, os autores identificaram que, em 15 casos de pacientes cujos ductos nasolacrimais estavam normais, estes não tinham sido preenchidos pelo gadolínio diluído.

Em 1999, Hoffmann et al. utilizaram a RM com instilação de gadolínio diluído (1:100) no estudo de 22 olhos, identificando estenoses em 18 casos. Nesse estudo, obtiveram-se imagens tanto no plano axial quanto no plano coronal. 
Kirchhof et al. em 2000 e Karagülle et al., em 2002, publicaram seus trabalhos com o uso da seqüência de RM com ponderação T1, após instilação de gadolínio diluído (1:100), e ambos relataram sensibilidade de $100 \%$ do método para a detecção de obstrução das vias lacrimais. No estudo de Karagülle et al. houve discrepância entre a DCG e a RM em dois casos. A discordância referia-se ao nível da obstrução, assumido como canalicular pela RM e identificado no nível do saco lacrimal pela DCG. 
3. MÉTODOS 


\section{MÉTODOS}

\subsection{TIPO DE ESTUDO, SELEÇÃO DE PACIENTES E VARIÁVEIS CLÍNICAS}

Este trabalho consistiu em um estudo prospectivo com o objetivo de aferir a capacidade da dacriocistografia por RM na detecção de obstrução das vias lacrimais, em pacientes com sintomatologia de hiperlacrimejamento, comparando-a com o método de imagem padrão-ouro nessa condição, a dacriocistografia por RX. Foram estudados pacientes encaminhados, após avaliação realizada por um oftalmologista com experiência e atuação específica em doenças das vias lacrimais, no período de junho de 2006 a junho de 2007.

O projeto foi aprovado pelas Comissões de Ética para Análise de Projetos de Pesquisa (CAPPesq) do Hospital São Luiz, sob o número 109 / 2005, em dezembro de 2005, e do Hospital das Clínicas da Faculdade de Medicina da USP, sob o número 401, em junho de 2006 (Anexos A e B) . O Consentimento Livre e Esclarecido, assinado por todos os pacientes ou por seus responsáveis legais, foi devidamente aprovado. Nele foram incluídas as devidas explicações e orientações acerca do procedimento, utilizando-se linguagem adequada à compreensão dos pacientes e de seus acompanhantes (Anexo C).

Os critérios de inclusão foram:

1. pacientes de qualquer sexo e idade;

2. queixa de lacrimejamento excessivo com qualquer tempo de evolução dos sintomas; 
3. concordância e assinatura do termo de consentimento para a realização da dacriocistografia por RM.

Os critérios de exclusão estão descritos abaixo:

1. indivíduos com contra-indicações absolutas à realização do exame de RM, a saber: uso de marca-passo ou desfibrilador cardíaco, presença de clipe cirúrgico ferromagnético de aneurisma, presença de implante coclear ou de fragmentos metálicos oculares;

2. mulheres grávidas;

3. vigência de processo inflamatório agudo na via lacrimal (p. ex., dacriocistite aguda);

4. claustrofobia.

A amostra foi composta por 32 pacientes com queixa clínica de lacrimejamento excessivo, sendo 26 mulheres $(81,25 \%)$ e 6 homens $(18,75 \%)$, com idades oscilando entre 5 e 84 anos e média de idade de 55,4 $\pm 21,5$ anos. A evolução temporal dos sintomas oscilou entre três meses e 20 anos (Anexo D, Tabela 1). Os 32 pacientes contribuíram com 63 vias lacrimais estudadas pela RM (uma via lacrimal foi excluída, em virtude de manipulação cirúrgica prévia) e com 60 vias lacrimais estudadas pela dacriocistografia por $\mathrm{RX}$ (duas vias lacrimais não cateterizadas, uma descartada pela presença de manipulação cirúrgica prévia e outra descartada por irregularidades provavelmente relacionadas com a manipulação prévia). Efetivamente 60 vias lacrimais foram estudadas por ambos os métodos e utilizadas para a análise dos observadores. 
Os pacientes foram avaliados por um oftalmologista que, além de coletar a história clínica, procedia ao exame oftalmológico, tentando caracterizar a presença e o nível de obstrução. A obstrução era classificada em alta (proximal ao saco lacrimal, isto é, canalicular) ou baixa (do saco lacrimal para baixo). As informações sobre o nível da obstrução baseadas no exame oftalmológico foram recuperadas para apenas 17 olhos de 14 pacientes e estão resumidas na Tabela 2 (Anexo E). A figura 2 demonstra um caso de obstrução baixa obtida em diferentes seqüências de RM e de DCG. 

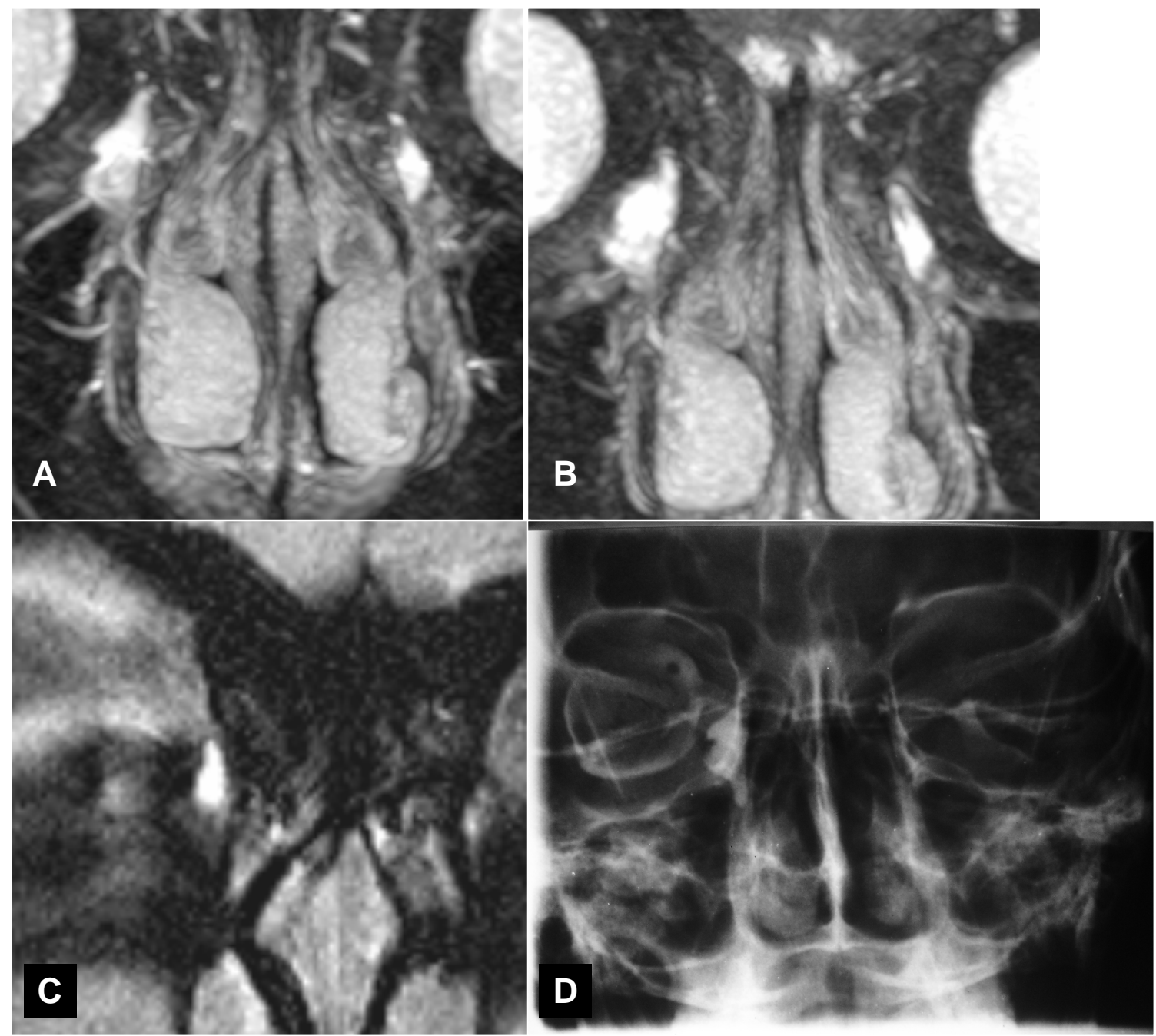

Figura 2 - Caso número 19. Reconstruções MIP das seqüências STIR sem (a) e com instilação de soro fisiológico (b), imagem-fonte da seqüência T1, após instilação de gadolínio diluído (c) e DCG (d). Obstrução da via lacrimal direita no nível da transição saco-ducto nasolacrimal observada por meio das seqüências de RM. A DCG evidencia que a obstrução ocorre no segmento proximal do ducto nasolacrimal, pouco mais distal do que a RM demonstrou. 


\subsection{DACRIOCISTOGRAFIA POR RESSONÂNCIA MAGNÉTICA}

\subsubsection{Equipamento de RM e preparo para a realização do exame}

Os exames de RM foram realizados no Serviço de Ressonância Magnética do Hospital São Luiz - Unidade Morumbi.

Os exames foram realizados em um aparelho INTERA 1,5 T - PHILIPS, Netherlands, utilizando-se seqüências e protocolos disponíveis comercialmente.

Os pacientes eram recepcionados no Serviço de RM do Hospital São Luiz, onde recebiam as informações necessárias acerca do exame, preenchiam e assinavam o Termo de Consentimento Livre e esclarecido. Caso algum item do vestuário fosse considerado inadequado ao uso no interior da sala de RM, oferecia-se ao paciente avental apropriado. Não foi realizada punção venosa, pois o protocolo não incluiu estudo com aplicação de contraste intravenoso.

Os pacientes eram posicionados em decúbito dorsal horizontal na mesa de exame, com um travesseiro para apoio da cabeça. A seguir, posicionava-se uma bobina de superfície circular (C1) com diâmetro interno de cerca de $16 \mathrm{~cm}$, sobre a face do paciente, de tal forma que, na área interna da bobina, ficavam incluídas a glabela, ambas as órbitas e o mento. A bobina era fixada à face com o auxílio de tiras adesivas e faixas próprias. Entregava-se ao paciente um alarme sonoro, sob a forma de "pêra", que poderia ser acionado a qualquer momento, durante o exame, caso houvesse algum desconforto ou 
intercorrência. Antes do início do exame, fazia-se tentativa de esvaziamento do saco lacrimal, massageando-o.

\subsubsection{TÉCNICA DE EXAME E SEQÜÊNCIAS UTILIZADAS}

1‥ A primeira seqüência realizada era o LOCALIZADOR (SURVEY) que consistia em uma seqüência com ponderação T2, multiplanar, que permitia a identificação da topografia das vias lacrimais na região periorbitária (perissinusal), assegurando a programação adequada de toda sua extensão (Tabela 3).

20. A segunda seqüência do exame era uma seqüência Turbo Spin Eco (TSE) com ponderação T2, com técnica de saturação (supressão) de gordura (SPIR) e sem instilação de qualquer meio de contraste, no plano axial, cuja programação incluía como limite superior a topografia das glândulas lacrimais e como limite inferior o palato duro (teto da cavidade oral). Isso permitia a avaliação das vias lacrimais em toda a sua extensão, especialmente da mucosa do saco lacrimal e ducto nasolacrimal. Essa seqüência permitia, também, a avaliação da mucosa das cavidades paranasais adjacentes (Tabela 3).

3o. A seguir, realizava-se a seqüência STIR ponderada em T2, no plano coronal, sem instilação de nenhum meio de contraste (Figura 3), incluindo-se toda a extensão ântero-posterior das vias lacrimais. Nessa seqüência, tentava-se caracterizar as estruturas normais das vias lacrimais, 
a presença e o eventual nível de obstrução. Essa seqüência gerava uma reconstrução tridimensional com técnica de Projeção de Intensidade Máxima - MIP (Tabela 3).
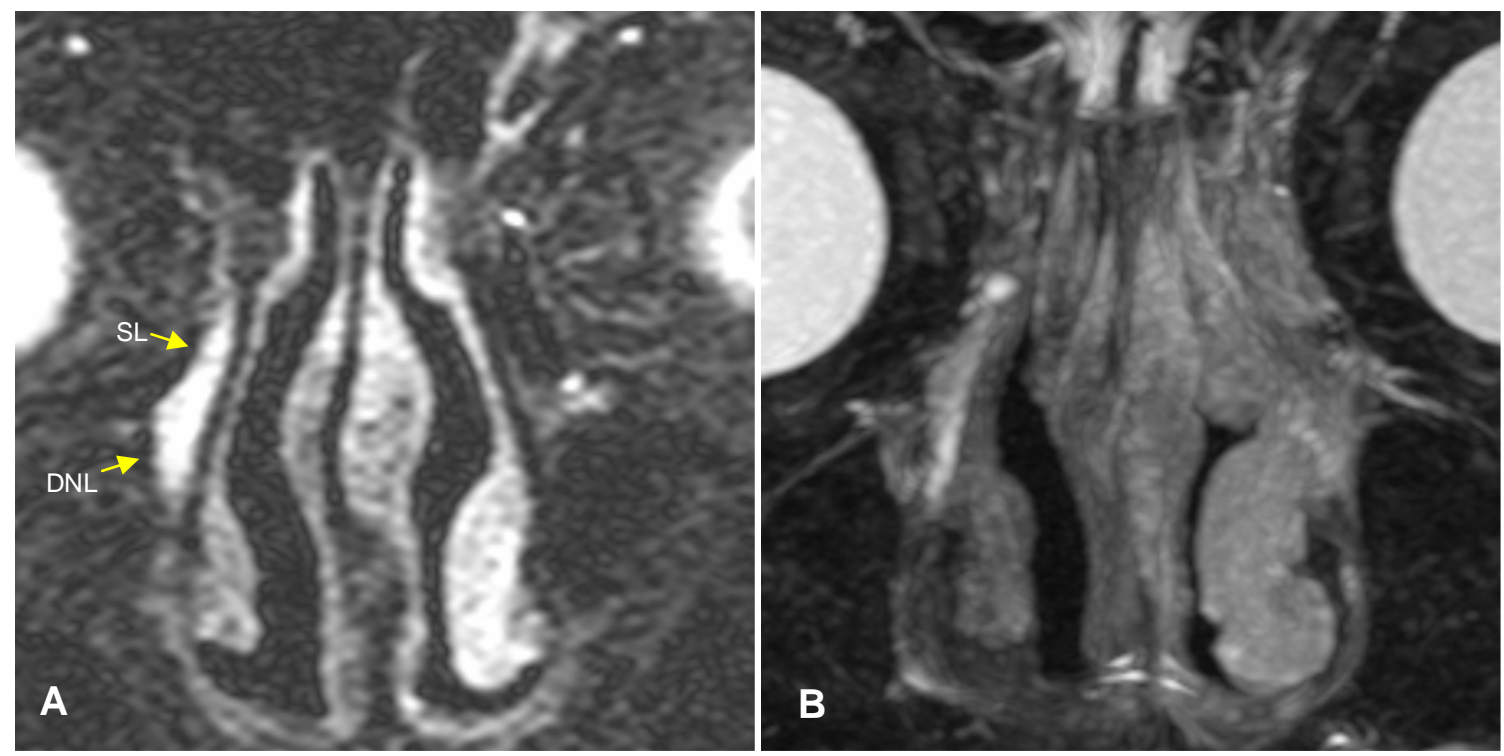

Figura 3 - Seqüência STIR no plano coronal, sem nenhuma instilação. Imagemfonte (a) e reconstrução MIP (b). Ë possível identificarem-se o saco lacrimal $(\mathrm{SL})$ e a porção proximal do ducto nasolacrimal (DNL), à direita (setas). A imagem MIP (b) mostra a via lacrimal direita parcialmente definida, com dimensões normais.

4‥ Seqüência STIR ponderada em T2, no plano coronal, após instilação conjuntival de Soro Fisiológico a $\mathbf{0 , 9 \%}$ (Figura 4). Após o término da seqüência do item $3^{\circ}$, a mesa de exame e o paciente eram afastados, parcialmente, do centro do magneto, para que fosse realizada a instilação de Soro Fisiológico a 0,9 \%. Instilavam-se duas gotas de soro no saco conjuntival a cada minuto, durante cinco minutos, e em seguida, iniciava-se a mesma seqüência do item anterior. 


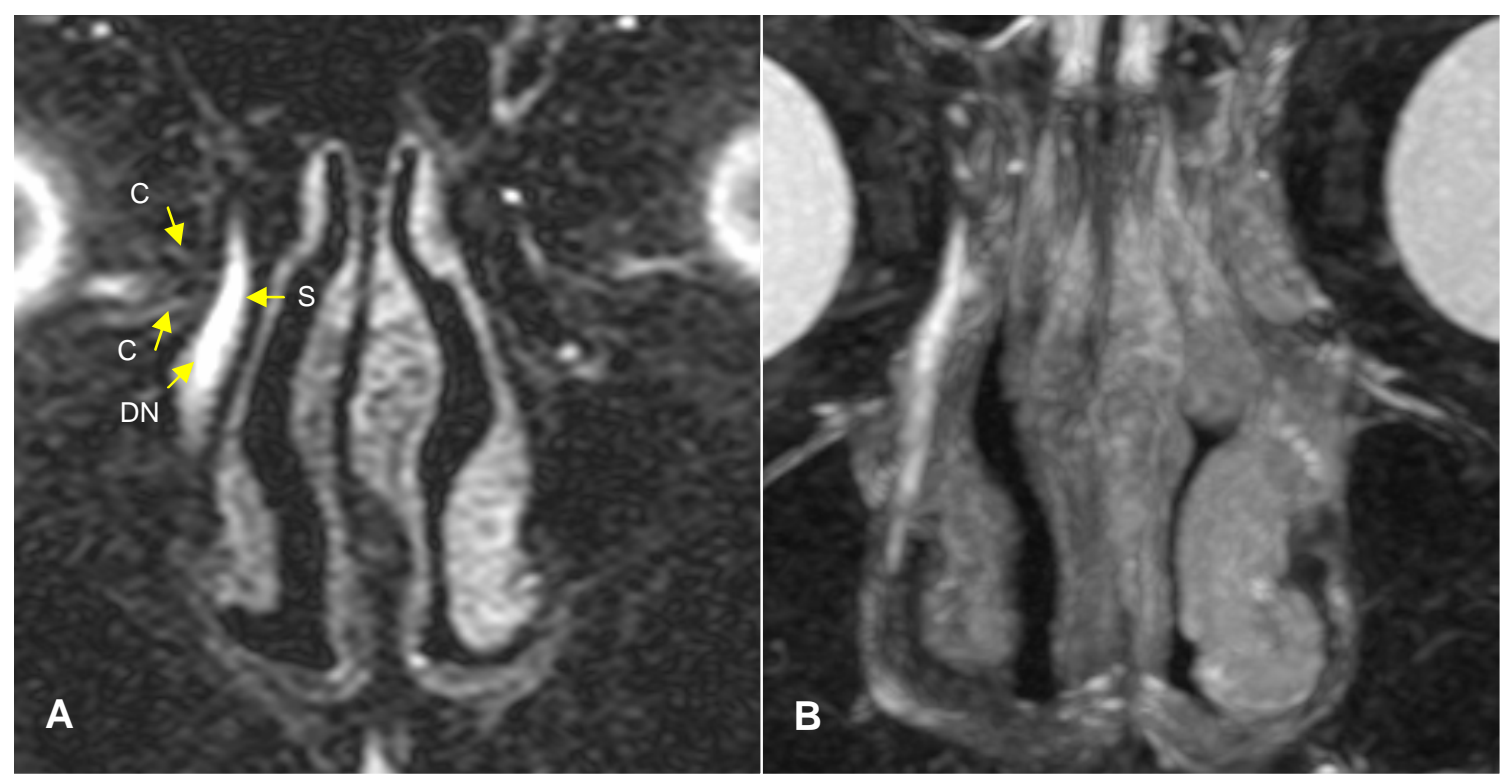

Figura 4 - Seqüência STIR no plano coronal, após instilação de SF. Imagemfonte (a) e reconstrução MIP (b). Ë possível identificarem-se os canalículos lacrimais (CL), o saco lacrimal (SL) e a porção proximal do ducto nasolacrimal (DNL), à direita (setas). A imagem MIP (b) mostra toda a extensão da via lacrimal direita com dimensões normais.

5o. Nesse momento do exame, o paciente era retirado do magneto e permanecia fora da sala de exame por cerca de 30 minutos, confortavelmente na posição sentada. Esse intervalo tinha por objetivo permitir o eventual clareamento do soro no interior da via lacrimal.

60. Após o intervalo de 30 minutos, o paciente era reposicionado e reiniciavase a seqüência do item $1^{\circ}$ (LOCALIZADOR / SURVEY), com a finalidade de permitir a programação das demais seqüências.

7․ A mesma seqüência STIR ponderada em T2, no plano coronal, sem instilação de nenhum meio de contraste era novamente realizada, com o objetivo de caracterizar a presença de distensão remanescente das vias lacrimais pelo soro fisiológico anteriormente utilizado. 
8‥ Para finalizar o exame, realizava-se a seqüência Gradiente-eco (FFE) ponderada em T1, no plano coronal, após instilação de uma solução de Gadolínio (Optimark ${ }^{\circledR}$ - Gadoversetamida, Mallinkrodt) diluído em Soro Fisiológico, com diluição de 1:100 (Figura 5). Essa seqüência era avaliada pelo pesquisador; se este julgasse ser adequado o preenchimento das vias lacrimais, o exame era encerrado. Nos casos em que a preenchimento de qualquer das vias lacrimais parecia insuficiente, procedia-se à nova instilação de gadolínio, com repetição da aquisição. Essa seqüência gerava uma reconstrução tridimensional com técnica de Projeção de Intensidade Máxima - MIP (Tabela 3).

No início do exame de cada um dos pacientes, preparava-se a solução de gadolínio, diluindo-se 1,0 $\mathrm{ml}$ de Gadoversetamida em cem $\mathrm{ml}$ de soro fisiológico 0,9\%. Os exames abrangeram sempre as duas órbitas, mesmo quando a sintomatologia relatada era unilateral. Dessa forma, foram incluídas, na análise, vias lacrimais potencialmente normais. O tempo total do exame (excluindo-se o intervalo fora da sala de exame) foi de aproximadamente 40 minutos. 

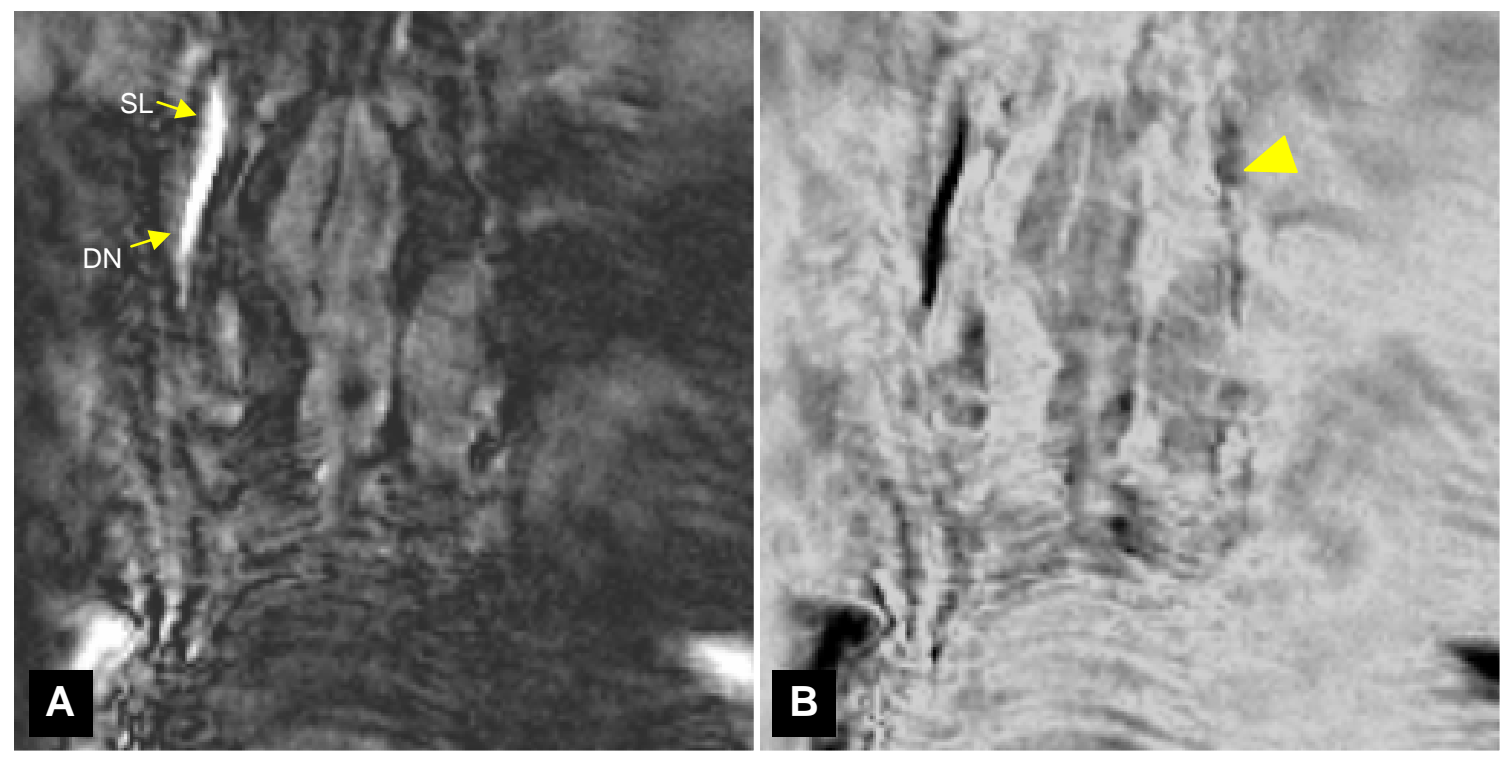

Figura 5 - Seqüência T1 gradiente-eco no plano coronal, após instilação de gadolínio diluído. Imagens-fonte com janela habitual (a) e janela invertida (b). Ë possível identificarem-se o saco lacrimal (SL) e a porção proximal do ducto nasolacrimal (DNL) à direita (setas). A via lacrimal esquerda é apenas parcialmente identificada e com tênue preenchimento pelo gadolínio (cabeça de seta em b).

Tabela 3: Principais parâmetros das seqüências de RM utilizadas na avaliação dos pacientes.

\begin{tabular}{lllll}
\hline & Localizador & T2 axial & STIR coronal & T1 coronal \\
\hline Seqüência de pulso & TSE & TSE & STIR & FFE* \\
Bobina & Circular(C1) & Circular(C1) & Circular(C1) & Circular(C1) \\
Plano de corte & Multiplanar & Axial & Coronal & Coronal \\
TR (mseg) & 12.325 & 4.365 & 3.745 & 32.8 \\
TE (mseg) & 250 & 100 & 90 & 4.0 \\
TI (mseg) & - & - & 180 & - \\
Campo de visão (cm) & $25 \times 25$ & $18 \times 18$ & $12 \times 12$ & $11 \times 11$ \\
Matriz & $512 \times 512$ & $512 \times 512$ & $512 \times 512$ & $256 \times 256$ \\
Espessura de corte (mm) & 5.0 & 3.0 & 1.8 & 3.0 \\
Espaçamento entre cortes (mm) & 0.6 & 0.3 & 0.0 & -1.5 \\
Número de cortes & 10 & 20 & 16 & 30 \\
Número de aquisições & 1 & 4 & 4 & 2 \\
Ângulo de inclinação & - & - & - & 30 \\
Trem de eco & 90 & 17 & 19 & 0 \\
Tempo de aquisição (minutos) & $01: 13$ & $03: 07$ & $02: 56$ & $04: 03$ \\
Supressão de gordura (SPIR) & Não & Sim & Não se aplica & Sim \\
\hline
\end{tabular}

${ }^{\star}$ Gradiente-eco 


\subsection{DACRIOCISTOGRAFIA POR RAIOS X}

\subsubsection{EQUIPAMENTO, PREPARO E TÉCNICA PARA A REALIZAÇÃo dO EXAME}

Os exames de dacriocistografia por Raios $\mathrm{X}$ eram obtidos em até duas semanas após a realização do exame de $\mathrm{RM}$ e foram realizados em aparelho Neodiagnomax (MEDICOR - Budapeste). A técnica escolhida foi a de macrodacriocistografia. No intervalo de tempo entre os exames, os pacientes não foram submetidos a nenhum tipo de intervenção nas vias lacrimais.

Os pacientes eram recepcionados no setor específico e posicionados na mesa de exames em decúbito dorsal. Procedia-se, então, à instilação de colírio anestésico (Cloridrato de proximetacaína - Anestalcon®, Alcon), uma gota em cada saco lacrimal por minuto, durante três minutos. Em seguida, era realizada a radiografia simples em projeção frontal, para aferir a qualidade técnica.

Depois, realizava-se a cateterização da via lacrimal, com preferência no canalículo lacrimal inferior, utilizando-se agulha butterfly número 25 , com bisel cortado, acoplada a seringa descartável de três $\mathrm{ml}$. Utilizou-se meio de contraste iodado não iônico hidrossolúvel (lobitridol - Henetix®, Guerbet), em um volume de cerca de 2,0 $\mathrm{ml}$ em cada seringa. A administração do meio de contraste era feita de forma lenta, intercalando-se radiografias na incidência frontal ântero-posterior (Figura 6). 


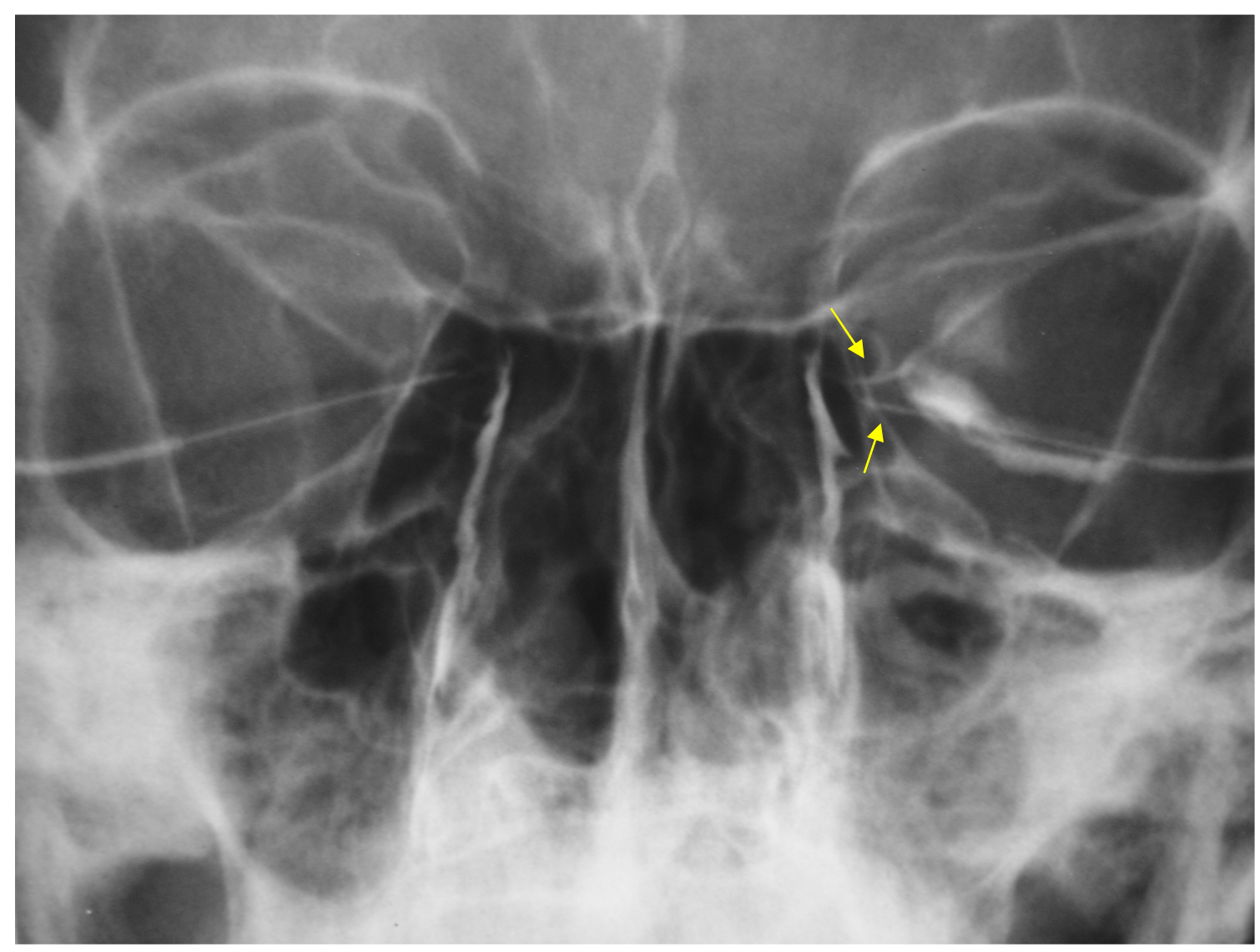

Figura 6 - Caso número 16. Dacriocistografia por Raios X. Vias lacrimais totalmente permeáveis e com dimensões normais. Os canalículos lacrimais, superior e inferior, são bem visibilizados, à esquerda (setas).

\subsection{INTERPRETAÇÃO DOS EXAMES DE RM E RAIOS X}

Após a realização dos exames de RM, as imagens foram analisadas por dois radiologistas, um deles especialista em Radiologia da Cabeça e Pescoço, com vinte anos de experiência, e o outro, não especialista, com dez anos de experiência. As imagens foram revisadas em uma estação de trabalho, adotando-se o programa E-film versão 2.1.0 (Merge). Após os exames de dacriocistografia convencional, as radiografias obtidas foram, igualmente, revisadas. 


\subsubsection{AVALIAÇÃO DOS EXAMES DE RM}

Cada um dos examinadores avaliou todas as seqüências de RM (axial T2 SPIR, coronal STIR sem instilação, coronal STIR com instilação de soro fisiológico e T1 SPIR com instilação de gadolínio diluído), tentando identificar, inicialmente, em cada uma delas, a presença, ou não, de obstrução das vias lacrimais. Caso o observador julgasse ter ocorrido obstrução, deveria aferir-lhe o nível.

Considerou-se que alguma obstrução estaria presente, quando se pudesse caracterizar ao menos uma das situações abaixo:

$\checkmark$ Dilatação da via lacrimal a montante de um determinado ponto analisado;

$\checkmark$ Ausência de preenchimento de estruturas a jusante de um determinado ponto analisado;

$\checkmark$ Assimetria das estruturas das vias lacrimais, com aumento de suas dimensões no lado obstruído.

Os níveis de obstrução estabelecidos foram:

$\checkmark$ Canalículos lacrimais (C): obstrução alta, proximal ao saco lacrimal;

$\checkmark$ Saco lacrimal (SL): obstrução no nível do saco lacrimal, sem identificação do ducto nasolacrimal;

$\checkmark$ Ducto nasolacrimal (D): obstrução em qualquer nível do ducto nasolacrimal. 
A via lacrimal poderia ainda ser considerada como Não preenchida (NP), quando o observador não conseguisse caracterizar a presença de "material" de contraste em sua topografia. Quanto ao material de contraste poderia tratar-se de lágrima ou secreção (para a seqüência sem nenhuma instilação), soro fisiológico ou gadolínio diluído (Figura 7).

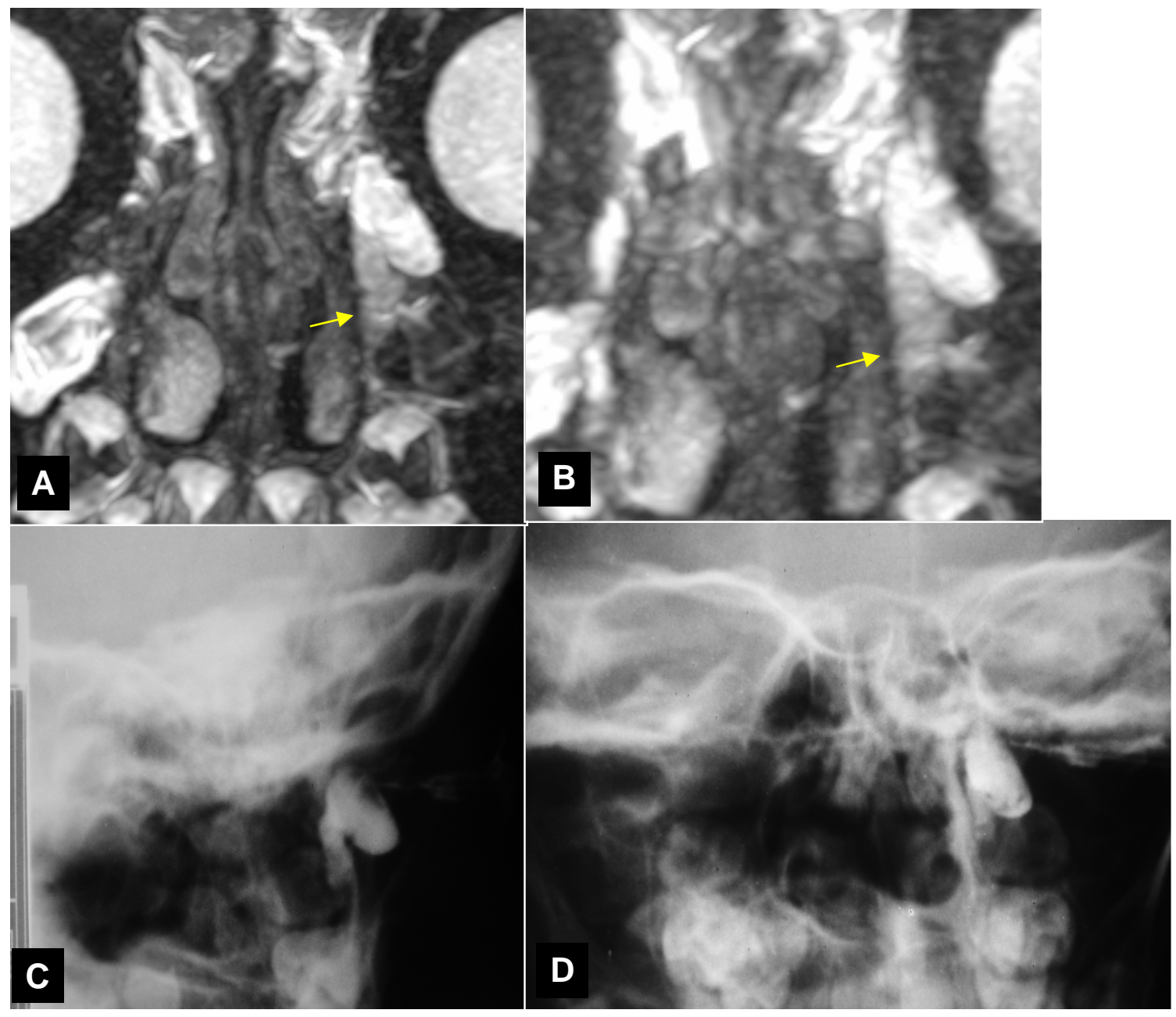

Figura 7 - Caso número 27. Criança de cinco anos de idade, com história de epífora, à esquerda, desde o nascimento. Reconstrução MIP das seqüências STIR sem instilação (a) e com instilação de soro fisiológico (b) e imagens da DCG (c,d). A RM evidencia a obstrução no nível do ducto nasolacrimal, à esquerda (setas), caracterizando-se conteúdo heterogêneo, destacando-se material com sinal intermediário nas porções mais distais do ducto, devendo corresponder à secreção espessa. A DCG (frente e perfil) confirma o nível e o aspecto da obstrução. 
Para a avaliação das imagens de RM, puderam ser usados todos os recursos disponíveis no programa da estação de trabalho, tais como magnificação (zoom), inversão de janela, mensurações e reconstruções multiplanares, tanto para as imagens-fonte quanto para aquelas com técnica de máxima intensidade de projeção (MIP).

Os dois observadores fizeram suas análises individualmente. Analisaram cada uma das seqüências de RM, separadamente, em dias distintos, sem o conhecimento do lado afetado ou dos resultados da dacriocistografia por $\mathrm{RX}$. Cada seqüência de RM foi avaliada, sem o conhecimento dos resultados obtidos com as outras duas técnicas.

\subsubsection{AVALIAÇÃO DOS EXAMES DE RAIOS X (DACRIOCISTOGRAFIA)}

Cada um dos examinadores analisou as imagens dos exames de dacriocistografia, individualmente e em dias separados, sem o conhecimento dos resultados obtidos pela RM. Os exames foram efetuados em ambos os olhos de 30 pacientes e apenas no olho sintomático de dois pacientes. Os examinadores determinaram a presença ou ausência de obstrução das vias lacrimais por esse método, descrevendo o nível de obstrução quando presente, a saber:

$\checkmark$ Canalículos lacrimais (C): obstrução alta, proximal ao saco lacrimal;

$\checkmark$ Saco lacrimal (SL): obstrução no nível do saco lacrimal, sem identificação do ducto nasolacrimal; 
$\checkmark$ Ducto nasolacrimal (D): obstrução em qualquer nível do ducto nasolacrimal.

A dacriocistografia por Raios X foi considerada o "padrão-ouro" para a caracterização da obstrução da via lacrimal.

\subsection{ANÁLISE ESTATÍSTICA}

Inicialmente, verificou-se a eficácia de cada uma das seqüências de RM na detecção da presença, ou não, de obstrução da via lacrimal, em comparação com o padrão-ouro (dacriocistografia por RX), para cada observador individualmente, portanto, não consensual. Para tal análise foi empregado o Teste exato de Fischer com nível de significância de 1\%, além do cálculo de concordância, aplicando-se o índice Kappa (também com nível de significância de 1\%). Os cálculos foram efetuados utilizando-se o software SPSS. Para cada uma das seqüências de RM, a concordância interobservador foi avaliada com a mesma metodologia descrita acima. Nessa análise, foram incluídas apenas as vias lacrimais consideradas, pelos observadores, como preenchidas por algum meio de contraste.

Fizeram-se os cálculos de: sensibilidade, especificidade e valores preditivos positivo e negativo, para cada uma das técnicas de RM. Tais cálculos foram efetivados para dois cenários distintos. No primeiro cenário, excluiram-se as vias lacrimais consideradas como não preenchidas, utilizando-se apenas como números de casos os que não despertaram dúvidas nos observadores 
quanto à real identificação da via lacrimal. No outro cenário, usou-se o número total de vias lacrimais estudadas, incluindo-se, portanto, até mesmo aquelas consideradas como não preenchidas. Em virtude da natureza dicotômica de nossos resultados possíveis (obstrução = teste positivo $\mathrm{x}$ não obstrução $=$ teste negativo), ao incluirmos os casos de não preenchimento, classificamos como obstrução presente na RM, baseando-nos em uma classificação prévia proposta por Hoffmann et al. (1999), em que ausência de preenchimento da via lacrimal na RM, por qualquer meio de contraste (inclusive a lágrima), era interpretada como sinal de obstrução alta, isto é, canalicular (Figura 8). 

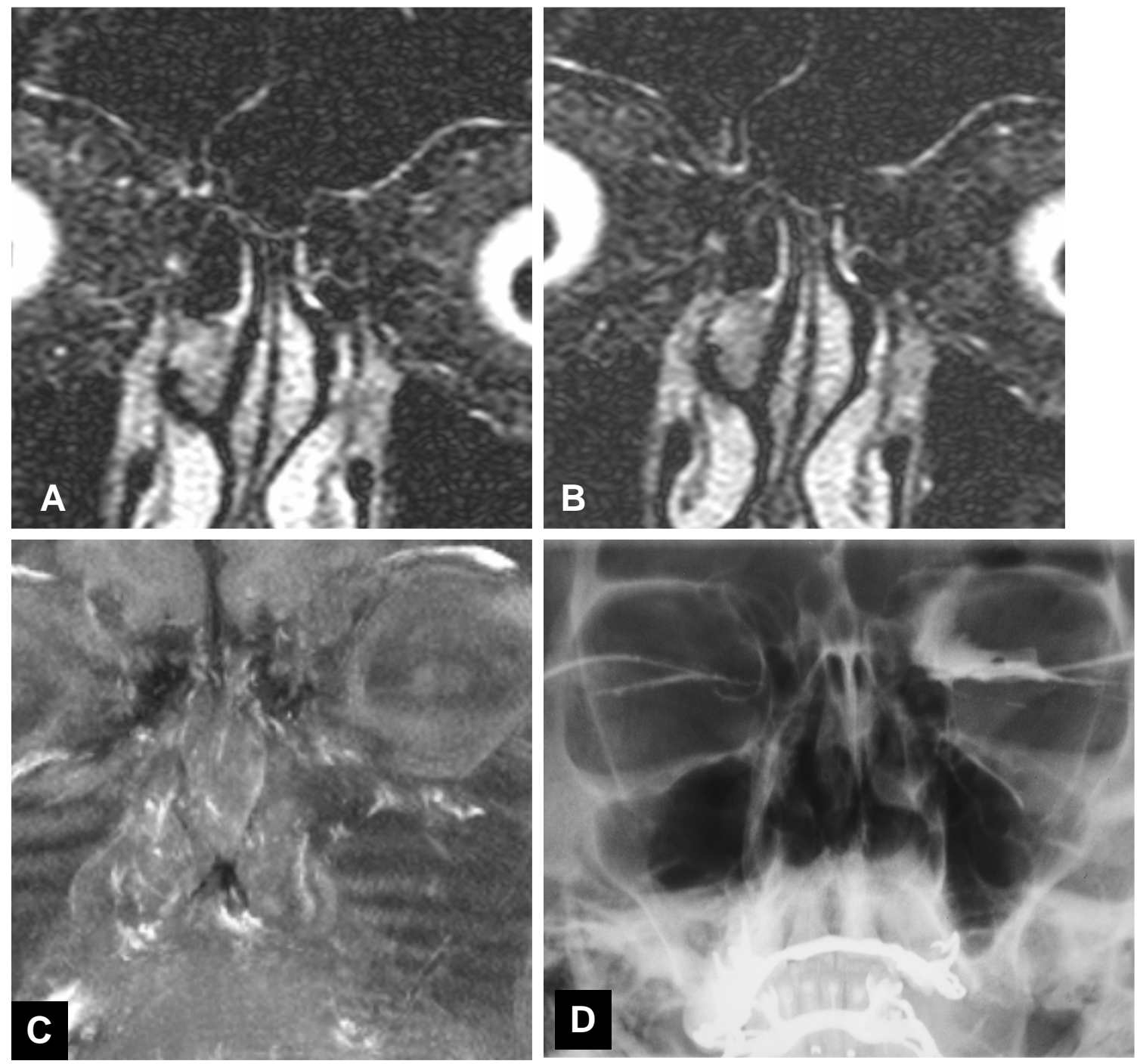

Figura 8 - Caso número 17. A RM com seqüências STIR sem instilação (a) e após instilação de soro fisiológico (b) e com seqüência T1 após instilação de gadolínio diluído (c) evidencia que as vias lacrimais estão não preenchidas. A dacriocistografia por Raios X (d) evidenciou obstrução alta (no nível dos canalículos comuns) em ambos os olhos, justificando a ausência de preenchimento das vias lacrimais por qualquer meio de contraste à RM. 
A análise subseqüente contemplou a avaliação da eficácia de cada uma das seqüências de RM na identificação do nível da obstrução, quando esta estava presente, incluindo apenas os casos em que a RM e a DCG concordavam quanto à existência de obstrução da via lacrimal. Para esse propósito foram utilizados o Teste exato de Fischer e o índice Kappa de concordância. Para essa análise, em algumas situações, tornou-se necessária uma variação da técnica para cálculo do índice Kappa, conhecida como Agreement test, conforme proposta de Scott e Maxwell \& Pilliner (Fleis, 1981). Esse procedimento foi adotado, porque o cálculo do índice Kappa exige que se obtenha uma matriz realmente quadrada, ou seja, todas as caselas da tabela devem apresentar expressão numérica (isto é, não serem nulas). Para algumas análises de detecção do nível da obstrução, ocorreu a situação em que determinado observador não identificara nenhum caso em que a obstrução apresentasse um nível específico (por exemplo, obstrução em nível canalicular para o observador 2). Dessa forma, a matriz assumiu um formato assimétrico, exigindo utilização da técnica supracitada.

Avaliou-se, ainda, a concordância entre os dois observadores, tanto para o diagnóstico da obstrução, quanto para o do nível de obstrução das vias lacrimais por meio da RM, utilizando-se o índice Kappa. Segundo Landis e Koch (1977), o índice Kappa foi interpretado em cada uma das situações, conforme a tabela abaixo (Tabela 4). 
Tabela 4: Interpretação do índice Kappa (Landis e Koch, 1977).

\begin{tabular}{|c|c|}
\hline \multicolumn{2}{|c|}{ Valores do Kappa Interpretação } \\
\hline$<0$ & Sem concordância \\
\hline $0-0,19$ & Concordância pobre \\
\hline $0,20-0,39$ & Concordância satisfatória \\
\hline $0,40-0,59$ & Concordância moderada \\
\hline $0,60-0,79$ & Concordância substancial \\
\hline $0,80-1,00$ & Concordância quase perfeita \\
\hline
\end{tabular}


4. RESULTADOS 


\section{RESULTADOS}

Dos 32 pacientes incluídos em nossa amostra, 68,75\% (22/32) queixavamse de lacrimejamento unilateral, $43,75 \%$ (14/32), no olho esquerdo e $25 \%$ (8/32), no olho direito. Em 31,25\% (10/32), a queixa era bilateral (Figura 9).

Dos 60 exames de DCG realizados, 68,3\% (41/60) evidenciaram obstrução de vias lacrimais e 31,7\% (19/60) não a evidenciaram. Nos casos com obstrução, 85,3\% (35/41) foram de localização baixa (saco lacrimal $63,4 \%$ ou ducto nasolacrimal - 21,9\%) e 14,7\% (6/41) comprovaram obstrução alta, isto é, canalicular (Figura 10).

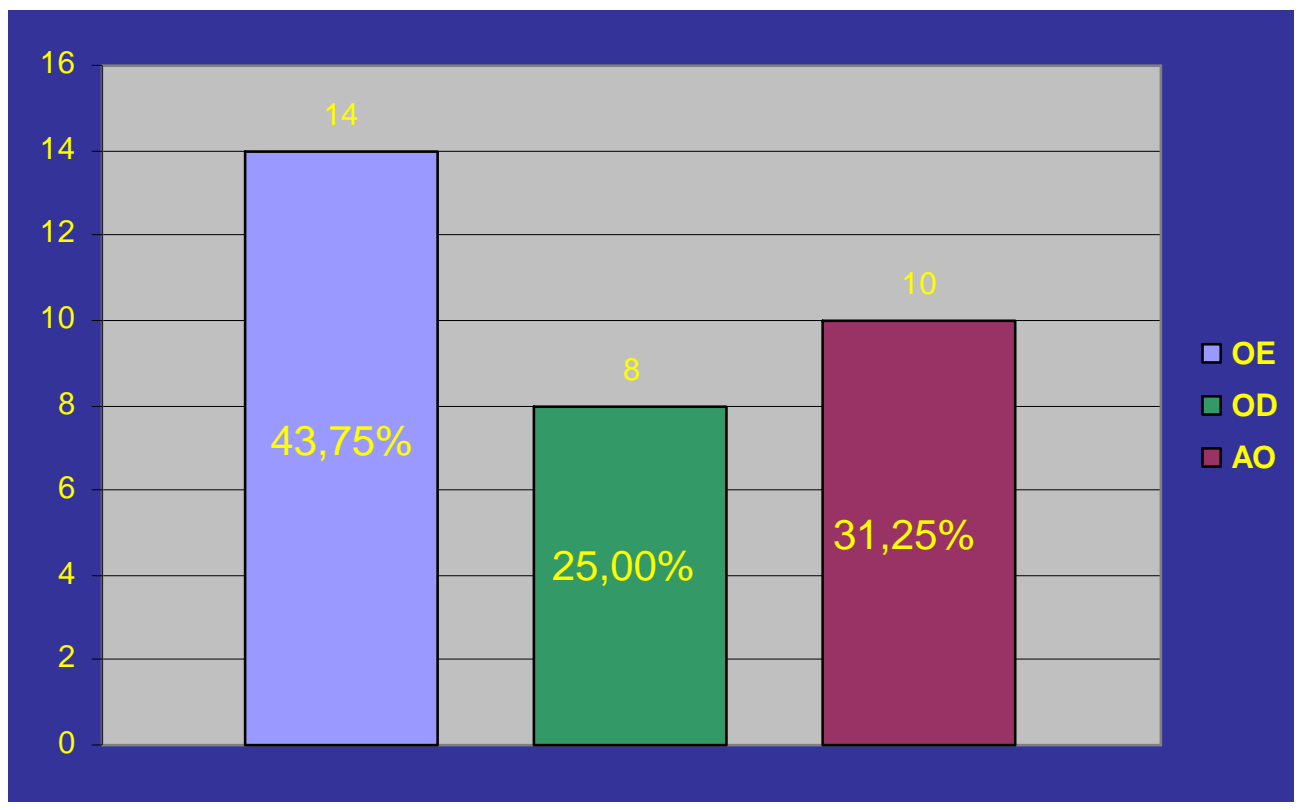

Figura 9 - Distribuição da sintomatologia de hiperlacrimejamento quanto ao olho acometido (OD = olho direito; $\mathrm{OE}$ = olho esquerdo; $\mathrm{AO}=$ ambos os olhos). 


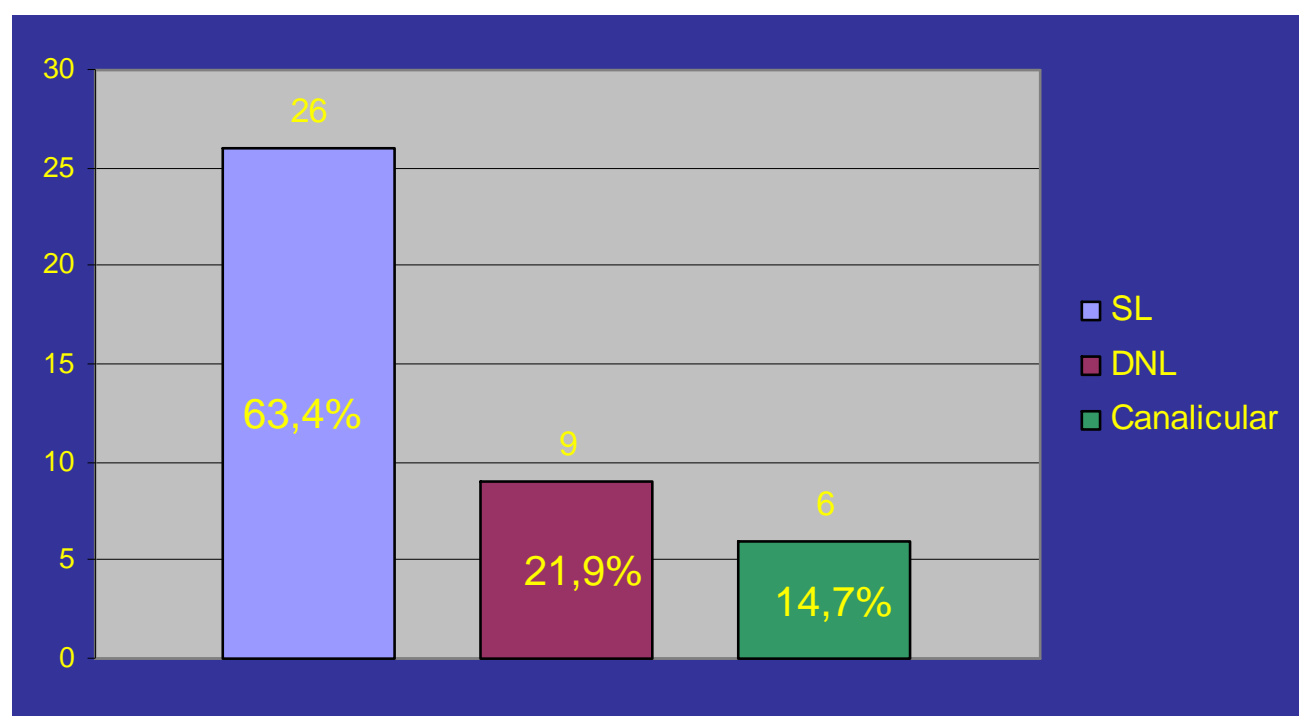

Figura 10 - Distribuição das obstruções das vias lacrimais de acordo com o nível. SL = saco lacrimal; $\mathrm{DNL}=$ ducto nasolacrimal

A figura 11 exemplifica um caso de obstrução de ambas as vias lacrimais, no nível dos sacos lacrimais (em suas bases), nível mais freqüentemente encontrado na amostra analisada em nosso estudo. 

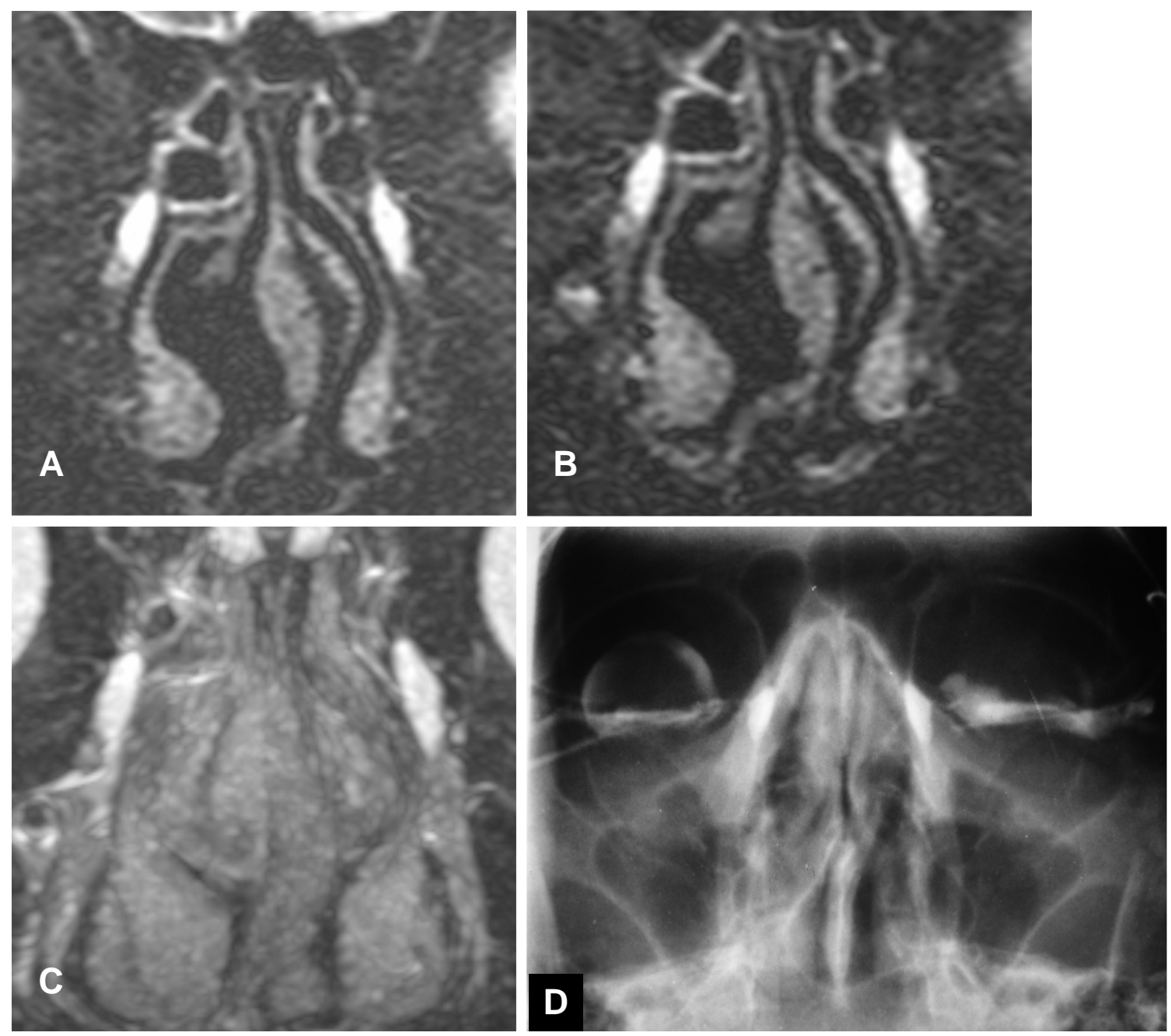

Figura 11 - Caso número 32. Imagem - fonte da seqüência STIR sem instilação (a), imagem-fonte (b) e reconstrução MIP (c) da seqüência STIR após instilação de soro fisiológico e DCG (d). A RM demonstra, claramente, a obstrução de ambas as vias lacrimais no nível dos sacos lacrimais (válvula de Krause), confirmada pela DCG.

Os pacientes toleraram bem o exame de RM, não se registrando queixas de irritação ocular, após a instilação do soro fisiológico ou do gadolínio diluído. Não se tornou necessária nenhuma espécie de anestesia para a realização dos exames de RM, nem mesmo para a criança de cinco anos de idade, que suportou o exame tranqüilamente, sem uso de sedação. 


\subsection{RESULTADOS - DIAGNÓSTICO DA PRESENÇA OU AUSÊNCIA DE OBSTRUÇÃO DA VIA LACRIMAL}

Para cada um dos observadores, foi avaliado o nível de significância estatística da concordância dos diagnósticos realizados por meio de cada seqüência de $\mathrm{RM}$ e pelo $\mathrm{RX}$ e entre as seqüências de $\mathrm{RM}$ entre si (concordância intra-observador). Foram calculados a sensibilidade, especificidade e valores preditivos (positivo e negativo) para cada uma das seqüências de RM. Foi avaliada a concordância interobservador para o diagnóstico de obstrução das vias lacrimais, para cada uma das seqüências de RM.

\subsubsection{ANÁLISE DA CONCORDÂNCIA ENTRE OS DIAGNÓSTICOS REALIZADOS POR MEIO DE CADA SEQÜÊNCIA DE RM E PELA DCG PARA CADA OBSERVADOR INDIVIDUALMENTE}

Como mencionado anteriormente, para a análise da concordância entre os diagnósticos obtidos por meio da RM e da DCG, contabilizaram-se apenas os casos em que a via lacrimal se encontrava preenchida por algum conteúdo líquido, excluindo-se as vias lacrimais não preenchidas, conforme o parecer dos observadores. Do total de 63 vias lacrimais estudadas, na seqüência STIR sem instilação, foram excluídas dez (15,9\%) vias lacrimais pelo observador 1 (um total de 53 analisadas) e treze (20,6\%) vias lacrimais pelo observador 2 
(um total de 49 analisadas). Considerando-se a seqüência STIR com instilação de soro fisiológico, o observador 1 excluiu apenas três (4,8\%) vias lacrimais (60 analisadas) e o observador 2 excluiu oito (12,7\%) vias lacrimais (55 analisadas). Para a seqüência T1 com instilação de gadolínio diluído, o observador 1 excluiu 14 (22,2\%) vias lacrimais (47 analisadas) e o observador 2 excluiu $13(20,6 \%)$ vias lacrimais (48 analisadas). A seqüência em que o maior número de casos foi incluído na análise foi STIR com instilação de soro fisiológico, obtendo-se o menor número de exclusões para ambos os observadores. O observador 2, de forma geral, considerou um maior número de casos como não preenchidos. Entretanto, mesmo adotando critérios mais restritivos, o número de casos considerados como não preenchidos atingiu, no máximo, cerca de $20 \%$ (dois em cada grupo de dez vias lacrimais).

A avaliação da significância estatística da concordância entre os diagnósticos realizados em cada uma das seqüências de RM e pela DCG está sumarizada nas tabelas a seguir. 
Tabela 5: Concordância dos diagnósticos de obstrução das vias lacrimais entre a seqüência STIR sem instilação e a DCG, para os observadores 1 e 2 .

\begin{tabular}{lll} 
& & \multicolumn{2}{c}{ Número de concordâncias $(\%)$} & Indice Kappa \\
\hline Observador 1 & $49 / 53(92,4 \%)$ & $0,828(\mathrm{p}<0,001)$ \\
Observador 2 & $47 / 49(95,9 \%)$ & $0,904(\mathrm{p}<0,001)$
\end{tabular}

Os resultados expressos na Tabela 5 demonstram que houve concordância estatisticamente significante entre os diagnósticos de presença ou ausência de obstrução das vias lacrimais, feitos por ambos os observadores, valendo-se da seqüência STIR sem instilação, em comparação com o padrãoouro - DCG (teste exato de Fischer e Kappa com $p<0,001$ ). Os índices de Kappa de ambos os observadores $(\mathrm{K}=0,828$ para o observador 1 e $\mathrm{K}=0,904$ para o observador 2) evidenciaram concordância quase perfeita (Figura 12). 

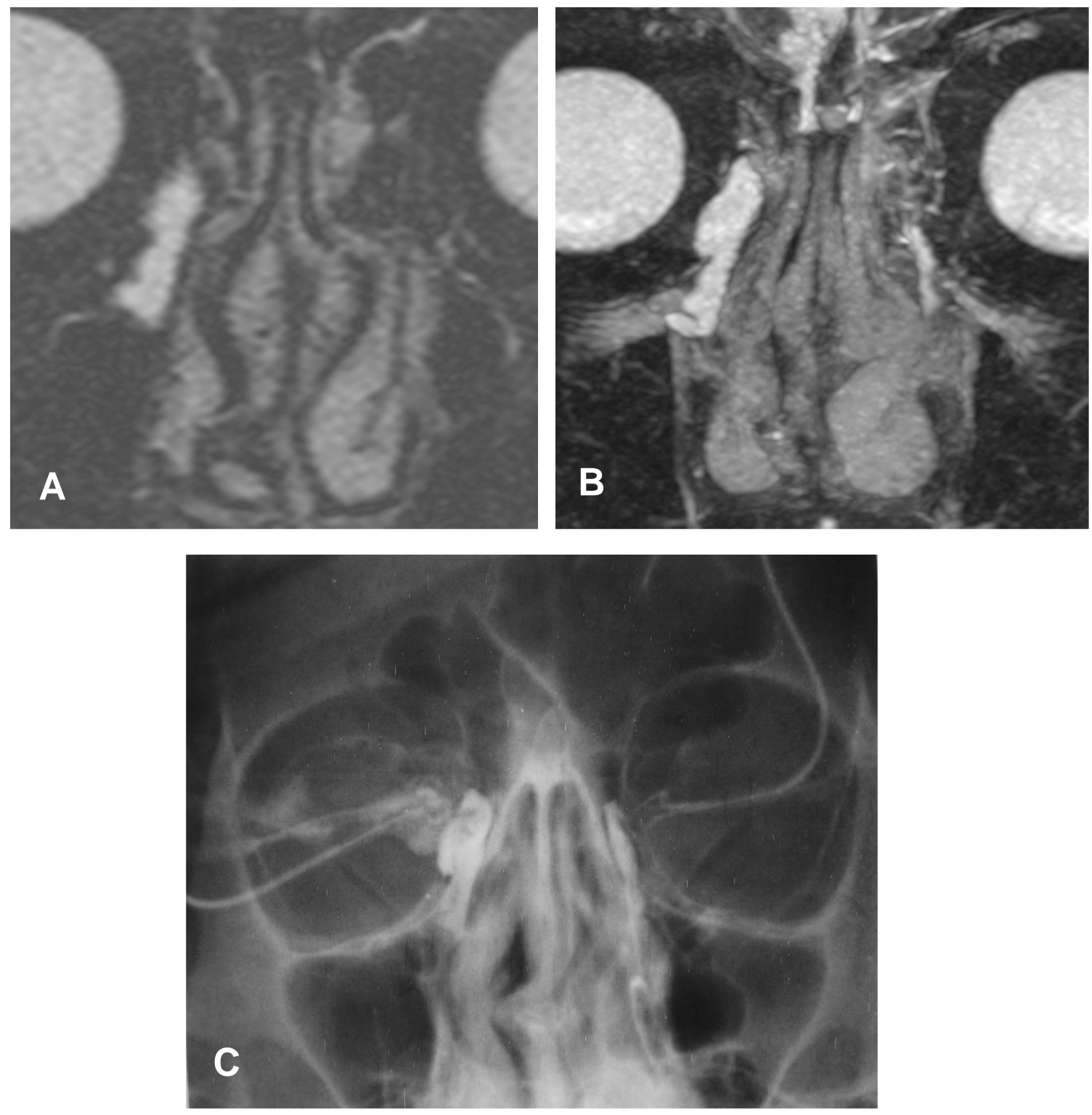

Figura 12 - Caso número 1. Paciente com história de trauma facial há sete anos, evoluindo com epífora, à direita, desde a época. Seqüência STIR sem nenhuma instilação. Imagem - fonte (a) e reconstrução MIP (b), evidenciando, claramente, a obstrução da via lacrimal direita no nível do ducto nasolacrimal. A DCG (c) confirma a presença e o nível da obstrução. 
Tabela 6: Concordância dos diagnósticos de obstrução das vias lacrimais entre a seqüência STIR com instilação de soro fisiológico e a DCG, conforme os observadores 1 e 2 .

\begin{tabular}{lll}
\hline & Número de concordâncias (\%) & Índice Kappa \\
\hline Observador 1 & $57 / 60(95 \%)$ & $0,879(\mathrm{p}<0,001)$ \\
Observador 2 & $52 / 55(94,5 \%)$ & $0,881(\mathrm{p}<0,001)$ \\
\hline
\end{tabular}

Os resultados expressos na Tabela 6 demonstram que houve concordância estatisticamente significante entre os diagnósticos de presença ou ausência de obstrução das vias lacrimais, feitos por ambos os observadores, valendo-se da seqüência STIR com instilação de soro fisiológico, em comparação com o padrão-ouro - DCG (teste exato de Fischer e Kappa com p<0,001). Os índices de Kappa de ambos os observadores $(K=0,879$ para o observador 1 e $\mathrm{K}=0$ 0,881 para o observador 2) evidenciaram concordância quase perfeita (Figura 13). 


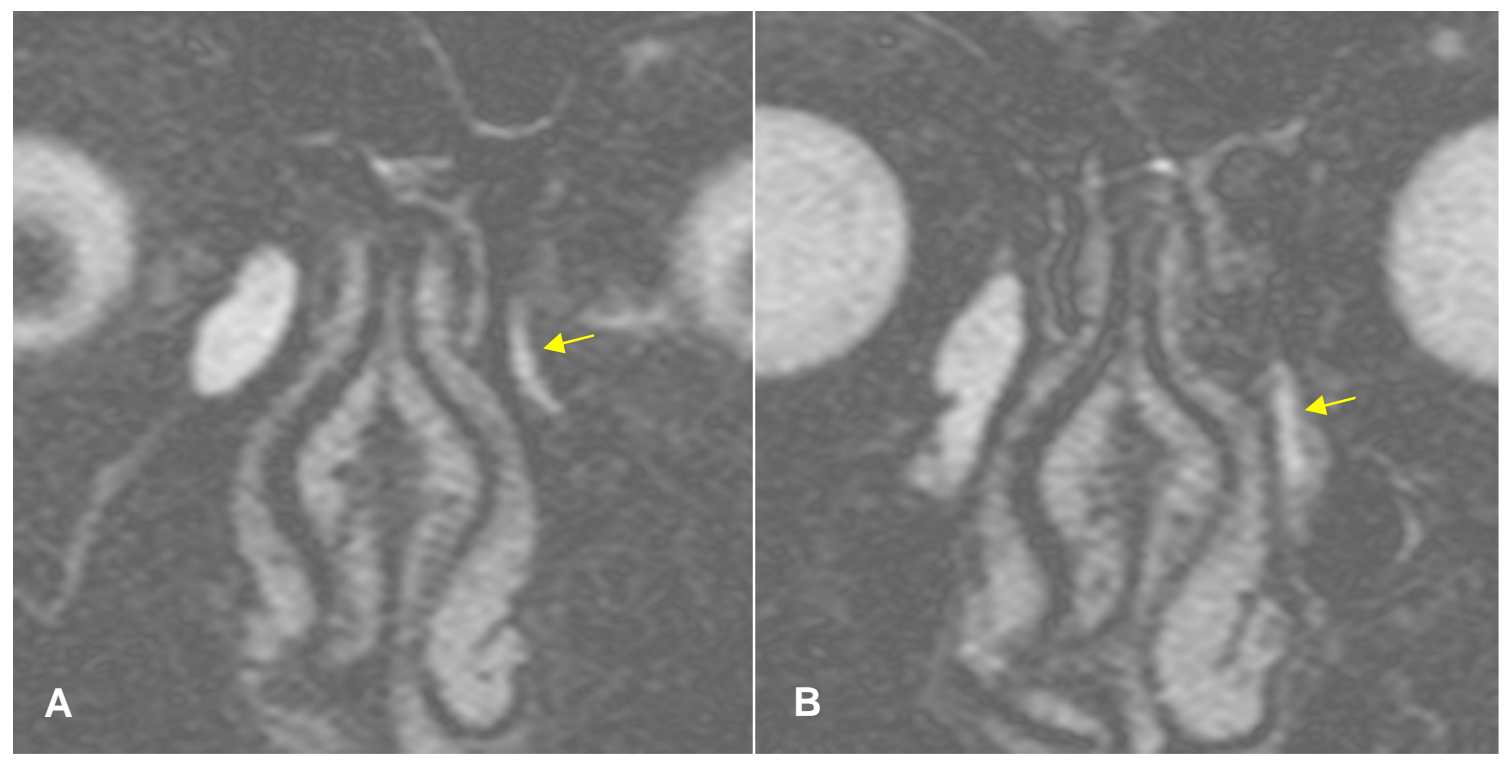

Figura 13 - Caso número 1. Seqüência STIR com instilação de soro fisiológico. Imagens-fonte, evidenciando a obstrução da via lacrimal direita, no nível do ducto nasolacrimal. Pode-se, também, identificar a via lacrimal esquerda (saco lacrimal em A e ducto nasolacrimal em B) com calibre normal (setas).

Tabela 7: Concordância dos diagnósticos de obstrução das vias lacrimais entre a seqüência T1 com instilação de gadolínio diluído e a DCG, para os observadores 1 e 2 .

\begin{tabular}{lll}
\hline & Número de concordâncias $(\%)$ & Índice Kappa \\
\hline Observador 1 & $41 / 47(87,2 \%)$ & $0,716(p<0,001)$ \\
Observador 2 & $43 / 48(89,5 \%)$ & $0,780(p<0,001)$ \\
\hline
\end{tabular}

Os resultados expressos na Tabela 7 demonstram que houve concordância estatisticamente significante entre os diagnósticos de presença ou ausência de obstrução das vias lacrimais, feitos por ambos os observadores, utilizando-se a seqüência T1 com instilação de gadolínio diluído (1:100), em comparação com o padrão-ouro - DCG (teste exato de Fischer e Kappa com 
$\mathrm{p}<0,001)$. Os índices de Kappa de ambos os observadores $(\mathrm{K}=0,716$ para 0 observador 1 e $K=0,780$ para o observador 2) evidenciaram concordância substancial.

Cumpre ressaltar que, na seqüência T1 com instilação de gadolínio diluído (1:100), ocorreu o maior número de exclusões, pois ambos os examinadores concluíram como ausência de preenchimento das vias lacrimais. Apesar de a intensidade da concordância com a DCG ter-se mostrado pouco inferior ao observado para a seqüência STIR (sem e com instilação de gadolínio), a concordância foi substancial para ambos os observadores.

\subsubsection{ANÁLISE DA CONCORDÂNCIA DOS DIAGNÓSTICOS REALIZADOS ENTRE AS SEQÜÊNCIAS DE RM PELOS OBSERVADORES INDIVIDUALMENTE}

A avaliação da significância estatística da concordância entre os diagnósticos realizados para cada uma das seqüências de RM encontra-se sumarizada nas tabelas a seguir. 
Tabela 8: Concordância dos diagnósticos de obstrução das vias lacrimais entre a seqüência STIR sem instilação e STIR com instilação de soro fisiológico, para os observadores 1 e 2 .

\begin{tabular}{lll}
\hline & Número de concordâncias (\%) & Índice Kappa \\
\hline Observador 1 & $52 / 53(98,1 \%)$ & $0,958(\mathrm{p}<0,001)$ \\
Observador 2 & $50 / 50(100 \%)$ & $1,000(\mathrm{p}<0,001)$ \\
\hline
\end{tabular}

A Tabela 8 expressa haver concordância estatisticamente significante entre os diagnósticos de ambos os observadores sobre a presença ou ausência de obstrução das vias lacrimais, usando-se a seqüência STIR sem instilação de soro fisiológico e comparando-a com a mesma seqüência após a instilação desse soro (teste exato de Fischer e Kappa com $p<0,001$ ). Os índices de Kappa dos dois $(K=0,958$ para o observador 1 e $K=1,000$ para 0 observador 2) evidenciaram concordância quase perfeita (Figura 14). 

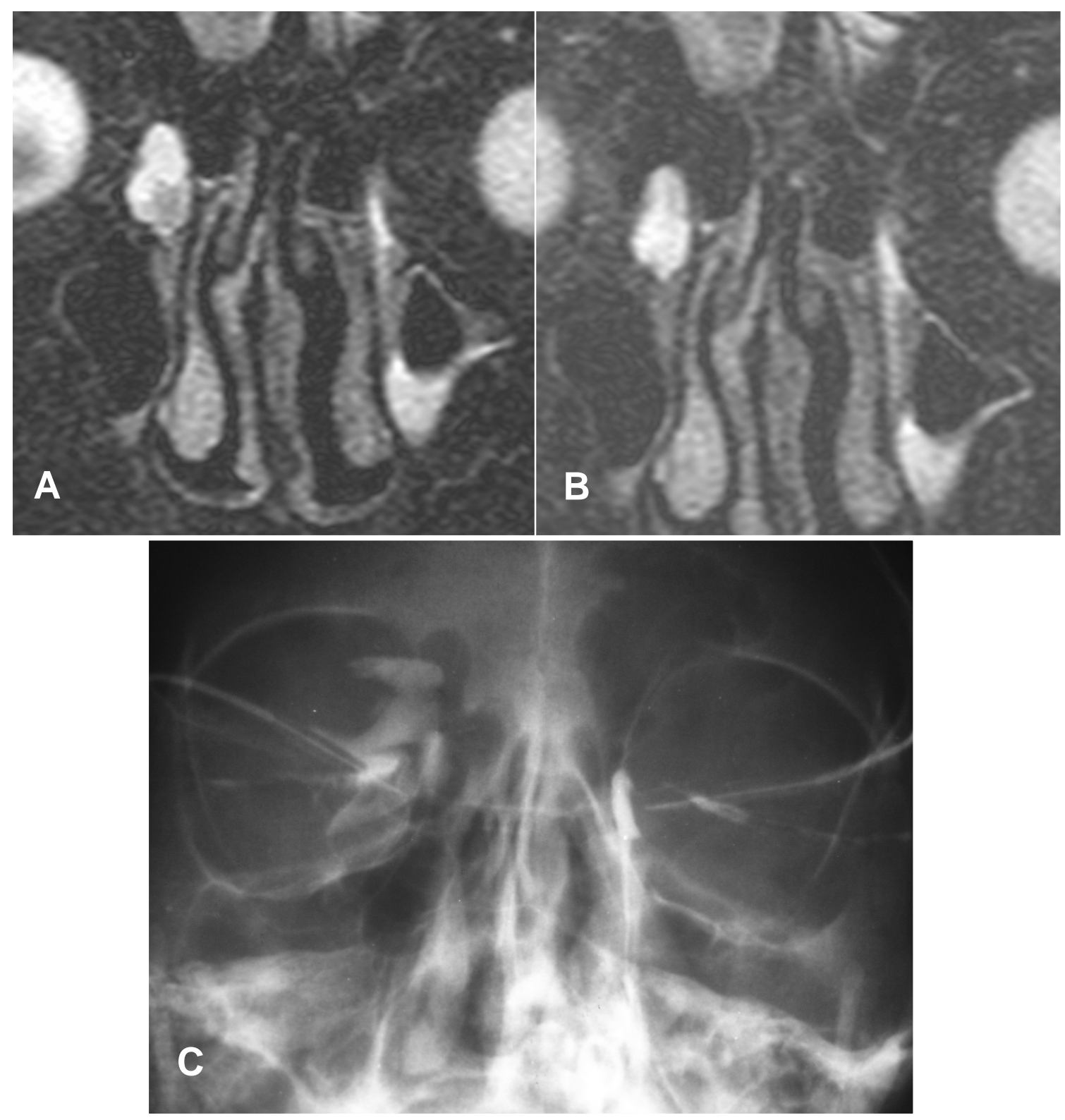

Figura 14 - Caso número 28. Imagens-fonte das seqüências STIR sem instilação (a) e com instilação de soro fisiológico (b) e DCG (c). Ambas as seqüências de RM e a DCG evidenciam obstrução da via lacrimal direita, no nível do saco lacrimal. A via lacrimal esquerda foi considerada permeável, tanto pela RM como pela DCG. 
Tabela 9: Concordância dos diagnósticos de obstrução das vias lacrimais entre a seqüência STIR sem instilação e T1 com instilação de gadolínio diluído, para os observadores 1 e 2 .

\begin{tabular}{lll}
\hline & Número de concordâncias (\%) & Índice Kappa \\
\hline Observador 1 & $38 / 42(90,4 \%)$ & $0,795(p<0,001)$ \\
Observador 2 & $39 / 41(95,1 \%)$ & $0,895(p<0,001)$ \\
\hline
\end{tabular}

A Tabela 9 demonstra a concordância estatisticamente significante entre os diagnósticos dos dois examinadores sobre a presença, ou não, de obstrução das vias lacrimais, empregando-se a seqüência STIR sem instilação de soro fisiológico e comparando-a com a seqüência T1, após instilação de gadolínio diluído (teste exato de Fischer e Kappa com $p<0,001$ ). Os índices de Kappa evidenciaram concordância substancial para o observador $1(K=0,795)$ e concordância quase perfeita para o observador $2(K=0,895)$.

Tabela 10: Concordância dos diagnósticos de obstrução das vias lacrimais entre a seqüência STIR com instilação de soro fisiológico e T1 com instilação de gadolínio diluído, para os observadores 1 e 2 .

\begin{tabular}{lll}
\hline & Número de concordâncias $(\%)$ & Índice Kappa \\
\hline Observador 1 & $40 / 44(90,9 \%)$ & $0,800(p<0,001)$ \\
Observador 2 & $43 / 47(91,5 \%)$ & $0,825(p<0,001)$ \\
\hline
\end{tabular}


Os resultados expressos na Tabela 10 comprovam a concordância estatisticamente significante entre os diagnósticos dos dois analisadores sobre a presença, ou não, de obstrução das vias lacrimais, aplicando a seqüência STIR com instilação de soro fisiológico e comparando-a com a seqüência T1 após a instilação de gadolínio diluído (teste exato de Fischer e Kappa com $\mathrm{p}<0,001)$. Os índices de Kappa de ambos os observadores $(\mathrm{K}=0,800$ para o observador 1 e $K=0,825$ para o observador 2) evidenciaram concordância quase perfeita.

\subsubsection{ANÁLISE DA CONCORDÂNCIA DOS DIAGNÓSTICOS DOS DOIS OBSERVADORES EM RELAÇÃO A CADA UMA DAS SEQÜÊNCIAS DE RM E DA DCG}

Tabela 11: Concordância interobservador para os diagnósticos de obstrução das vias lacrimais, para cada uma das seqüências de RM e para a DCG.

\begin{tabular}{|c|c|c|}
\hline & Número de concordâncias (\%) & İ́ndice Kappa \\
\hline STIR sem instilação & $49 / 49(100 \%)$ & $1,000(p<0,001)$ \\
\hline STIR com SF & 52 / $53(98,1 \%)$ & $0,958(p<0,001)$ \\
\hline T1 com Gd diluído & $43 / 45(95,5 \%)$ & $0,900(p<0,001)$ \\
\hline DCG & $60 / 60(100 \%)$ & $1,000(p<0,001)$ \\
\hline
\end{tabular}

A concordância entre os dois observadores foi estatisticamente significante para todas as seqüências de RM e para a DCG (teste exato de 
Fischer e Kappa com p < 0,001). Os índices de concordância interobservador para a RM (para as três seqüências analisadas em nosso trabalho) e para a DCG, expressos na Tabela 11, revelaram concordância quase perfeita (Kappa oscilando entre 0,900 e 1,000$)$.

\subsubsection{AVALIAÇÃO DA SENSIBILIDADE, ESPECIFICIDADE, VALOR PREDITIVO POSITIVO E VALOR PREDITIVO NEGATIVO DE CADA UMA DAS SEQÜÊNCIAS DE RM CONFORME CADA UM DOS OBSERVADORES}

Como já exposto previamente, o cálculo da sensibilidade (S), especificidade (E) e dos valores preditivos positivo (VPP) e negativo (VPN) foi efetuado levando-se em consideração dois cenários diferentes: um deles com exclusão dos casos não preenchiidos por meio da RM e o outro com inclusão desses casos na categoria obstrução presente ao método (por possível obstrução alta).

Excluindo-se os casos considerados pelos observadores como não preenchidos, a sensibilidade da RM para a detecção de obstrução das vias lacrimais foi elevada para as três seqüências utilizadas, oscilando entre $89,5 \%$ e $93,3 \%$ segundo o observador 1 e $91,9 \%$ e $94,3 \%$ conforme o observador 2 . $\mathrm{Na}$ avaliação do observador 1 (Tabela 12), a seqüência mais sensível foi STIR com instilação de soro fisiológico; enquanto, para o observador 2 (Tabela 13) a mais sensível foi STIR sem instilação. 
Quanto à especificidade, para ambos os observadores, as seqüências STIR sem e com instilação de soro fisiológico demonstraram elevada especificidade (100\%). A seqüência T1 com instilação de gadolínio indicou especificidade inferior, de acordo com ambos os observadores, sendo de $76,5 \%$, para o observador 1 e 84,2\%, para o observador 2 (Tabelas 12 e 13).

O valor preditivo positivo das seqüências STIR sem e com instilação de soro fisiológico também foi elevado ( $100 \%$ para ambos os observadores). Novamente a seqüência T1 com instilação de gadolínio revelou resultados inferiores, com VPP de $87,5 \%$ para o observador 1 e $90 \%$ para o observador 2 (Tabelas 12 e 13).

O valor preditivo negativo oscilou entre $78,9 \%$ e $88,9 \%$, tendo sido conseguidos os melhores resultados com a seqüência T1 com instilação de gadolínio, segundo ambos os observadores (observador $1=86,7 \%$; observador $2=88,9 \%)$.

Tabela 12: Sensibilidade (S), Especificidade (E), Valor Preditivo Positivo (VPP) e Valor Preditivo Negativo (VPN) de cada uma das seqüências de RM para o diagnóstico de obstrução das vias lacrimais, para o observador 1, excluindo-se os casos não preenchidos.

\begin{tabular}{lllll}
\hline & S & E & VPP & VPN \\
\hline STIR sem instilação & $89,5 \%$ & $100 \%$ & $100 \%$ & $78,9 \%$ \\
STIR com SF & $93,2 \%$ & $100 \%$ & $100 \%$ & $84,2 \%$ \\
T1 com Gd diluído & $93,3 \%$ & $76,5 \%$ & $87,5 \%$ & $86,7 \%$ \\
\hline
\end{tabular}


Tabela 13: Sensibilidade (S), Especificidade (E), Valor Preditivo Positivo (VPP) e Valor Preditivo Negativo (VPN) de cada uma das seqüências de RM para o diagnóstico de obstrução das vias lacrimais, para o observador 2, excluindo-se os casos não preenchidos.

\begin{tabular}{lllll}
\hline & S & E & VPP & VPN \\
& & & & \\
\hline STIR sem instilação & $94,3 \%$ & $100 \%$ & $100 \%$ & $87,5 \%$ \\
STIR com SF & $91,9 \%$ & $100 \%$ & $100 \%$ & $85,7 \%$ \\
T1 com Gd diluído & $93,1 \%$ & $84,2 \%$ & $90 \%$ & $88,9 \%$ \\
\hline
\end{tabular}

A análise dos dados, incluindo-se os casos não preenchidos por meio da RM e considerando-os como obstrução presente (Tabelas 14 e 15), evidenciou que a sensibilidade de todas as seqüências se manteve alta, inclusive com leve elevação de seus valores, oscilando entre $90,5 \%$ e $95,2 \%$. Em contrapartida, foi possível observar-se que, com esse tipo de interpretação, houve redução da especifidade e do valor preditivo positivo das seqüências STIR sem e com instilação de soro fisiológico, com valores que oscilaram entre $77,7 \%$ e $94,4 \%$ e entre $90,9 \%$ e $97,5 \%$, respectivamente. O valor preditivo negativo de cada uma das seqüências não se modificou de forma significativa com a inclusão dos casos não opacificados. 
Tabela 14: Sensibilidade (S), Especificidade (E), Valor Preditivo Positivo (VPP) e Valor Preditivo Negativo (VPN) de cada uma das seqüências de RM para o diagnóstico de obstrução das vias lacrimais, para o observador 1, incluindo-se os casos não preenchidos.

\begin{tabular}{lllll}
\hline & S & E & VPP & VPN \\
\hline STIR sem instilação & $90,5 \%$ & $83,3 \%$ & $92,7 \%$ & $78,9 \%$ \\
STIR com SF & $92,8 \%$ & $88,8 \%$ & $95,1 \%$ & $84,2 \%$ \\
T1 com Gd diluído & $95,2 \%$ & $72,2 \%$ & $88,7 \%$ & $86,6 \%$ \\
\hline
\end{tabular}

Tabela 15: Sensibilidade (S), Especificidade (E), Valor Preditivo Positivo (VPP) e Valor Preditivo Negativo (VPN) de cada uma das seqüências de RM para o diagnóstico de obstrução das vias lacrimais, para o observador 2, incluindo-se os casos não preenchidos.

\begin{tabular}{lllll}
\hline & S & E & VPP & VPN \\
\hline STIR sem instilação & $95,2 \%$ & $77,7 \%$ & $90,9 \%$ & $87,5 \%$ \\
STIR com SF & $92,8 \%$ & $94,4 \%$ & $97,5 \%$ & $85,0 \%$ \\
T1 com Gd diluído & $95,2 \%$ & $83,3 \%$ & $93,0 \%$ & $88,2 \%$ \\
\hline
\end{tabular}

As tabelas 23 e 24 (Anexo F) resumem os valores de sensibilidade, especificidade e valores preditivos positivo e negativo para os diagnósticos de obstrução das vias lacrimais para cada seqüência de RM. 


\subsection{RESULTADOS - DIAGNÓSTICO DA IDENTIFICAÇÃO DO NÍVEL DA OBSTRUÇÃO DA VIA LACRIMAL}

Para a análise da identificação do nível da obstrução das vias lacrimais, foram incluídos apenas os casos em que, tanto as seqüências de RM, quanto a DCG concordaram com a presença de obstrução. Dessa forma, foram excluídos os casos cujos métodos discordavam quanto à presença de obstrução, e obviamente, excluíram-se, também, os casos considerados como sem obstrução.

\subsubsection{ANÁLISE DA CONCORDÂNCIA ENTRE OS DIAGNÓSTICOS DO NÍVEL DE OBSTRUÇÃO REALIZADOS PARA CADA SEQÜÊNCIA DE RM E PELA DCG, CONFORME CADA OBSERVADOR INDIVIDUALMENTE.}

A avaliação da significância estatística da concordância entre os diagnósticos realizados para cada uma das seqüências de RM e pela DCG está sumarizada nas tabelas a seguir. 
Tabela 16: Concordância dos diagnósticos do nível de obstrução das vias lacrimais entre a seqüência STIR sem instilação e a DCG, para os observadores 1 e 2 .

\begin{tabular}{lll}
\hline & Número de concordâncias (\%) & Indice Kappa \\
\hline Observador 1 & $24 / 34(70,6 \%)$ & $0,246(p<0,058)$ \\
Observador 2 & $25 / 31(80,6 \%)$ & $0,404(p<0,005)^{*}$ \\
$*$ NOTA: Agreement test (Scott and Maxwell \& Pilliner), in Fleiss (1981)
\end{tabular}

Quanto à identificação do nível da obstrução, a concordância entre a seqüência STIR sem instilação e o padrão-ouro (Tabela 16) afigurou-se moderada, quando se analisaram as avaliações efetuadas pelo observador 2 ( $\mathrm{K}$ $=0,404$ com $p<0,005)$. Para o observador 1 , não se demonstrou concordância estatisticamente significante entre os dois métodos, quanto à identificação do nível de obstrução, destacando-se discordância quanto à caracterização da obstrução no nível do ducto nasolacrimal. Das nove obstruções dos ductos nasolacrimais pela DCG, o observador 1 só categorizou duas. Apesar de ter julgado corretamente a presença da obstrução como baixa (tendo considerado os demais sete casos como obstruídos em nível do saco lacrimal), categorizoua de maneira diferente da do padrão-ouro. 
Tabela 17: Concordância dos diagnósticos do nível de obstrução das vias lacrimais entre a seqüência STIR com instilação de soro fisiológico e a DCG, para os observadores 1 e 2 .

\begin{tabular}{lll}
\hline & Número de concordâncias (\%) & Indice Kappa \\
\hline Observador 1 & $31 / 38(81,5 \%)$ & $0,582(\mathrm{p}<0,001)$ \\
Observador 2 & $26 / 32(81,2 \%)$ & $0,464(\mathrm{p}<0,002)^{*}$ \\
& & \\
NOTA: Agreement test (Scott and Maxwell \& Pilliner), in Fleiss (1981)
\end{tabular}

Servindo-se da seqüência STIR com instilação de soro fisiológico, ambos os observadores identificaram concordância estatisticamente significante entre os níveis de obstrução, verificados por meio da RM, e aqueles observados no exame padrão-ouro - DCG (Tabela 17). A concordância foi considerada moderada (observador $1-K=0,582 ; p<0,001$ e observador $2-K=0,464 ; p<$ $0,002)$.

Tabela 18: Concordância dos diagnósticos do nível de obstrução das vias lacrimais entre a seqüência T1 com instilação de gadolínio diluído e a DCG, para os observadores 1 e 2 .

\begin{tabular}{lll}
\hline & Número de concordâncias (\%) & Índice Kappa \\
\hline Observador 1 & $19 / 25(76 \%)$ & $0,194(p<0,102)$ \\
Observador 2 & $21 / 23(91 \%)$ & $0,623(p<0,001)^{*}$ \\
\cline { 2 - 2 } NOTA: Agreement test (Scott and Maxwell \& Pilliner), in Fleiss (1981)
\end{tabular}


A identificação do nível da obstrução, utilizando-se a seqüência T1 com instilação de gadolínio diluído assinalou concordância estatisticamente significante com o padrão-ouro apenas para as avaliações do observador 2 (Tabela 18). Observou-se uma concordância substancial $(K=0,623$ com $p<$ 0,001). Segundo o observador 1, não se demonstrou concordância estatisticamente significante entre os dois métodos quanto à identificação do nível de obstrução, observando-se, de novo, discordância relativamente às obstruções no nível do ducto nasolacrimal. De sete obstruções dos ductos nasolacrimais, visíveis pela DCG, o observador 1 só categorizou uma nesse nível. O observador 1 caracterizou as outras seis vias lacrimais como obstruídas no nível do saco lacrimal. Deve-se lembrar que, apesar de não ter havido precisão na identificação do nível de obstrução, essa foi ainda corretamente identificada como baixa (Figuras 15 e 16). 


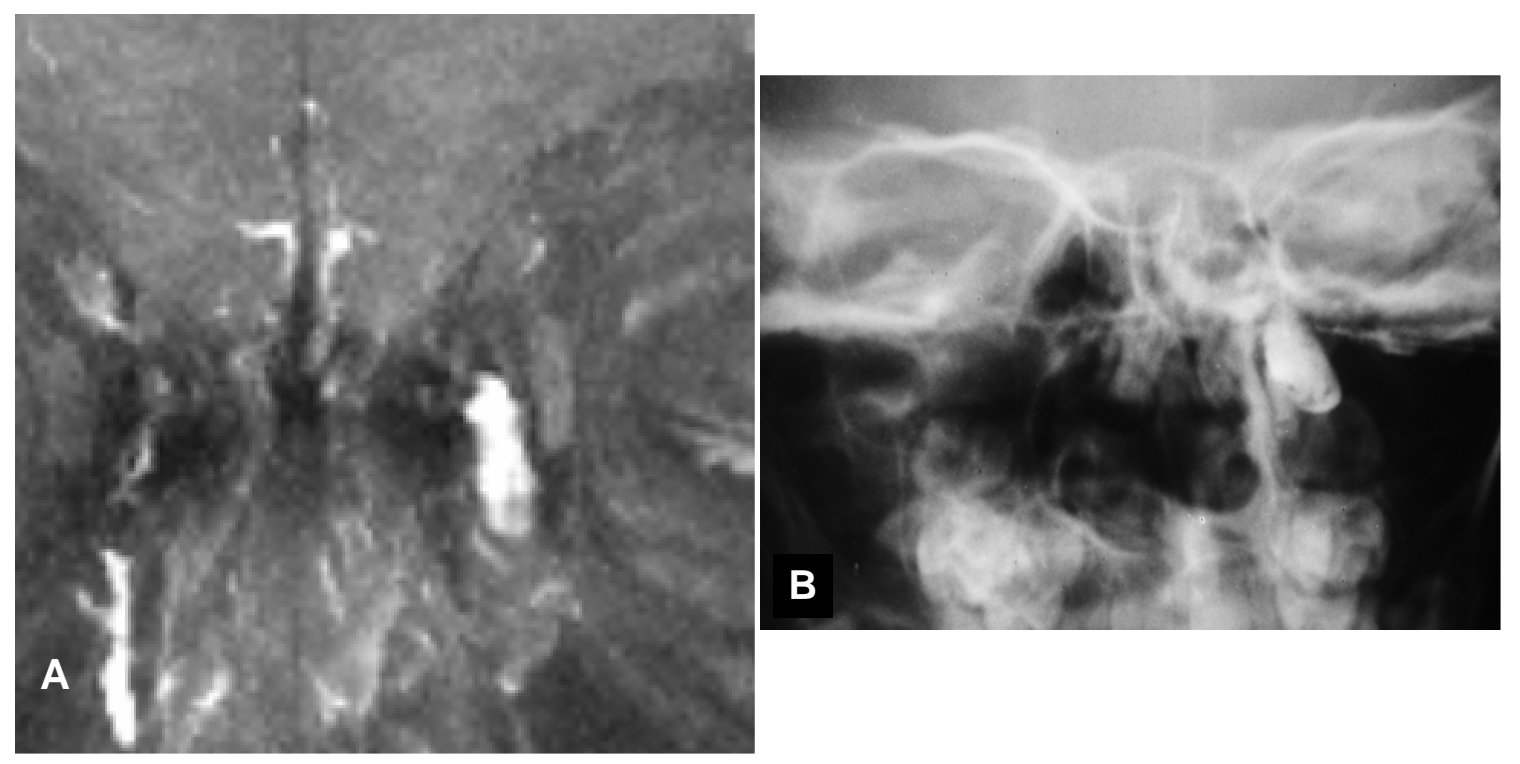

Figura 15 - Caso número 27. Reconstrução MIP da seqüência T1. Após instilação de gadolínio diluído (a), confirmou-se a obstrução no nível do ducto nasolacrimal. Entretanto, o aspecto de grande distensão do saco lacrimal bem identificado à DCG (b) não se tornou evidente com essa técnica, provavelmente por diluição do meio de contraste por secreção intra-sacular.
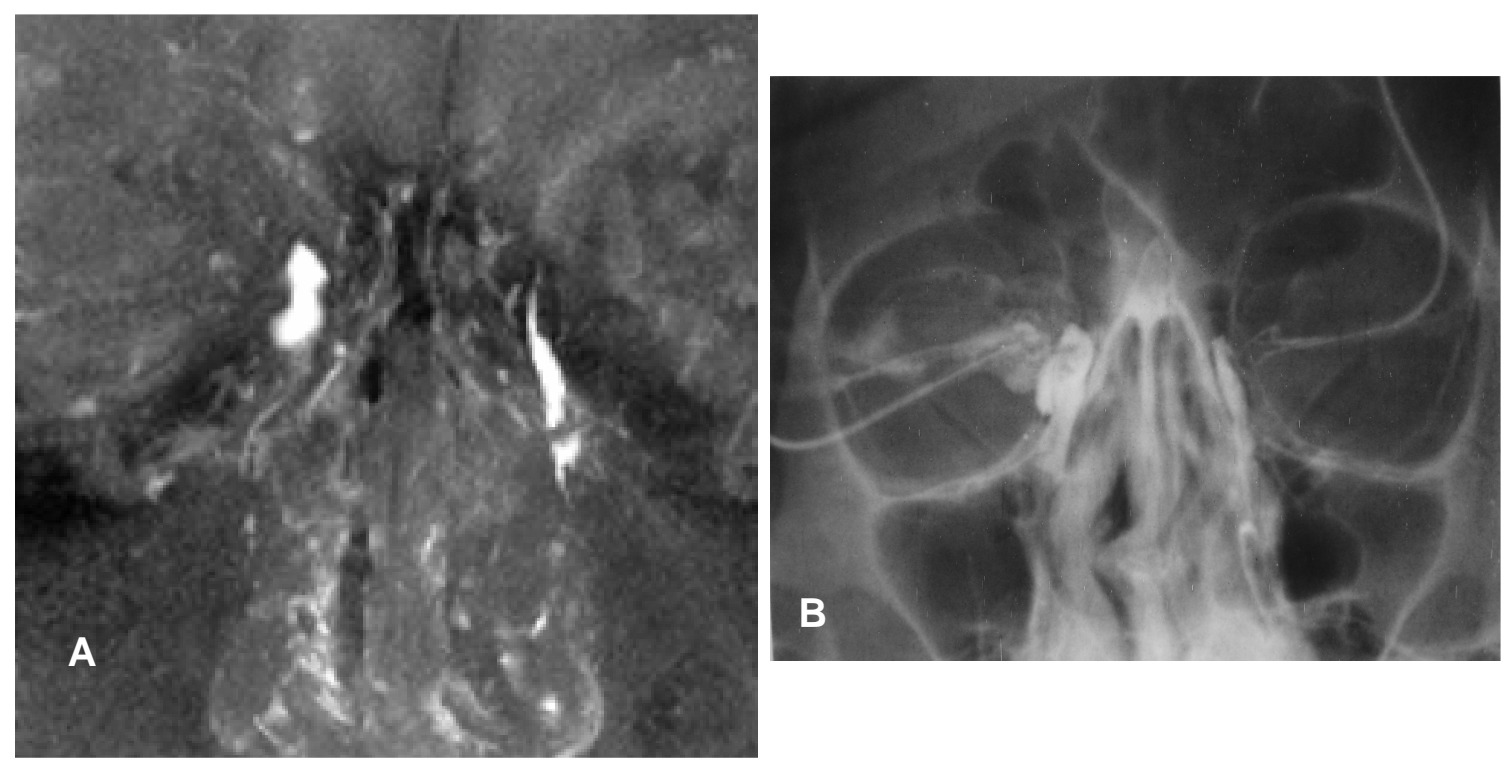

Figura 16 - Caso número 1. Seqüência T1 com instilação de gadolínio diluído, reconstrução MIP (a) evidenciando preenchimento parcial da via lacrimal direita dilatada, determinando falha na interpretação do nível correto da obstrução. Pela DCG (b), a obstrução é identificada em nível mais distal. 


\subsubsection{ANÁLISE DA CONCORDÂNCIA DOS DIAGNÓSTICOS DO NÍVEL DE OBSTRUÇÃO DAS VIAS LACRIMAIS REALIZADOS ENTRE CADA UMA DAS SEQÜÊNCIAS DE RM, CONFORME CADA OBSERVADOR INDIVIDUALMENTE.}

Tabela 19: Concordância dos diagnósticos do nível de obstrução das vias lacrimais entre a seqüência STIR sem instilação e STIR com instilação de soro fisiológico, para os observadores 1 e 2 .

\begin{tabular}{lll}
\hline & Número de concordâncias (\%) & Indice Kappa \\
\hline Observador 1 & $30 / 34(88,2 \%)$ & $0,684(\mathrm{p}<0,001)$ \\
Observador 2 & $29 / 31(93,5 \%)$ & $0,763(\mathrm{p}<0,001)^{*}$ \\
& & \\
NOTA: Agreement test (Scott and Maxwell \& Pilliner), in Fleiss (1981)
\end{tabular}

Os diagnósticos dos níveis de obstrução realizados por ambos os observadores, utilizando-se as seqüências STIR sem e com instilação de soro fisiológico apontaram concordância estatisticamente significante (Tabela 19). A concordância foi considerada substancial por ambos os observadores $(\mathrm{K}=$ 0,684; $\mathrm{p}<0,001$ para o observador 1 e $\mathrm{K}=0,763$; $\mathrm{p}<0,001$ para o observador 2). 
Tabela 20: Concordância dos diagnósticos do nível de obstrução das vias lacrimais entre a seqüência STIR sem instilação e T1 com instilação de gadolínio diluído, para os observadores 1 e 2.

\begin{tabular}{lll}
\hline & Número de concordâncias (\%) & Indice Kappa \\
\hline Observador 1 & $18 / 23(78,2 \%)$ & $-0,075(\mathrm{p}<0,639)$ \\
Observador 2 & $20 / 21(95,2 \%)$ & - \\
\hline
\end{tabular}

De acordo com o observador 1, não se identificou concordância estatisticamente significativa entre as seqüências STIR sem instilação e T1 com instilação de gadolínio diluído (Tabela 20), na caracterização do nível correto de obstrução $(K=-0,075 ; p<0,639)$.

Em relação ao observador 2, não foi possível calcular o índice Kappa de concordância entre as duas seqüências supracitadas, uma vez que os dados gerados por sua análise resultaram em uma tabela de formato não quadrado. Todas as obstruções visualizadas por esse observador na seqüência STIR foram incluídas em uma única categoria (saco lacrimal). Nessas situações, o valor de Kappa torna-se zero, inviabilizando seu cálculo. Optou-se, portanto, por realizar apenas a avaliação da concordância absoluta, que se mostrou elevada, notando-se 20 concordâncias em 21 casos (95\%). 
Tabela 21: Concordância dos diagnósticos do nível de obstrução das vias lacrimais entre a seqüência STIR com instilação de soro fisiológico e T1 com instilação de gadolínio diluído, para os observadores 1 e 2 .

\begin{tabular}{|c|c|c|}
\hline & Número de concordâncias (\%) & Indice Kappa \\
\hline Observador 1 & $20 / 24(83,3 \%)$ & $-0,067(p<0,699)$ \\
\hline Observador 2 & 20 / 22 (90,9\%) & $0,645(p<0,001)$ \\
\hline
\end{tabular}

Observou-se concordância estatisticamente significante entre os diagnósticos feitos pelo observador 2 para a identificação do nível da obstrução das vias lacrimais (Tabela 21), comparando-se as seqüências STIR com instilação de soro fisiológico e T1 com instilação de gadolínio diluído $(K=0,645$; $p<.0,001-$ concordância substancial).

Entretanto, em relação ao observador 1, não se identificou concordância estatisticamente significante $(K=-0,067 ; p<0,699)$. 


\subsubsection{ANÁLISE DA CONCORDÂNCIA DOS DIAGNÓSTICOS DO NÍVEL DE OBSTRUÇÃO REALIZADOS PARA CADA UMA DAS SEQÜÊNCIAS DE RM E PELA DCG ENTRE OS DOIS OBSERVADORES}

Tabela 22: Concordância interobservador para os diagnósticos do nível de obstrução das vias lacrimais, para cada uma das seqüências de RM e para a DCG.

\begin{tabular}{lll}
\hline & Número de concordâncias (\%) & Índice Kappa \\
\hline STIR sem instilação & $28 / 31(90,3 \%)$ & $0,518(\mathrm{p}<0,003)$ \\
STIR com SF & $30 / 32(93,7 \%)$ & $0,765(\mathrm{p}<0,001)$ \\
T1 com Gd diluído & $25 / 25(100 \%)$ & $1,000(\mathrm{p}<0,001)$ \\
DCG & $35 / 39(89,7 \%)$ & $0,812(\mathrm{p}<0,001)$ \\
\hline
\end{tabular}

Houve concordância estatisticamente significante entre os dois observadores, quanto aos diagnósticos dos níveis de obstrução para todas as seqüências de RM e para a DCG (Tabela 22). Considerando-se a RM, a concordância interobservador foi classificada como moderada para a seqüência STIR sem instilação ( $K=0,518 ; p<0,003)$, substancial para a seqüência STIR com instilação de soro fisiológico $(K=0,765 ; p<0,001)$ e quase perfeita para a seqüência $T 1$ com instilação de gadolínio diluído $(K=1,000 ; p<0,001)$.

Cumpre destacar que a concordância interobservador da DCG, padrãoouro para o diagnóstico de obstrução das vias lacrimais, se mostrou elevada, classificada, também, como quase perfeita $(K=0,812 ; p<0,001)$. 
As tabelas 25 e 26 (Anexo G) resumem os valores das concordâncias intra- e interobservadores para os diagnósticos de obstrução e do nível de obstrução das vias lacrimais para cada seqüência de RM em comparação com a DCG e entre as seqüências de RM entre elas mesmas. 
5. DISCUSSÃO 


\section{DISCUSSÃO}

Em nosso trabalho, o grupo de indivíduos que formou a amostra, apresentava distribuição semelhante à relatada na literatura, notando-se predominância dos casos de obstrução de vias lacrimais em pacientes do sexo feminino $(81,2 \%)$ e com idade acima da quinta década $(84,6 \%)$. No grupo feminino, a causa mais provável da gênese da obstrução da via lacrimal a ser lembrada é a obstrução nasolacrimal primária (OPADN). Em nossa casuística, houve inclusão de uma criança de cinco anos de idade, na qual, pelas seqüências de RM e pela DCG, se caracterizou obstrução no nível do ducto nasolacrimal, possivelmente decorrente de obstrução congênita distal. Foi incluído, também, um caso em que o paciente tinha apresentado trauma de face previamente e, posteriormente ao acidente, desenvolvido epífora.

Do mesmo modo, nossa casuística coincide com a literatura no que diz respeito à freqüência do nível da obstrução das vias lacrimais. Conforme Som e Curtin (2003) e Francisco et al. (2007), o sítio mais comum de obstrução é o "colo" ou base do saco lacrimal (topografia da válvula de Krause). Nosso trabalho confirmou como sítio mais prevalente de obstrução o saco lacrimal (base do saco lacrimal - 63,4\%). 
Conforme os relatos do trabalho de Guzek et al. (1997), no qual foram analisados os pontos fracos e fortes dos exames clínicos e de imagem, na detecção de obstrução das vias lacrimais em pacientes com epífora, concluiuse que dois ou mais testes são necessários para tal objetivo, especialmente nos casos de obstrução parcial ou funcional. Dessa forma, exames de imagem são importantes para caracterizar melhor o sítio e a natureza da obstrução, o que pode auxiliar na decisão quanto à terapêutica a ser instituída.

Revisando a literatura que concerne à utilização da RM como um método para estudo das vias lacrimais (dacriocistografia por RM), pudemos identificar apenas dois trabalhos em que se realizou o cálculo da sensibilidade do método para a detecção de obstrução.

Em 2000, Kirchhof et al. publicaram um trabalho em que nove pacientes portadores de epífora foram submetidos a exame por RM com instilação de gadolínio diluído e a DCG com subtração digital. Considerando-se a identificação da obstrução das vias lacrimais, os autores relataram sensibilidade de $100 \%$ para a RM. Quando se considerou o nível de obstrução, a concordância reduziu-se para $67 \%$ e $89 \%$ para cada observador, respectivamente.

Em 2002, Karagülle et al., utilizando uma seqüência de RM ponderada em T1 após instilação de gadolínio diluído (1:100) em 17 pacientes, obtiveram, também, sensibilidade de $100 \%$ para o diagnóstico da presença de obstrução da via lacrimal. Quando se considerou o nível da obstrução, a concordância 
citada pelos autores foi de $100 \%$ para os níveis canalicular e ductal, porém atingiu $80 \%$, quando se consideraram obstruções em nível sacular.

Obtivemos, igualmente, elevados valores de sensibilidade para 0 diagnóstico da presença, ou não, de obstrução das vias lacrimais, com as três distintas técnicas de RM efetuadas. As sensibilidades médias para os dois observadores oscilaram entre $89,5 \%$ e $94,3 \%$, considerando-se apenas os casos em que classificaram as vias lacrimais como preenchidas por um "material" de contraste. Incluindo-se as vias lacrimais não opacificadas na análise, os valores da sensibilidade mantiveram-se altos, observando-se até certa elevação, para ambos os analisadores (95,2\%). De forma semelhante ao observado por Kirchhof et al. (2000), os níveis de concordância das seqüências de RM com a DCG, para a identificação do nível da obstrução lacrimal, em nosso trabalho, oscilaram entre cerca de $70 \%$ e $90 \%$.

Do ponto de vista da especificidade para o diagnóstico da obstrução das vias lacrimais, a RM demonstrou valores entre $80 \%$ e $100 \%$. As seqüências STIR sem e com instilação do soro fisiológico assinalaram as especificidades mais altas (100\%), indicando seu potencial para a caracterização de uma via lacrimal sem obstruções anatômicas.

Os valores preditivos positivos e negativos de cada uma das seqüências de $\mathrm{RM}$ variaram, respectivamente, entre $87,5 \%$ e $100 \%$ e $78,9 \%$ e $88,9 \%$. Os valores preditivos positivos mais elevados foram observados com as seqüências STIR sem e com instilação de soro fisiológico, indicando que um exame de RM, julgado alterado por essas seqüências, provavelmente provém 
de um paciente com obstrução da via lacrimal em questão. Notou-se valor preditivo negativo mais elevado com a seqüência T1, após instilação de gadolínio diluído. Portanto, diante de um exame considerado normal por essa seqüência, há grande chance de que o indivíduo, realmente, não apresente doença obstrutiva da via lacrimal.

Os valores descritos acima foram calculados excluindo-se os casos não preenchidos por meio de contraste. Ao incluirmos estes casos não e considerando-os como com obstrução presente, observamos relativa redução da especificidade e do valor preditivo positivo das seqüências de RM, variando entre $72,2 \%$ e $94,4 \%$ e entre $88,7 \%$ e $97,5 \%$, respectivamente. Os valores preditivos negativos não se modificaram de forma significativa.

Calculamos ainda, de forma inédita até então, os níveis de concordância intra- e interobservador tanto para o diagnóstico de obstrução propriamente dita das vias lacrimais, quanto para o nível de tal obstrução. Os níveis de concordância inter e intra-observadores foram bastantes elevados para 0 diagnóstico da presença ou ausência de obstrução das vias lacrimais, tanto quando se comparou cada uma das seqüências de RM com a DCG, quanto entre as seqüências de RM entre si. Esses resultados agregam valor à RM como técnica para estudo das vias lacrimais, pois apontam para a reprodutibilidade da análise, mesmo por observadores diferentes.

Quanto à identificação do nível de obstrução das vias lacrimais, houve diferenças na concordância intra-observador para os observadores 1 e 2. Para o observador 1, apenas a seqüência STIR com instilação de soro fisiológico 
assinalou concordância estatisticamente significante com a DCG e com a seqüência STIR sem instilação ( $K=0,582$ e $K=0,684$ respectivamente). Em contrapartida, para o observador 2, houve concordância estatisticamente significante entre todas as seqüências de RM e a DCG e entre as seqüências de RM entre si, para o diagnóstico do nível da obstrução ( $\mathrm{K}$ variando entre $0,404$ e 0,763$)$. Isso mostra que, de forma geral, o observador 2 foi mais consistente (concordante) em sua análise. Tal fato pode derivar de sua maior experiência com doenças das vias lacrimais. Convém lembrar, entretanto, que parte dessa concordância maior pode dever-se ao fato de ter sido mais restritivo na inclusão de casos em sua análise. Ao realizar um número maior de exclusões do que o observador 1 , por considerar mais vias lacrimais como não opacificadas, o segundo observador aumentou sua eficiência diagnóstica. Esse fato indica que uma curva de aprendizado é necessária para a melhora do desempenho diagnóstico individual, com prováveis impactos positivos sobre os resultados, com o acúmulo de experiência.

Quando consideramos a concordância interobservador para o diagnóstico do nível de obstrução, observamos que os níveis de concordância foram bastantes elevados ( $\mathrm{K}$ oscilando entre 0,518 e 1,000), mesmo em se tratando de observadores com experiências distintas.

Nosso trabalho é o primeiro da literatura a utilizar uma seqüência com ponderação T2 (STIR em nosso caso), no plano coronal, sem instilação de qualquer meio de contrate, para a avaliação das vias lacrimais. Anteriormente, Yoshikawa et al. e Takeharaki et al., em 2000, em seus trabalhos, valeram-se 
de seqüências Fast Spin-eco com ponderação T2 no plano axial, com técnica para supressão do sinal da gordura, com o objetivo de descartar lesões expansivas e de estudar a mucosa das vias lacrimais. Tais estudos, no entanto, não obtiveram imagens das vias lacrimais de forma semelhante à conseguida pela DCG com essas seqüências.

Ao realizar, em nossos pacientes, a seqüência STIR sem instilação alguma, obtivemos imagens das vias lacrimais, aproveitando as lágrimas ou a mistura das lágrimas com eventuais secreções mais espessas, como meio de contraste para a opacificação delas. Quando o conteúdo lacrimal era fluido e homogêneo, o lúmen das vias lacrimais obstruídas estava ocupado por conteúdo com elevado sinal em T2. Na presença de secreções mais espessas (com maior conteúdo protéico), o sinal observado era pouco menos intenso, de aspecto semelhante ao relatado por Som et al., em 1989, quando constataram que secreções crônicas espessas no interior das cavidades paranasais se manifestavam com sinal aumentado em $\mathrm{T} 1$ e sinal relativamente reduzido em T2. Mesmo preenchidas por material com essas características, as vias lacrimais podem ser visibilizadas em seqüências com ponderação T2.

Nesta pesquisa, a seqüência STIR sem instilação mostrou-se bastante eficaz para o diagnóstico de obstrução das vias lacrimais, com sensibilidade e especificidade máximas de $94,3 \%$ e 100\% respectivamente, além de elevadas concordâncias intra e interobservadores (concordâncias quase perfeitas; K oscilando entre 0,828 e 1,000). Por tratar-se de uma seqüência completamente inócua (nada é instilado para sua aquisição), acreditamos que deva fazer parte 
de um protocolo de RM para investigação de obstrução das vias lacrimais, como a primeira seqüência do estudo. Quanto à identificação do nível da obstrução, nossos resultados reconheceram diferenças entre as análises dos dois observadores. Para apenas um deles houve concordância moderada com os diagnósticos feitos por meio da DCG. Entretanto, se considerarmos obstruções no nível do saco lacrimal, essa seqüência denota ótimos resultados: o observador 1 identificou 21 das 23 (91,3\%) obstruções saculares com essa seqüência e o observador 2 identificou 22 das 23 (95,6\%).

Em nosso trabalho, empregamos, também, a seqüência STIR ponderada em T2 após a instilação de soro fisiológico. Em 1998, Caldemeyer et al. fizeram uso em voluntários assintomáticos de uma seqüência Fast spin-eco ponderada em T2, com técnica para supressão do sinal da gordura, para estudo das vias lacrimais. Nesse trabalho também se instilou soro fisiológico, de forma semelhante à que procedemos em nosso estudo (duas gotas por minuto em cada saco conjuntival, por cinco minutos). Em 22 vias lacrimais analisadas, tanto o saco lacrimal quanto as porções proximais do ducto nasolacrimal, foram identificados em praticamente todos os casos. Entretanto, os autores relataram menor êxito na identificação de estruturas mais delicadas das vias lacrimais (canalículos), com taxas de sucesso bem inferiores (10 a 12 canalículos em 22 estudados).

Em nosso trabalho, a seqüência STIR após instilação do soro fisiológico apontou elevada sensibilidade e especificidade para o diagnóstico de obstrução das vias lacrimais $(93,2 \%$ e $100 \%$, respectivamente), além de elevadas 
concordâncias inter e intra-observador ( $\mathrm{K}>0,8$; concordância quase perfeita). Além disso, essa seqüência apresentou boa concordância com o padrão-ouro (DCG) no diagnóstico do nível da obstrução, para ambos os observadores individualmente e para os dois observadores em conjunto.

O bom desempenho da seqüência supracitada pode ser decorrente da escolha de um meio de contraste com características físico-químicas, (especialmente viscosidade), semelhantes às da lágrima: o soro fisiológico. Após sua instilação, não deve haver restrição ao trânsito por viscosidade elevada. O soro pode progredir livremente ou apenas até o ponto em que a via lacrimal se encontra obstruída, tendendo a delimitar o nível da obstrução. A existência de conteúdo espesso retido no interior da via lacrimal pode prejudicar a caracterização da presença do soro fisiológico no interior dela, seja por impedir a progressão através das estruturas anatômicas em questão, seja por diluição em permeio ao conteúdo anômalo.

Em 2000, Yoshikawa et al. propuseram a utilização de seqüências de RM com ponderação T2, após instilação de soro fisiológico como screening para problemas das vias lacrimais, por considerá-la não invasiva, mais barata (quando comparada à instilação de gadolínio diluído) e por permitir avaliação das condições da mucosa luminal e das partes moles adjacentes.

A seqüência T1, após instilação de gadolínio diluído, foi a que demonstrou os piores resultados globais, quando comparada com a seqüência STIR, sem e com instilação de soro fisiológico. Com essa seqüência, ambos os observadores decidiram excluir o maior número de vias lacrimais de suas 
análises, por considerá-las não preenchidas. As razões que podem explicar esse comportamento já foram relatadas previamente na literatura. Em 2000, Yoshikawa et al., empregando uma seqüência gradiente-eco T1 para estudo das vias lacrimais, comentaram que tais seqüências são mais susceptíveis a heterogeneidades do campo magnético (por exemplo, determinadas por material metálico dentário, ar em cavidades paranasais etc). Como resultados, surgem imagens de pior qualidade, com comprometimento da identificação do meio de contraste (no caso, gadolínio diluído), no interior da via lacrimal. Em nosso trabalho, houve o relato dos dois observadores quanto à presença de artefatos de susceptibilidade magnética prejudicando a visibilização das vias lacrimais (dois casos relatados pelo observador 1 e um caso relatado pelo observador 2).

Em 2002, Karagülle et al. publicaram um trabalho em que faziam uso de uma seqüência gradiente-eco ponderada em T1 (em um aparelho de 1,0 Tesla), após instilação de gadolínio diluído (1:100), obtendo imagens no plano axial, que eram posteriormente reconstruídas no plano coronal. Nesse trabalho, 34 vias lacrimais foram estudadas, comparando-se a RM com ocorrências da DCG. Os autores notificaram discrepâncias nos resultados dos dois métodos em dois casos (obstruções nos sacos lacrimais foram consideradas como obstruções canaliculares). A razão para essas discrepâncias, pode, inclusive, ter motivado algumas discordâncias em nosso trabalho. Os autores relataram que o sítio preciso da obstrução da via lacrimal pode estar indetectável na RM, em virtude da presença do acúmulo de secreção em seu interior, ocasionando 
diluição do meio de contraste no segmento pré-estenótico, provocando a não identificação da estrutura anatômica.

Esse dado foi coincidente com o identificado em nosso estudo. Em, pelo menos, cinco casos analisados pelo observador 1 e em quatro analisados pelo observador 2, verificou-se a presença de diluição do gadolínio, em permeio ao conteúdo anômalo das vias lacrimais, resultando em não opacificação ou em erro de interpretação do nível de obstrução, considerando-o mais proximal do que efetivamente o era.

$\mathrm{Na}$ análise dos resultados, pudemos observar que nos seis casos em que havia obstruções no nível dos canalículos, detectadas pela DCG, as seqüências de RM não concordaram com o padrão-ouro. Em dois casos analisados o observador 1 considerou a possibilidade de obstruções canaliculares, efetivamente presentes na DCG; em um dos casos (caso 17) o diagnóstico baseou-se na seqüência STIR com instilação de soro fisiológico; no caso 18, a hipótese foi resultante da análise das seqüências STIR sem e com instilação do soro fisiológico. Em relação ao observador 2, este último não fez a hipótese de obstrução canalicular em nenhuma de suas análises. Entretanto, é relevante relatar que o observador 2 considerou as vias lacrimais obstruídas em nível canalicular como não preenchidas em quatro dos seis casos, e em todas as seqüências de RM. Os dois únicos casos em que o observador 2 não considerou as vias lacrimais como não preenchidas, apresentaram particularidades que devem ser destacadas. No caso 8, apesar de haver obstrução canalicular no olho esquerdo, havia, também, acentuada dilatação e 
estase de conteúdo no interior do saco lacrimal (dacriocistocele). Isso ocasionou erro de interpretação do nível da obstrução para ambos os observadores, que consideraram a obstrução em nível sacular. Em relação ao olho direito no caso 30, a DCG demonstrou, com má definição, a porção superior da via lacrimal, inferindo-se obstrução canalicular nesse caso. Importa lembrar que a paciente não se queixava de lacrimejamento desse lado. Em 1998, Caldemeyer et al. já haviam relatado que a RM demonstrava os canalículos lacrimais de maneira menos consistente que a TC, em indivíduos assintomáticos. Essa constatação deve ser levada em consideração quando são estudados casos em que o nível de obstrução é alto (canalicular), pois a possibilidade de não identificação dos canalículos, mesmo que obstruídos, pode ainda ser considerada.

Em contrapartida, Hoffmann et al. em 1999, e Karagülle et all, em 2002, adotaram como critério para a caracterização de obstruções canaliculares vistas pela RM, a ausência de preenchimento do saco lacrimal e ducto nasolacrimal, pelo gadolínio diluído instilado nos dois trabalhos. Com esse critério, o grupo de Karagülle relatou a detecção de obstrução canalicular em 100\% dos casos.

Em nosso trabalho, a ausência de opacificação das vias lacrimais não foi considerada como premissa, nem como critério para o diagnóstico de obstrução canalicular, porque nosso protocolo de exame incluiu uma seqüência em que não havia instilação de nenhum meio de contraste. Dessa forma, assumimos que poderíamos deparar-nos com vias lacrimais não opacificadas por lágrimas em indivíduos normais, conforme já relatado previamente por Russell et al., em 
1985. Entretanto, se considerarmos apenas as seqüências em que houve instilação efetiva de algum meio de contraste (soro fisiológico ou gadolínio), e excluindo-se o caso em que a dacriocistocele promoveu prejuízo da interpretação, a porcentagem de vias lacrimais consideradas não preenchidas por ambos os observadores foi relativamente elevada $(68 \%$ - 15 em 22 analisadas).

Portanto, diante de uma via lacrimal não preenchida por soro fisiológico ou por gadolínio diluído em um exame de RM, parece-nos razoável considerar a possibilidade de obstrução alta (canalicular), especialmente se o quadro clínico de excesso de lacrimejamento for condizente com o lado em que a alteração foi identificada na RM. Corroborando com essa impressão, a análise que incluiu vias lacrimais não preenchidas, considerando-as como obstruídas em nível canalicular revelou valores de sensibilidade ainda mais altos para o diagnóstico da presença da obstrução, ao se comparar com a análise com exclusão de tais vias lacrimais. Nos casos em que a dúvida persistir, outros métodos poderão ser utilizados, dentre os quais a RM com cateterização das vias lacrimais e administração de meio de contraste, como se adotou nos trabalhos de Manfré, et al. (2000) e Takehara et al. (2000).

Acreditamos, ainda, que a identificação mais precisa do conteúdo preenchedor das vias lacrimais em exame de RM seja influenciada pela relação sinal-ruído. Portanto, confiamos que novos estudos com bobinas de superfície de diâmetros menores (as denominadas bobinas microscópicas) poderão reduzir o número de vias lacrimais consideradas como não 
preenchidas por qualquer tipo de contraste, na medida em que o possível aumento da conspicuidade da detecção do meio líquido na via lacrimal tornará mais fácil a identificação do nível de obstrução.

Uma aplicação potencial da RM na avaliação das vias lacrimais, e que representa uma vantagem em relação à DCG, é o fato de ser possível obter informações funcionais do estudo feito com a instilação de um meio de contraste. Por não se administrar o meio de contraste sob pressão, como ocorre nos estudos de DCG após a cateterização canalicular, observa-se o seu trânsito pela via lacrimal, na dependência da preservação dos mecanismos fisiológicos de excreção da lágrima e da presença, ou não, de obstrução mecânica. Em 1999, Pariselle et al. avaliaram nove indivíduos (dois deles assintomáticos), utilizando seqüência T1, após instilação de gadolínio diluído (1:10). Esses autores analisaram o tempo de progressão do gadolínio diluído, de maneira segmentar, caracterizando o tempo de chegada ao saco lacrimal, o tempo de chegada à porção óssea do ducto nasolacrimal e o tempo de chegada à porção mucosa do ducto nasolacrimal. Os autores observaram que o tempo total de passagem do meio de contraste pelas vias lacrimais dos indivíduos assintomáticos era, em média, de aproximadamente cem segundos, e nos demais indivíduos com queixa de epífora, porém com vias lacrimais permeáveis (prováveis alterações funcionais), o tempo de passagem era mais prolongado, intermediário entre o dos assintomáticos e o dos com obstrução completa.

Em nosso trabalho, pudemos exemplificar o potencial da RM na caracterização de prováveis distúrbios funcionais das vias lacrimais. O caso 7 
tratava de uma paciente do sexo feminino de 72 anos de idade, com história de lacrimejamento excessivo há dois anos, notoriamente mais significativo à esquerda. A paciente não relatava cirurgias ou manipulações prévias das vias lacrimais. O estudo por RM foi considerado, pelos dois observadores, como sem sinais de obstruções, quando adotaram a seqüência STIR sem e com instilação de soro fisiológico. Entretanto, ao estudo realizado com a seqüência T1 após instilação de gadolínio diluído, ambos os observadores identificaram que o meio de contraste progrediu apenas até a base do saco lacrimal à esquerda (Anexo H, Figura 17), mesmo quando se analisou uma seqüência tardia, cerca de 20 minutos após o início da primeira instilação (nesse caso a seqüência foi realizada duas vezes e a instilação do gadolínio também foi feita duas vezes). Os observadores interpretaram como possível obstrução no nível do saco lacrimal, apesar de o saco lacrimal não se ter apresentado dilatado. A DCG realizada nessa paciente evidenciou permeabilidade completa das vias lacrimais, sem sinais de estenoses ou dilatações significativas. Portanto, nesse caso em particular, a RM apontou a possibilidade de alguma alteração da via lacrimal esquerda, em que o distúrbio funcional pode ser considerado em um contexto clínico adequado.

Considerando-se a técnica de RM utilizada em nosso estudo, aplicando-se seqüências sem e com instilação de um meio de contraste, em detrimento à técnica com cateterização, semelhante à utilizada na DCG, pode ser considerada como potencial desvantagem a possibilidade de superestimar obstruções das vias lacrimais. Tal possibilidade baseia-se no fato de que, por 
instilação, o meio de contraste não é administrado sob um regime de pressão, e, portanto, apresenta limitação para sobrepujar eventual área de estenose parcial (não completa). Isso pode resultar tanto na quantificação equivocada da intensidade da obstrução, quanto na caracterização equivocada do nível da obstrução (mais proximal do que o real). Essa última situação aconteceu em praticamente todas as seqüências, para ambos os observadores, notando-se que classificaram alguns casos como obstruídos no nível do saco lacrimal, quando a obstrução, ao exame padrão-ouro (DCG), mostrou-se relativamente mais distal (porções diversas do ducto nasolacrimal). No contexto de nosso trabalho, o diagnóstico da obstrução não foi comprometido por tal situação, uma vez que, ou classificada no nível do saco lacrimal ou no do ducto nasolacrimal, pôde ser considerada como baixa.

Do ponto de vista fisiológico, contrariamente ao exposto acima, a técnica com instilação, ao invés da administração após cateterização, tende a oferecer uma informação mais fidedigna quanto à real intensidade da sintomatologia experimentada pelo paciente, porque reproduz as condições normalmente vivenciadas pelo indivíduo.

Baseando-se nos métodos atualmente disponíveis para o estudo radiológico das vias lacrimais, e analisando-os à luz dos resultados obtidos em nosso trabalho, é possível a proposição de um algoritmo de investigação para um paciente que se apresente com queixa de lacrimejamento excessivo.

Em virtude das vantagens de ausência de invasibilidade, ausência de exposição do cristalino à radiação ionizante, capacidade de caracterização de 
estruturas de partes moles perilacrimais (Anexo I, Figura 18) e possibilidade de um estudo de cunho mais fisiológico, bilateral e simultâneo, a RM pode ser considerada como método diagnóstico para a investigação da obstrução das vias lacrimais.

Em nossa visão, os elevados valores de sensibilidade e especificidade e dos índices de concordância inter e intra-observador, para a detecção da presença de obstrução, credenciam o método como uma técnica válida no estudo de pacientes com queixa de lacrimejamento excessivo. O exame pode ser realizado com seqüências com ponderação T2 (STIR), no plano coronal, sem e com a instilação de um meio inócuo (Soro fisiológico 0,9\%) ou com seqüência com ponderação T1 após instilação de gadolínio diluído (1:100). Deve-se considerar que, com base em nossos resultados, a seqüência T1 após a instilação de gadolínio diluído foi a que apresentou os piores resultados globais.

Portanto, quando a via lacrimal estiver preenchida à $\mathrm{RM}$, perante a identificação de obstrução da via lacrimal do tipo baixa, (isto é, no nível do saco lacrimal ou do ducto nasolacrimal), sugerimos término da investigação por imagem, em virtude da elevada concordância entre a RM com as seqüências utilizadas em nosso estudo e o padrão-ouro (DCG) para esse diagnóstico.

Se o estudo for realizado inicialmente com a seqüência STIR sem instilação alguma, e não houver identiticação clara da via lacrimal, deve-se proceder a nova aquisição dessa seqüência, após instilação de soro fisiológico (duas gotas por minuto por cinco minutos). 
Se as seqüências STIR e T1, após instilação de soro fisiológico e de gadolínio diluído, resultarem em vias lacrimais não preenchidas pelos mesmos, poderemos considerar duas possibilidades distintas:

$\checkmark$ obstrução alta (isto é, canalicular);

$\checkmark$ distúrbio funcional (falência da bomba lacrimal).

Deve-se considerar, então, nova instilação dos meios de contraste ou apenas nova aquisição, para tentativa de caracterização de distúrbio funcional com retardo no trânsito das lágrimas.

Se mesmo após a nova seqüência, a via lacrimal persistir sem evidências de preenchimento, deve-se considerar o estudo radiológico por outro método, para diferenciação entre as possibilidades de obstrução canalicular e distúrbio funcional. As opções poderão incluir: RM com cateterização canalicular, DacrioTC, Dacriocintilografia ou DCG (Anexo J).

Analisando as limitações de nosso estudo, devemos destacar principalmente, a utilização de apenas dois observadores para a análise dos dados. Essa metodologia pode despertar como possível crítica a limitação para avaliar sua real capacidade de oferecer adequada concordância entre observadores diferentes. Em contrapartida, lembramos que, apesar de termos utilizado apenas dois observadores, estes apresentavam experiências distintas, um deles com experiência em Radiologia da Cabeça e Pescoço e o outro com formação radiológica generalista. Essa diferença de experiência permitiu-nos considerar que a concordância interobservador da RM é adequada, pois a despeito da heterogeneidade de experiência, os índices de concordância inter 
e intra-observador foram bastante significativos, especialmente para a detecção da presença, ou não, de obstrução das vias lacrimais.

Quanto ao uso do método padrão-ouro para a confirmação do diagnóstico de obstrução das vias lacrimais (DCG), utilizamos a técnica de macrodacriocistografia, sem subtração digital, em virtude da indisponibilidade de equipamento com tecnologia mais atualizada para o estudo de nossos pacientes. Entretanto, os observadores não relataram comprometimento da capacidade de detectarem o nível de obstrução das vias lacrimais, com a técnica de Radiologia convencional utilizada.

Optamos por adotar como padrão-ouro a DCG, para comparação da eficácia da RM na detecção da obstrução das vias lacrimais. Infelizmente não obtivemos confirmações cirúrgicas de nenhum de nossos casos. Quanto à correlação com dados clínicos, obtivemos os resultados dos exames oftalmológicos de 17 dos nossos 32 pacientes. Em virtude do número relativamente pequeno desses dados, não pudemos submetê-los à análise estatística. Entretanto, pudemos mensurar a concordância relativa (percentual) entre os diagnósticos realizados por meio de cada uma das seqüências de RM e pela DCG em comparação com aquele obtido pelo exame oftalmológico. Nessa comparação, foram considerados os diagnósticos de obstrução alta (canalicular) ou baixa (SL / DNL) das vias lacrimais, já que essa é a classificação utilizada após o exame oftalmológico. As seqüências STIR sem e com instilação de soro fisiológico apresentaram-se concordantes com o exame clínico em 15 dos 17 casos (88,2\% das vezes), a seqüência T1 após instilação 
de gadolínio diluído foi concordante em 11 dos 17 casos (64,7\% das vezes) e a DCG foi concordante em 16 dos 17 casos (94,1\% das vezes).

Em termos de perspectivas futuras, a aplicação da RM como método para a avaliação das vias lacrimais, pode ainda se tornar mais ampla, com a utilização de bobinas microscópicas. Vários relatos na literatura, entre eles os de Nitsu e Ikeda, em 2004 e de Sumi et al., em 2006, têm ressaltado o grande potencial da utilização de bobinas de superfície microscópicas (com diâmetros menores ou iguais a $5,0 \mathrm{~cm}$ ) para estudo de estruturas anatômicas de localização superficial. Nitsu e Ikeda (2004) estudaram estruturas do aspecto medial do joelho, enquanto Sumi et al. (2006) estudaram linfonodos cervicais normais e patológicos. Nesse último trabalho, uma bobina microscópica de 4,7 cm permitiu que fossem obtidas imagens de alta resolução desses linfonodos. Utilizando-se os critérios de alteração da arquitetura linfonodal e de restrição à difusão da água, os autores obtiveram acurácia de 90\% e 93\%, respectivamente, para a diferenciação entre linfonodos metastáticos e linfoma. Os benefícios da bobina microscópica estão relacionados à melhora significativa da relação sinal - ruído, permitindo a utilização de cortes de menor espessura e de campos de visão também menores, sem o inconveniente de se obter imagens extremamente ruidosas ou não diagnósticas.

Pela localização superficial das vias lacrimais, bobinas de superfície microscópicas são uma excelente alternativa em potencial para aprimorar a caracterização das estruturas anatômicas. Em um trabalho realizado por nós e submetido recentemente à publicação (setembro de 2007) na Revista 
Radiologia Brasileira ${ }^{10}$, estudamos as vias lacrimais de cinco indivíduos assintomáticos, utilizando seqüência STIR após instilação de soro fisiológico, comparando bobinas de superfície convencionais e microscópicas. Em todos os indivíduos estudados, as imagens obtidas com a bobina microscópica permitiram identificar as estruturas das vias lacrimais (inclusive os canalículos) com melhor definição, quando comparadas às imagens obtidas com bobinas convencionais. O escore atribuído a todas as estruturas das vias lacrimais foi em média 1,17 pontos mais alto com as bobinas microscópicas. Considerou-se também, de maneira subjetiva, melhora significativa da relação sinal-ruído nas imagens obtidas com a bobina de $4,7 \mathrm{~cm}$ de diâmetro, em todos os casos, mesmo naqueles em que se identificavam artefatos de movimento.

O uso de bobinas microscópicas, com as seqüências já descritas ou com outras seqüências, especialmente de aquisição rápida, poderá melhorar a acurácia da RM na caracterização do nível de obstrução das vias lacrimais, que apresentaram resultados menos satisfatórios em nosso estudo.

Deve-se lembrar que o aumento da disponibilidade de equipamentos de RM com campo magnético de 3,0 Tesla (ou superiores), poderá ampliar ainda mais a relação sinal-ruído, permitindo que se utilizem menores espessuras de corte e aquisições volumétricas, sem prejuízo da resolução temporal, resultando em melhora global da qualidade.

${ }^{10}$ Abreu Jr. L, Borri ML, Wolosker AMB, D'Ippolito G, Castro CC, Hartmann LGC, Galvão $\mathrm{F}^{\circ} \mathrm{MM}$. Ressonância magnética das vias lacrimais: estudo comparativo entre bobinas de superfície convencionais e microscópicas. Radiol Bras. In press 2008. 
6. CONCLUSÕES 


\section{CONCLUSÕES}

1. A RM é um método eficaz para a detecção de obstrução das vias lacrimais, apresentando elevadas sensibilidade e especificidade, além de elevados índices de concordância inter e intra-observador.

2. A RM mostrou-se eficaz para a detecção do nível de obstrução das vias lacrimais, quando se utilizou a seqüência STIR com instilação de soro fisiológico, que resultou em concordâncias inter e intra-observador estatisticamente significantes, em confronto com o método padrão-ouro (DCG).

3. O protocolo de exame de RM para investigação de obstrução das vias lacrimais deve ser iniciado com a seqüência STIR sem instilação alguma, seguida dessa mesma seqüência após instilação de soro fisiológico. $\mathrm{O}$ uso da seqüência $T 1$, após instilação de gadolínio, representa uma opção, devendo-se lembrar, entretanto, que a mesma demonstrou os piores resultados globais neste estudo. Quando o exame de RM resultar em uma via lacrimal não preenchida por qualquer meio líquido, as possibilidades de obstrução alta (canalicular) ou de distúrbio funcional devem ser consideradas. 
7. ANEXOS 


\section{ANEXO A}

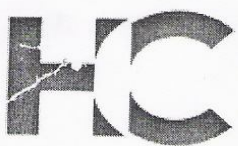

\section{HOSPHTL DAS GLHICHS}

Ao

Departamento de Radiologia

O Presidente da Comissão de Ética para Análise de Projetos de Pesquisa - CAPPesq da Diretoria Clínica do Hospital das Clínicas e da Faculdade de Medicina da Universidade de São Paulo, em 07.06.06, tomou ciência da execução do Protocolo de Pesquisa $n^{\circ} 461 / 06$, intitulado: "Avaliação da eficácia da Dacriocistografia por ressonância magnética no estudo de pacientes com obstrução das vias lacrimais".

No que tangue sua parte empírica será desenvolvido no Hospital e Maternidade São Luiz, tendo seu Comitê de Ética aprovado o estudo em 08.02.06.

Pesquisador(a) Responsável: Prof. Dr. Cláudio Campi de Castro Pesquisador(a) Executante: Dr. Luiz de Abreu Junior CAPPesq, 07 de Jüunho de 2006.

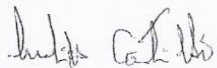

PROF. DR. EUCLIDES AYRES DE CASTILHO Presidente da Comissão de Ética para Análise de Projetos de Pesquisa

Comissão de Ética para Análise de Projetos de Pesquisa do HCFMUSP e da FMUSP

Diretoria Clínica do Hospital das Clínicas da Faculdade de Medicina da Universidade de São Paulo Rua Ovídio Pires de Campos. 225, $5^{\circ}$ andar - CEP 05403010 - São Paulo - SP

Fone: 011 - 30696442 fax:011-30696492-e-mail : cappesq@hcnet.usp.br / secretariacappesq2@hcnet.usp.br 


\section{ANEXO B}

\section{$5 \longdiv { 1 0 } 0$ - \\ Centro de \\ Estudos}

PARECER FINAL

COMITÊ DE ÉTICA EM PESQUISA DA BENEFICÊNCIA MÉDICA BRASILEIRA S/A - HOSPITAL E MATERNIDADE SÃO LUIZ

$N^{\circ}$ CEP: $109 / 2005$

TíTULO: "Avaliação da eficácia da Dacriocistografia por Ressonância Magnética no estudo de pacientes com obstrução das vias lacrimais". INVESTIGADOR PRINCIPAL: Dr. Cláudio Campi de Castro

PROFISSÃO: Médico Radiologista

PROTOCOLO: 20.12.05

Saibam, quantos este PARECER FINAL virem, que o Comitê de Ética em Pesquisa da Beneficência Médica Brasileira S/A Hospital e Maternidade São Luiz, em Reunião ordinária realizada em 08.02.2006, APROVOU, por unanimidade, o projeto/estudo/pesquisa em epigrafe, nos termos do relatório e voto do Relator designado.

Relatório: Este projeto tem como objetivo estebelecer o papel da dacriocistografia por RM na avaliação pré-operatória de pacientes com obstrução das vias lacrimais, correlacionando-se com o exame clínico e com a dacriocistografia por raios- $X$ e com achados cirúrgicos, sempre que possivel.

Parecer. Projeto aprovado sem reservas do ponto de vista ético.

Pelo exposto, o Comitê de Ética em Pesquisa, vem pela presente informar seu parecer FAVORÁVEL à realização do projeto/estudo/pesquisa apresentado, consignando seu necessário CONSENTIMENTO, conforme disposto no Parágrafo $1^{\circ}$, da Cláusula $6^{a}$, de seu Regimento Interno. Solicitamos que nos enviem relatórios semestrais e final sobre os resultados desta pesquisa. 


\section{S10 \\ Centro de \\ Estudos}

Tudo em conformidade com a ata de Reunião ordinária, lavrada no dia 08.02.2006. Presidiu a Reunião o Dr. Antonio Carlos P. Chagas - Presidente do Comitê de Ética em Pesquisa da Beneficência Médica Brasileira S/A - Hospital e Maternidade São Luiz.

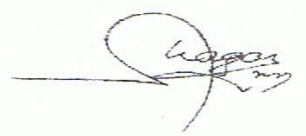

Prof. Dr. Antonio Carlos P.Chagas

PRESIDENTE

Comitê de Ética em Pesquisa Hospital e Maternidade São Luiz 


\section{ANEXO C}

\section{HOSPITAL DAS CLÍNICAS}

DA

FACULDADE DE MEDICINA DA UNIVERSIDADE DE SÃO PAULO

TERMO DE CONSENTIMENTO LIVRE E ESCLARECIDO

(Instruções para preenchimento no verso)

\section{I - DADOS DE IDENTIFICAÇÃO DO SUJEITO DA PESQUISA OU RESPONSÁVEL LEGAL}

1. NOME DO PACIENTE .

DOCUMENTO DE IDENTIDADE № : SEXO : .M $\square \mathrm{F}$

DATA NASCIMENTO:

ENDEREÇO

$/ \ldots \ldots . . . . . . .$.

BAIRRO:

CEP:
№ APTO:

2.RESPONSÁVEL LEGAL:

NATUREZA (grau de parentesco, tutor, curador etc.)

DOCUMENTO DE IDENTIDADE : SEXO: $M \square \mathrm{F} \square$

DATA NASCIMENTO:

ENDEREÇO:

BAIRRO:

CIDADE

TELEFONE:DDD(

.)

CEP:

CIDADE:

№

APTO:

TELEFONE: DDD

.)

\section{II - DADOS SOBRE A PESQUISA CIENTÍFICA}

1. TÍTULO DO PROTOCOLO DE PESQUISA : Avaliação da eficácia da Dacriocistografia por Ressonância Magnética no estudo de pacientes com obstrução das vias lacrimais.

PESQUISADOR: Dr. Luiz de Abreu Junior

CARGO/FUNÇÃO: Médico radiologista. INSCRIÇÃO CONSELHO REGIONAL № 77.158

UNIDADE DO HCFMUSP: Instituto de Radiologia

3. AVALIAÇÃO DO RISCO DA PESQUISA:

\begin{tabular}{|c|c|c|c|}
\hline SEM RISCO & $\square$ & RISCO MÍNIMO X & RISCO MÉDIO \\
\hline RISCO BAIXO & ${ }^{-}$ & RISCO MAIOR & \\
\hline
\end{tabular}

(probabilidade de que o indivíduo sofra algum dano como conseqüência imediata ou tardia do estudo) 4.DURAÇÃO DA PESQUISA : 2 ANOS 


\section{III - REGISTRO DAS EXPLICAÇÕES DO PESQUISADOR AO PACIENTE OU A SEU REPRESENTANTE LEGAL SOBRE A PESQUISA CONSIGNANDO:}

1. justificativa e os objetivos da pesquisa

O procedimento a ser realizado (Ressonância Magnética) é bastante seguro e é utilizado na Medicina para estudar vários As vias lacrimais são estruturas que fazem parte dos nossos olhos e que são responsáveis pela eliminação das lágrimas, depois que elas foram produzidas. As lágrimas são muito importantes para nossos olhos, porque mantêm sua lubrificação, impedindo que eles fiquem secos. O problema é que, às vezes, esses canais, que fazem a drenagem das lágrimas, ficam entupidos, e começa a haver o acúmulo de lágrimas nos olhos; então a pessoa fica com um lacrimejamento constante, que é desconfortável e que pode até incomodar a sua visão. Nesses casos, muitas vezes é necessária uma cirurgia para desentupir a via de drenagem. Para sabermos o local exato em que os canais estão entupidos, podemos usar alguns tipos de exames. A Ressonância Magnética é um bom exame, porque não utiliza radiação e não é necessário colocar agulhas para poder estudar os canais que drenam as lágrimas. Basta pingar soro fisiológico ou um contraste muito diluído e estudar as imagens que são obtidas.

2. procedimentos que serão utilizados e propósitos, incluindo a identificação dos procedimentos que são experimentais

órgãos. O exame fornece imagens do corpo humano, sem usar radiação (como o $R X$ ) e sem efeito colateral algum, podendo ser repetido quantas vezes forem necessárias. A RM funciona como um grande ímã associado a antenas que emitem ondas de radiofreqüência (semelhantes às ondas de rádio) que são enviadas ao órgão a ser estudado. O propósito deste estudo é utilizar a Ressonância Magnética para identificar em qual ponto o sistema de canais que drena as lágrimas está entupido, ajudando o médico oftalmologista na decisão de qual é a melhor programação de tratamento para o paciente.

3. desconfortos e riscos esperados

Durante o exame, o paciente estará deitado sobre um colchão, devendo ficar imóvel enquanto as seqüências são adquiridas, caracterizando-se por ruídos altos e ritmados. $O$ exame não provoca nenhuma dor ou mal-estar. Durante o exame, será necessário pingar nos olhos soro fisiológico e um contraste diluído para podermos identificar os canais que drenam as lágrimas dos olhos. Esse contraste não é o mesmo usado na Tomografia Computadorizada ou em Raios $X$, e é bastante seguro. Como ele não vai ser injetado na veia, não há riscos de reações alérgicas. Esse contraste não deve causar irritações ou problemas em seus olhos.

4. benefícios que poderão ser obtidos 
Realizando-se a RM, poderemos oferecer mais informações ao oftalmologista quanto à localização do ponto em que há a obstrução (entupimento) nos canais lacrimais, permitindo que ele selecione com mais tranqüilidade o tratamento a ser escolhido. Em casos de cirurgia, será mais tranqüilo identificar o local a ser abordado.

5. procedimentos alternativos que possam ser vantajosos para o indivíduo

Não se aplicam.

\title{
IV - ESCLARECIMENTOS DADOS PELO PESQUISADOR SOBRE GARANTIAS DO SUJEITO DA PESQUISA CONSIGNANDO:
}

1. acesso, em qualquer tempo, às informações sobre procedimentos, riscos e benefícios relacionados com a pesquisa, inclusive para dirimir eventuais dúvidas.

2. liberdade de retirar seu consentimento a qualquer momento e de deixar de participar do estudo, sem que isto traga prejuízo à continuidade da assistência.

3. salvaguarda da confidencialidade, sigilo e privacidade.

4. disponibilidade de assistência no HCFMUSP, por eventuais danos à saúde, decorrentes da pesquisa.

5. viabilidade de indenização por eventuais danos à saúde decorrentes da pesquisa.

\section{INFORMAÇÕES DE NOMES, ENDEREÇOS E TELEFONES DOS RESPONSÁVEIS PELO ACOMPANHAMENTO DA PESQUISA, PARA CONTATO EM CASO DE INTERCORRÊNCIAS CLÍNICAS E REAÇÕES ADVERSAS.}

\author{
Dr. Luiz de Abreu Junior
}

Av. Engenheiro Oscar Americano,

Telefones: 3093-1386 / 8331-8462

\section{OBSERVAÇÕES COMPLEMENTARES:}

\section{VII - CONSENTIMENTO PÓS-ESCLARECIDO}

Declaro que, após convenientemente esclarecido pelo pesquisador e ter entendido o que me foi explicado, consinto em participar do presente Protocolo de Pesquisa
São Paulo,
de
de 20 


\section{ANEXO D}

Tabela 1: Distribuição dos pacientes incluídos em nosso estudo, segundo sexo, idade, tempo de sintomatologia e olho sintomático.

\begin{tabular}{|c|c|c|c|c|c|}
\hline Paciente & Iniciais & Sexo & Idade (anos) & Tempo sintomas & Olho sintomático \\
\hline 1 & $\mathrm{CNO}$ & $M$ & 27 & 7 anos & OD \\
\hline 2 & HLF & $\mathrm{F}$ & 54 & 10 anos & OD \\
\hline 3 & RAG & $\mathrm{F}$ & 71 & 1 ano & OD \\
\hline 4 & EAS & $\mathrm{F}$ & 49 & 1 ano & OD \\
\hline 5 & OBO & $\mathrm{F}$ & 78 & 1 ano & $\mathrm{OE}$ \\
\hline 6 & EV & $\mathrm{F}$ & 72 & 2 anos & $\mathrm{AO}$ \\
\hline 7 & MLB & $\mathrm{F}$ & 75 & 10 anos & $\mathrm{AO}$ \\
\hline 8 & ESM & $\mathrm{F}$ & 37 & 1 ano & $\mathrm{AO}$ \\
\hline 9 & JEOS & M & 27 & 3 meses & OE \\
\hline 10 & $\mathrm{NCO}$ & $\mathrm{F}$ & 59 & 3 anos & $\mathrm{AO}$ \\
\hline 11 & JRFF & M & 49 & 5 anos & OE \\
\hline 12 & TMS & $\mathrm{F}$ & 84 & 5 anos & $\mathrm{AO}$ \\
\hline 13 & MRB & $\mathrm{F}$ & 55 & 10 anos & $\mathrm{AO}$ \\
\hline 14 & SRRAS & $\mathrm{F}$ & 45 & 3 meses & $\mathrm{AO}$ \\
\hline 15 & EJP & $\mathrm{F}$ & 58 & 20 anos & $\mathrm{AO}$ \\
\hline 16 & MLMF & $\mathrm{F}$ & 79 & 4 meses & OE \\
\hline 17 & MBG & $\mathrm{F}$ & 21 & 3 anos & OD \\
\hline 18 & MSR & $\mathrm{F}$ & 80 & não informado & $\mathrm{OE}$ \\
\hline 19 & MAF & $\mathrm{F}$ & 54 & 10 anos & $\mathrm{AO}$ \\
\hline 20 & $\mathrm{JHC}$ & M & 34 & 6 anos & $\mathrm{OE}$ \\
\hline 21 & TFP & $\mathrm{F}$ & 69 & 8 meses & OD \\
\hline 22 & $B O G$ & $\mathrm{~F}$ & 76 & 6 anos & OE \\
\hline 23 & MAS & $\mathrm{F}$ & 21 & 5 anos & OE \\
\hline 24 & IMC & $\mathrm{F}$ & 33 & 2 anos & OE \\
\hline 25 & PSJ & M & 5 & 5 anos & OE \\
\hline 26 & JAS & M & 37 & 3 anos & OD \\
\hline 27 & MEP & $\mathrm{F}$ & 59 & anos & OE \\
\hline 28 & TKT & $\mathrm{F}$ & 77 & 10 anos & $\mathrm{OE}$ \\
\hline 29 & MAFM & $\mathrm{F}$ & 80 & anos & $\mathrm{OE}$ \\
\hline 30 & COA & $\mathrm{F}$ & 73 & 2 anos & $\mathrm{AO}$ \\
\hline 31 & MMF & $\mathrm{F}$ & 79 & 1 ano & OD \\
\hline 32 & VRPP & $\mathrm{F}$ & 58 & 1 ano & $\mathrm{OE}$ \\
\hline
\end{tabular}


ANEXO E

Tabela 2: Classificação da obstrução das vias lacrimais em 17 olhos de 14 pacientes, segundo o exame oftalmológico.

\begin{tabular}{ll}
\hline Olho & Ex. oftalmológico \\
\hline $1 \mathrm{D}$ & Obstrução baixa \\
$2 \mathrm{D}$ & Obstrução baixa \\
4D & Obstrução baixa \\
$6 \mathrm{E}$ & Obstrução baixa \\
8D & Obstrução alta \\
$11 \mathrm{D}$ & Obstrução baixa \\
$11 \mathrm{E}$ & Obstrução baixa \\
$12 \mathrm{E}$ & Obstrução alta \\
20E & Obstrução baixa \\
$25 \mathrm{E}$ & Obstrução baixa \\
26E & Obstrução baixa \\
28D & Obstrução baixa \\
30E & Obstrução baixa \\
32D & Obstrução baixa \\
32E & Obstrução baixa \\
\hline
\end{tabular}




\section{ANEXO F}

Tabela 23 - Resumo dos valores de Sensibilidade, Especificidade e Valores Preditivos Positivo e Negativo para cada uma das seqüências de RM, para cada observador individualmente, excluindo-se os casos não preenchidos

\begin{tabular}{|c|c|c|c|c|c|c|c|c|}
\hline & \multicolumn{2}{|c|}{ Sensibilidade } & \multicolumn{2}{|c|}{ Especificidade } & \multicolumn{2}{|c|}{$\begin{array}{c}\text { Valor Preditivo } \\
\text { Positivo }\end{array}$} & \multicolumn{2}{|c|}{$\begin{array}{c}\text { Valor Preditivo } \\
\text { Negativo }\end{array}$} \\
\hline & Obs 1 & Obs2 & Obs 1 & Obs2 & Obs1 & Obs2 & Obs 1 & Obs2 \\
\hline RM STIR sem & $89,5 \%$ & $94,3 \%$ & $100 \%$ & $100 \%$ & $100 \%$ & $100 \%$ & $78,9 \%$ & $87,5 \%$ \\
\hline RM STIR SF & $93,2 \%$ & $91,9 \%$ & $100 \%$ & $100 \%$ & $100 \%$ & $100 \%$ & $84,2 \%$ & $85,7 \%$ \\
\hline RM T1 Gd & $93,3 \%$ & $93,1 \%$ & $76,5 \%$ & $84,2 \%$ & $87,5 \%$ & $90 \%$ & $86,7 \%$ & $88,9 \%$ \\
\hline
\end{tabular}

Tabela 24 - Resumo dos valores de Sensibilidade, Especificidade e Valores Preditivos Positivo e Negativo para cada uma das seqüências de RM, para cada observador individualmente, incluindo-se os casos não preenchidos

\begin{tabular}{llllccccc}
\hline & \multicolumn{2}{c}{ Sensibilidade } & \multicolumn{2}{c}{ Especificidade } & \multicolumn{2}{c}{ Valor Preditivo } & \multicolumn{2}{c}{ Valor Preditivo } \\
Positivo & Obgativo \\
& Obs1 & Obs2 & Obs1 & Obs2 & Obs1 & Obs2 & Obs1 & Obs2 \\
\hline RM STIR sem & $90,5 \%$ & $95,2 \%$ & $83,3 \%$ & $77,7 \%$ & $92,7 \%$ & $90,9 \%$ & $78,9 \%$ & $87,5 \%$ \\
RM STIR SF & $92,8 \%$ & $92,8 \%$ & $88,8 \%$ & $94,4 \%$ & $95,1 \%$ & $97,5 \%$ & $84,2 \%$ & $85,0 \%$ \\
RM T1 Gd & $95,2 \%$ & $95,2 \%$ & $72,2 \%$ & $83,3 \%$ & $88,7 \%$ & $93,0 \%$ & $86,6 \%$ & $88,2 \%$ \\
\hline
\end{tabular}


ANEXO G

Tabela 25 - Resumo das concordâncias intra-observadores para os diagnósticos da presença de obstrução e do nível de obstrução para as seqüências de RM em comparação à DCG e para as seqüências de RM entre elas mesmas.

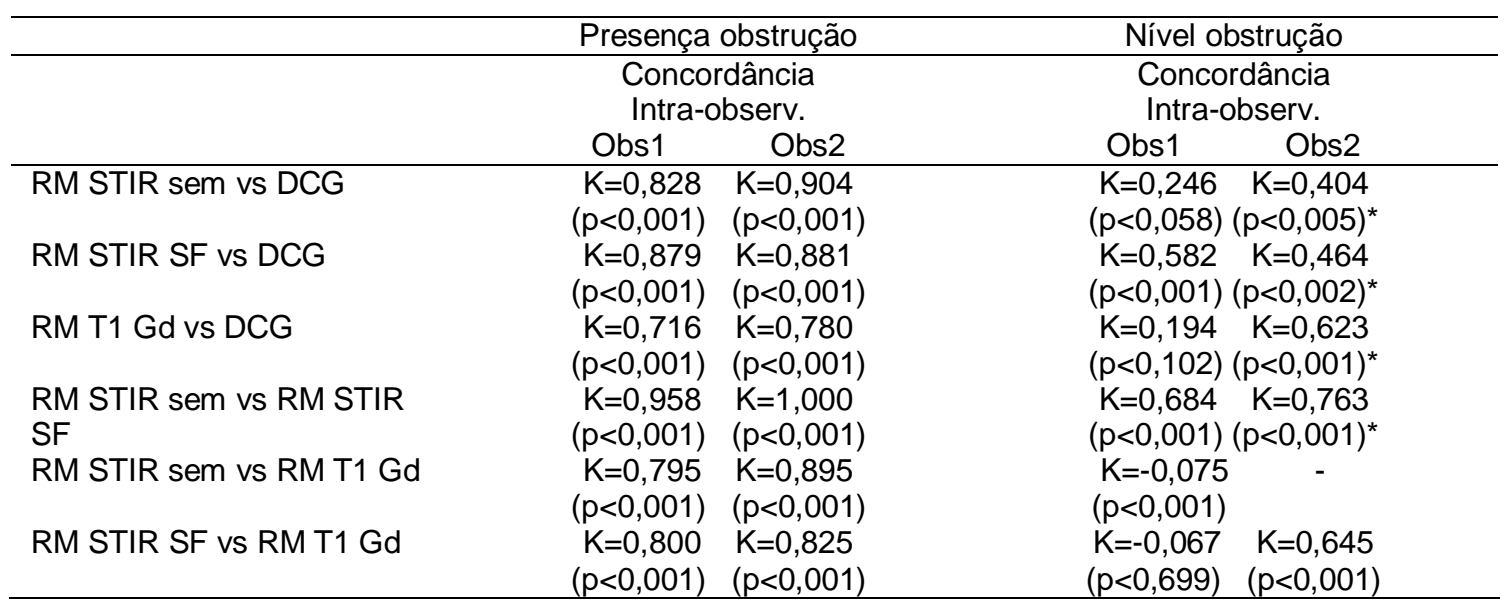

Tabela 26 - Resumo das concordâncias interobservadores para os diagnósticos da presença de obstrução e do nível de obstrução para as seqüências de RM e para a DCG.

\begin{tabular}{lcc}
\hline & Presença obstrução & Nível obstrução \\
\hline & $\begin{array}{c}\text { Concordância } \\
\text { Interobserv }\end{array}$ & $\begin{array}{c}\text { Concordância } \\
\text { Interobserv. }\end{array}$ \\
\hline RM STIR sem & $\mathrm{K}=1,000$ & $\mathrm{~K}=0,518$ \\
& $(\mathrm{p}<0,001)$ & $(\mathrm{p}<0,003)$ \\
RM STIR SF & $\mathrm{K}=0,958$ & $\mathrm{~K}=0,765$ \\
& $(\mathrm{p}<0,001)$ & $(\mathrm{p}<0,001)$ \\
RM T1 Gd & $\mathrm{K}=0,900$ & $\mathrm{~K}=1,000$ \\
& $(\mathrm{p}<0,001)$ & $(\mathrm{p}<0,001)$ \\
DCG & $\mathrm{K}=1,000$ & $\mathrm{~K}=0,812$ \\
& $(\mathrm{p}<0,001)$ & $(\mathrm{p}<0,001)$ \\
\hline
\end{tabular}




\section{ANEXO H}

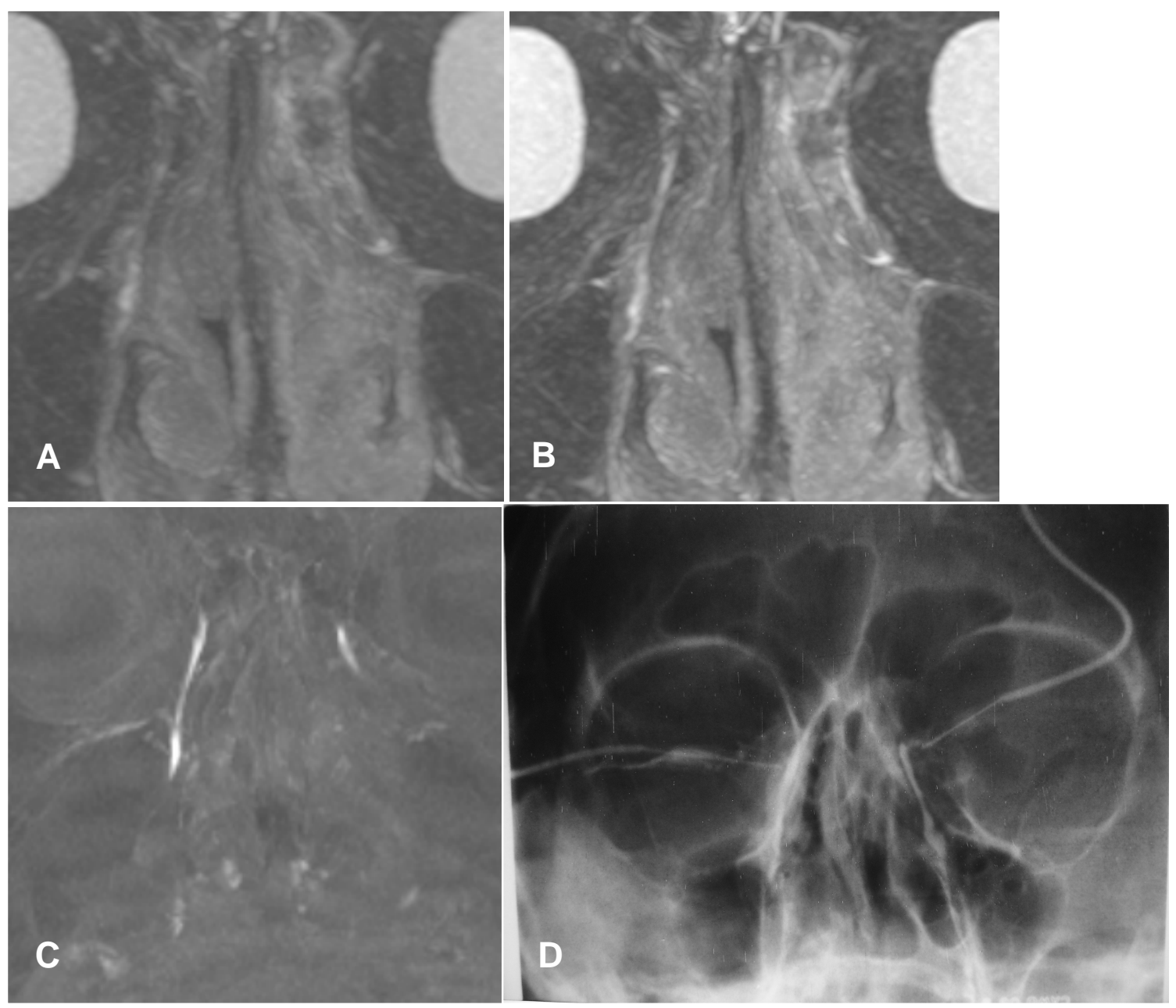

Figura 17 - Caso número 7. Paciente com história de lacrimejamento excessivo, à esquerda. Reconstruções MIP das seqüências STIR sem (a) e com instilação de soro fisiológico (b) e da seqüência T1, após instilação de gadolínio diluído e DCG (d). Este caso exemplifica o potencial da RM para estudo de distúrbios funcionais das vias lacrimais. A DCG demonstra permeabilidade total das vias lacrimais. A RM confirma a permeabilidade da via lacrimal direita e evidencia que, à esquerda, há apenas preenchimento do saco lacrimal, inferindo a possibilidade de distúrbio funcional, com retardo no tempo de trânsito em seu interior. 


\section{ANEXO I}

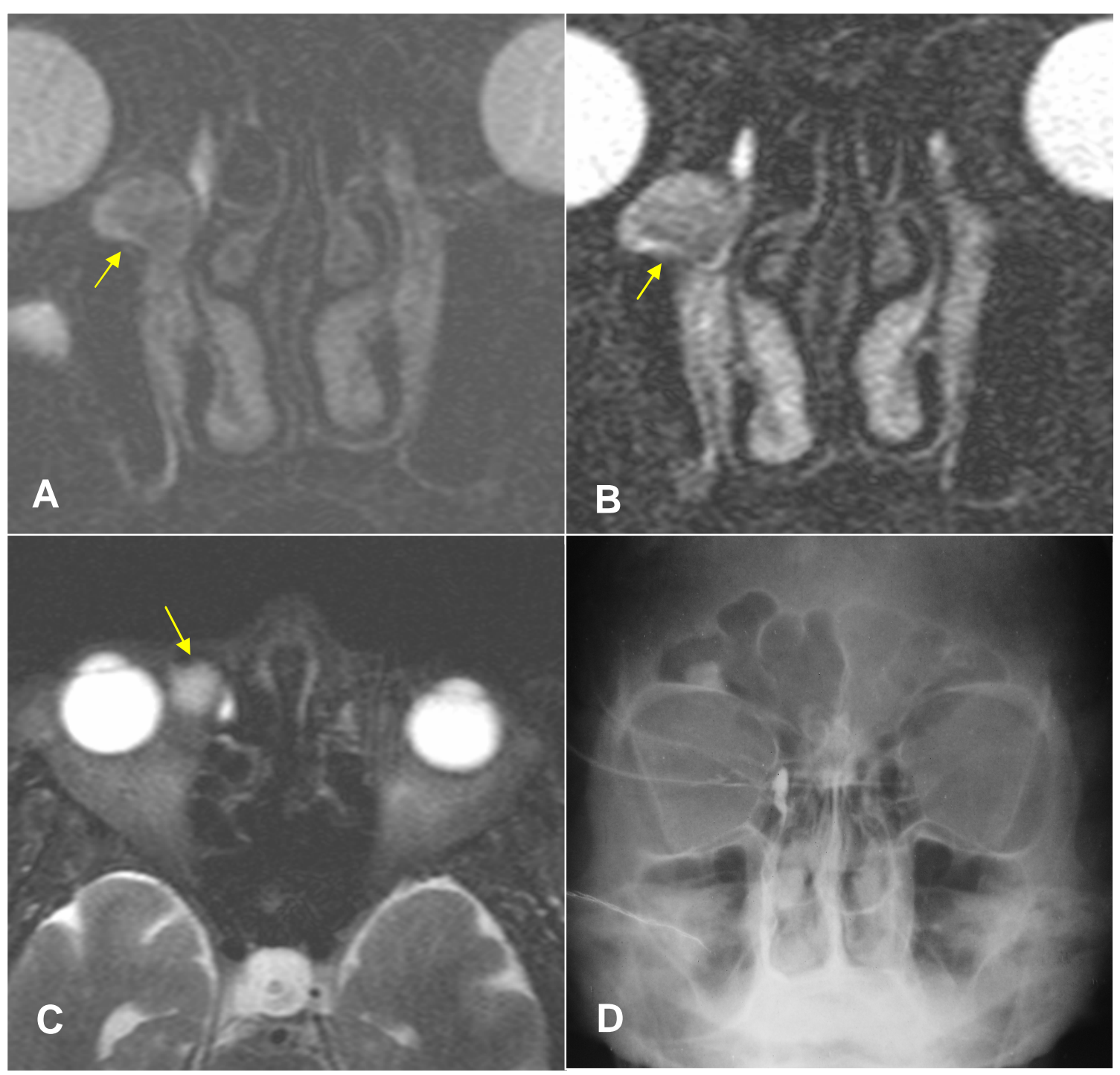

Figura 18 - Caso número 3. Imagens-fonte das seqüências STIR sem (a) e com instilação de soro fisiológico (b), seqüência T2 TSE axial (c) e DCG (d). Este caso exemplifica as vantagens da RM em relação à DCG. Além de demonstrar a obstrução da via lacrimal direita (por compressão extrínseca), a RM demonstrou, também, a presença de formação expansiva no canto interno da órbita direita (setas), que não pôde ser identificada pela DCG. 


\section{ANEXO J}

Proposta de algoritmo para investigação radiológica do paciente com epífora e suspeita de obstrução das vias lacrimais.

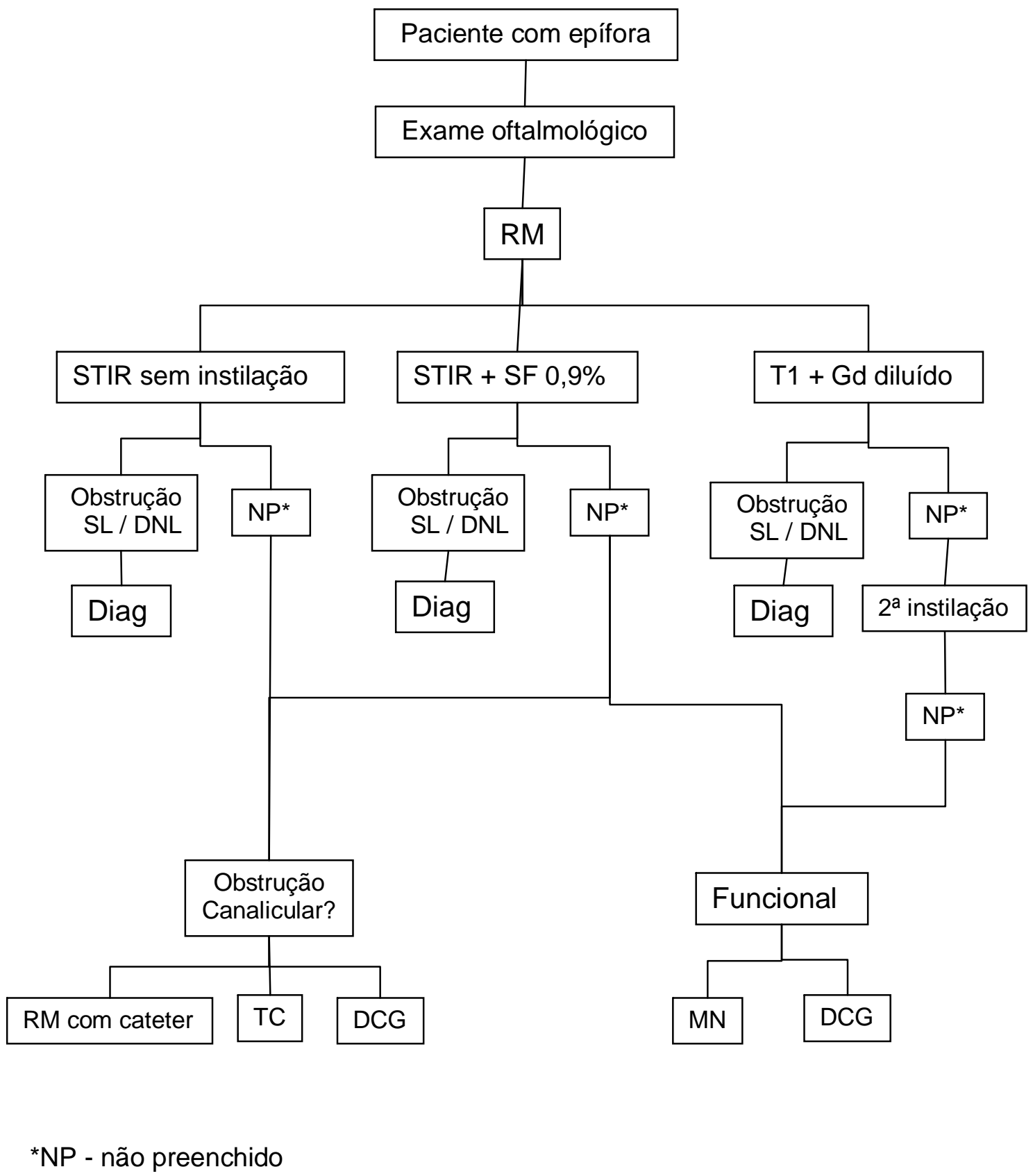


8. REFERÊNCIAS BIBLIOGRÁFICAS 


\section{REFERÊNCIAS BIBLIOGRÁFICAS}

Anderson NG, Wojno TH, Grossniklaus HE. Clinicopahologic findings from lacrimal sac biopsy specimens obtained during dacryocystorhinostomy. Ophthalmic Plastic Recon Surg. 2003; 19 (3): 173 - 176.

Bilaniuk LT, Schenck JF, Zimmerman RA, Hart HR, Foster TH, Edestein WA, Goldberg HI, Grossman RI. Ocular and orbital lesions: surface coil MR imaging. Radiology. 1985; 156: 669-674.

Caldemeyer K S, Stockberger,Jr S M, Broderick L S, Topical contrast-enhanced $\mathrm{CT}$ and MR dacryocystography: imaging the lacrimal drainage apparatus of healthy volunteers. AJR 1998; 171:1501-1504.

Camara JG, Bengzun AU. Nasolacrimal duct obstruction. 2006. Disponível em: http://www.emedicine.com.

D'Addario V, Pinto V, Anfossi A, Del Bianco A, Cantatore F. Antenatal sonographic diagnosis of dacryocystocele. Acta Ophthalmol. Scand. 2001; 79: 330-331.

DeAngelis D, Hurwitz J, Mazzulli T. The role of bacteriologic infection in the etiology of nasolacrimal duct obstruction. Can J Ophthalmol. 2001; 36 (3): 134139.

Fleiss, JL. Statistical methods for rates and proportions. New York: John Wiley. $2^{\text {nd }}$ ed. 1981.

Forbes GS, Sheedy PF, Waller RR. Orbital tumors evaluated by computed tomography. Radiology. 1980; 136: 101-111.

Francisco FC, Carvalho ACP, Francisco VFM, Francisco MC, Neto GT. Evaluation of 1.000 lacrimal ducts by dacryocystography. B J Ophthalmol. 2007; 91: 43-46.

Galloway JE, Kavic TA, Raflo GT. Digital subtraction dacryocystography: a new method of lacrimal system imaging. Ophthalmol. 1984; 91: 956-962.

Gmelin E., Rinast E., Bastian G.O., Hollands-Thorn G., Weiss, H.D. Dacryocystography and sialography with digital subtraction. Rofo. 1987;146: 643-646.

Goldberg RA, Heinz GW , Chiu L: Gadolinium magnetic ressonance imaging dacryocystography. Am. J.Ophthalmol.1993; (115): 738-741. 
Goss CM. Gray Anatomia. Rio de Janeiro: Guanabara Koogan. 29aㅗ ed. 1988

Groessl SA, Sires BS, Lemke BN. An anatomical basis for primary acquired nasolacrimal duct obstruction. Arch Ophthalmol. 1997; 115: 71-74.

Guzek JP, Ching AS, Hoang TA, Dure-Smith P, Llaurado JG, Yau DC, Elam DA. Clinical and radiological lacrimal testing in patients with epiphora. Ophthalmology. 1997; 104: 1875-1881.

Hahnel S., Jansen O., Zake S., Sartor K. Spiral CT in diagnosis of stenosis of the stenosis of the nasolacrimal duct system. Rofo. 1995; 163: 210- 214.

Hoffman KT, Hosten N, Lemke A-J, Sander B, Zwicker C, Felix R. Septum orbitale: high-resolution MR in orbital imaging. Am J Neuroradiol. 1998;19:91-94.

Hoffmann KT, Hosten N, Stroszczynski C, Liebig T, Hartmann C, Felix R. Highresolution conjunctival contrast-enhanced MRI dacryocystography. Neuroradiology 1999; 41: 208-213.

Ilgit ET, Meric N, Bor D, Öznur I, Konus Ö, Isik S. Lens of the eye: radiation dose in baloon dacryocystoplasty. Radiology. 2000;217:54-57.

Janssen AG, Mansour K, Bos JJ, Castelijns JA. Diameter of the bony lacrimal canal: normal values and values related to the nasolacrimal duct obstruction: assesment with CT. Am J Neuroradiol. 2001; 22: 845-850.

Kanski JJ. Clinical Ophthalmology: a systematic approach. London: ButterworthHeinemann. $3^{\text {rd }}$ ed. 1994.

Karagülle T, Erden A, Erden I, Zilelioglu G. Nasolacrimal system: evaluation with gadolinium-enhanced MR dacryocystography with a three-dimensional fast spoiled gradient-recalled technique. Eur Radiol 2002; 12: 2343-2348.

Kim JK, Tsirbas A. Epiphora caused by upper lacrimal drainage system problems. Compr Ophthalmol Update. 2005; 6(5): 231-236. Disponível em: www.medscape.com

Kirchhof K, Hähnel S, Jansen O, Zake S, Sartor K. Gadolinium-enhanced magnetic resonance dacryocystography in patients with epiphora. Journal of Computer Assisted Tomography 2000; 24(2): 327-331.

Landis JR, Koch GG. The measurement of observer agreement for categorical data. Biometrics. 1977; 33: 159-174. 
Linberg JV, McCormick, SA. Primary acquired nasolacrimal duct obstruction. A clinicopathologic report and biopsy technique. Ophthalmology. 1986; 93(8): 1055-1063.

Manfrè L, Marcello M, Todaro E, Mangiameli A, Francesco P, Lagalla R. MR dacryocystography: comparison with dacryocystography and CT dacryocystography. Am J Neuroradiol 2000; 21:1145-1150.

Massoud TF, Whittet HB, Anslow P. CT-dacryocystography for nasolacrimal duct obstruction following paranasal sinus surgery. Br J Radiol. 1993; 66: 223227.

Moran CC, Buckwalter K, Caldemeyer KS, Smith RR. Helical CT with topical water-soluble contrast media for ilmaging of the lacrimal drainage apparatus. AJR 1995; 164: 995-996.

Munk PL, Burhenne LW, Buffam FV, Nugent RA, Lin DT. Dacryocystography: comparison of water-soluble and oil-based contrast aAgents. Radiology 1989; 173: 827-830.

Niitsu M., Ikeda K. Magnetic resonance microscopic images with 50-mm field-ofview of the medial aspect of the knee. Acta Radiol. 2004 Nov;45(7):760-8.

Ostendorf M, Tost F. Imaging the lacrimal canaliculus with $20-\mathrm{MHz}$ ultrasonography: a normal diagnosis. J. Fr Ophtalmol. 2003; 26(10): 1031-1034.

Pariselle J, Froussart F, Sarrazin JL, Bidaux F, Rigal Sastourne JC, May F, Renard JP, Maurin JF. Contribuition of MRI for dynamic study of the lacrimal outflow system. J Fr Ophtalmol 1999; 22 (6): 628-634.

Robertson J.S., Brown M.L., Colvard D.M. Radiation absorbed dose to the lens in dacryoscintigraphy with ${ }^{99 m}$ TcO4. Radiology. 1979; 133:747-750.

Rubin PAD, Billyk JR, Shore JW, Sutula FC, Cheng HM : Magnetic resonance imaging of the lacrimal drainage system. Ophthalmollogy 1994; 101(2): 235243.

Russel E J, Czervionke L, Huckman M, Daniels D, McLachlan D. CT of the inferomedial orbit and the lacrimal drainage apparatus: normal and pathologic anatomy. AJR 1985; 145: 1147-1154.

Schenck JF, Hart HR, Foster TH, Edestein WA, Bottomley PA, Redington RW, Hardy CJ, Zimmerman RA, Bilaniuk LT. Improved MR imaging of the orbit at 1.5 T with surface coils. AJR. 1985; 144: 1033-1036. 
Schramm VL Jr, Curtin HD, Kennerdell JS. Evaluation of orbital cellulitis and results of treatment. Laryngoscope. 1982; 92: 732-738.

Som PM, Curtin HD. Head and Neck Imaging. Philadelphia: Mosby. $4^{\text {th }}$ ed. 2003.

Som PM, Dillon WP, Fullerton GD, Zimmerman RA, Rajagopalan B, Marom Z. Chronically obstructed sinonasal secretions: observations on T1 and T2 shortening. Radiology 1989; 172: 515-520.

Stupp T, Pavlidis M, Busse $\mathrm{H}$, Thanos $\mathrm{S}$. Presurgical and postsurgical ultrasound assessment of lacrimal drainage dysfunction. Am J Ophtalmol 2004; 138(5): 764-772.

Sumi M., Van Cauteren M., Nakamura T. MR microimaging of benign and malignant nodes in the neck. AJR Am J Roentgenol. 2006 Mar;186(3):749-57.

Takehara $\mathrm{Y}$, Kurihashi K, Isoda $\mathrm{H}$, Isogai S, Koraida N, Sugiyama M, Ozawa F, Masunaga H, Nozaki A, Takeda H, Sakahara H. Dynamic MR dacryocystography: a new method for evaluating nasolacrimal duct obstructions. AJR 2000; 175: 469-473.

Tasman W, Jaeger E.A. Duane's Ophthalmology - CD-ROM version. Philadelphia: Lippincott. Revised edition. 1995.

Tost F, Bruder R, Ostendorf M. High-frequence ultrasonography applied to disorers of the lacrimal canaliculi (part 2). J. Fr. Ophthalmol. 2003; 26(10): 10351038.

Wearne MJ, Pitts J, Frank J, Rose GE. Comparison of dacryocystography and lacrimal scintigraphy in the diagnosis of functional nasolacrimal duct obstruction. Br J Ophthalmol. 1999. 83: 1032-1035.

Weber A.L., De Velasquez A.R., Lucarelli M.J,, Cheng H.M. Normal anatomy and lesions of the lacrimal sac and duct: evaluated by dacryocystography, computed tomography and MR imaging. Neuroimaging Clin N Am. 1996 Feb;6(1):199-217.

Wilhelm K, Keller E, Textor J, Walther E, Schüller H, Schild H. MRT dacryocystography after conjuntival application of gadolinium solution. Fortschr Röntgenstr. 1997; 167(1): 58-61.

Yoshikawa T, Hirota S, Sugimura K. Topical Contrast-enhanced Magnetic Resonance dacryocystography. Radiation Medicine 2000; 18(6): 355-362. 
Zinreich SJ, Miller NR, Freeman LN, Glorioso LW, Rosenbaum AE. Computed tomographic dacryocystography using topical contrast media for lacrimal system visualization. Orbit. 1990; 9: 79-87. 